\title{
THE CHARACTERIZATION AND ELIMINATION OF THE EXTERNAL ACIDITY OF ZSM-5
}

\author{
Reinier Willem Weber \\ (BSc. Chem. Eng.) \\ Submitted to University of Cape Town \\ In fulfillment of the requirements for the degree \\ MASTER OF SCIENCE IN ENGINEERING
}

Department of Chemical Engineering

November 1993

University of Cape Town

Rondebosch

Cape Town

South Africa 
The copyright of this thesis vests in the author. No quotation from it or information derived from it is to be published without full acknowledgement of the source. The thesis is to be used for private study or noncommercial research purposes only.

Published by the University of Cape Town (UCT) in terms of the non-exclusive license granted to UCT by the author. 


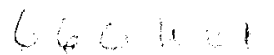

1 


\section{ACKNOWLEDGEMENTS}

Thanks are due to my supervisors, Dr. Jack Fletcher and Prof. Cyril O'Connor; for their help and guidance during this project, and for the motivation which they have given me.

It has been a great pleasure to work with all the guys and girls in the group because of the ambience that exists in the group, allowing us to enjoy the student-life we love to live. Salutations to James and Miles, who were always willing to share their wisdom and experience, either academically or socially.

Thanks to Klaus, for his invaluable suggestions when all else failed. Thanks to Connie, Leslie and Pam, without whom all the things we take for granted would never get done.

Without the technical support of Tony Barker, Rob Senekal and Charlie Ledger, I would not have had the equipment which by now has become one of my closest friends and greatest enemies.

A special thanks to my parents, Ton and Ank, for their unassuming belief in me, and to Marc and Marjolijn, who've had to put up with me for over two decades. 


\section{SYNOPSIS}

The zeolite ZSM-5 is well-known for its unique intersecting channel system. This channel system has a great bearing on the shape-selective properties and the long life-times of ZSM-5. In this study, ZSM-5 was modified in various ways to eliminate the external acidity of the catalyst to further improve these properties, and the success and effects of these modifications were investigated primarily using temperature programmed desorption techniques.

The internal surface of ZSM-5, a medium pore zeolite, plays a major role in the shape selective properties of this catalyst, due to the diffusional restrictions imposed by the channel system on bulky molecules. Even though the number of acid sites on the external surface is small compared to the total number of acid sites, these easily accessible and non-shape selective acid sites may provide a high turnover rate for non-shape selective reactions. Furthermore, the main cause of deactivation of ZSM-5 is thought to be the formation of polyaromatic molecules on the external surface, which block access to the channels of the catalyst.

To eliminate the external acidity of ZSM-5, the catalyst was modified by coating the crystals using two methods:

(i) Silicalite shells - the parent crystals (in various forms) were reimmersed into an aluminium-free synthesis mixture, in an attempt to deposit an inert silicalite-I shell around the crystals without blocking the channels.

(ii) Chemical vapour deposition - tetraethoxysilane was contacted with the catalyst (in varying amounts) in an attempt to either exchange Si for Al on the external surface, or to deposit an inert silica layer around the crystals without blocking the channels.

Ammonia and pyridine were used to probe the total acidity of these catalysts using temperature programmed desorption techniques. 4-Methyl quinoline was used to probe the external acidity of the catalysts using temperature programmed desorption techniques. 
These studies have confirmed that temperature programmed desorption is a suitable method for determining whether the elimination of the external acidity of ZSM-5 has been achieved. It has been shown that both $\mathrm{NH}_{3}$ and pyridine readily enter the channel system of ZSM-5 and that they are suitable probes for the total acidity of ZSM-5, although it has also been shown that diffusion and readsorption phenomena must be present in the channels during temperature programmed desorption of these adsorbates.

4-Methyl quinoline has been shown to be suitable as a selective probe for the external acidity of ZSM-5. It has been shown that 4-methyl quinoline is adsorbed solely onto the external surface of ZSM-5. Moreover, due to its high desorption temperatures, 4-methyl quinoline could be a suitable poison for the external surface acidity of ZSM-5. It has also been shown that 4-methyl quinoline decomposes upon desorption from ZSM-5.

The elimination of the external surface acidity has been successful for both samples modified by coating with silicalite shells and for samples modified by chemical vapour deposition.

(i) In each of the silicalite modified catalysts the internal acidity is still essentially intact. Thus the channel structure remains accessible to the adsorbates. The external acidity has been eliminated for the sample where the $\mathrm{NH}_{4}$-form of the parent crystal was used as seed material, but not for the Na-form of the seed crystals. The use of undetemplated seed crystals is preferred, in that the deposition of amorphous species in the channels can be prevented during the modification process.

(ii) In each of the samples modified by chemical vapour deposition, the internal acidity remained unchanged and accessible to the adsorbates. The external acidity was eliminated for the sample with high levels of tetraethoxysilane deposition (ie. using the longest deposition time and highest deposition temperature).

A description of the materials resulting from the two methods employed to eliminate the external acidity from ZSM-5 may be proposed as follows: 
(i) The nature of the material resulting from silicalite shell modification seems to be a combination of ZSM-5 and silicalite-I phases. The silicalite-I phase does not always coat the ZSM-5 crystal completely, but when it does a thick shell of silicalite-I is required to ensure coverage of the crystals. It appears that during the modification procedure with undetemplated seed crystals, a small amount of amorphous material may be formed. It may be speculated that the synthesis mixture of the modification step may extract aluminium out of the framework and replace it with silicon, provided the channels of the seed crystal have been detemplated (ie. the channels are not filled with template). The freed aluminium could thus be included in the formation of the shell, or in the formation of amorphous material. However, the channels are still accessible to the adsorbates.

(ii) The nature of the material resulting from modification using chemical vapour deposition is very similar to that of unmodified HZSM-5. The internal acidity and pore volume are unchanged. The external surface is thought to be covered only by a thin layer of inert silica (in the order of a few monolayers). 


\section{TABLE OF CONTENTS}

PAGE

Acknowledgements

Synopsis ..i

Table of contents ii

List of figures .v

List of tables xi

Nomenclature xiv .$x V$

\section{INTRODUCTION}

1.1 ZEOLITES 1

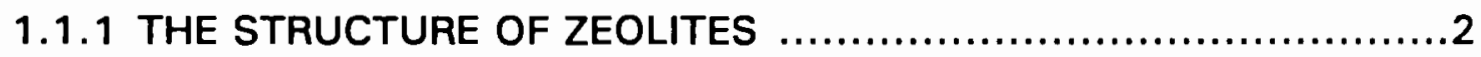

1.1.1.1 The primary building unit ................................2

1.1.1.2 The secondary building units .............................

1.1 .1 .3 Building blocks ..........................................

1.1.1.4 Zeolite groups ........................................5

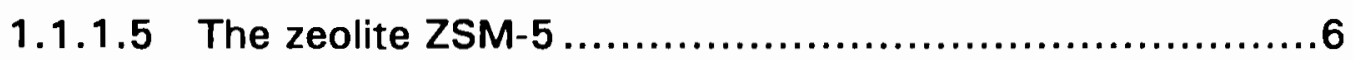

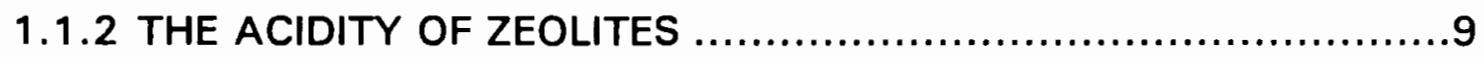

1.1.3 SHAPE SELECTIVITY IN ZEOLITES .............................. 12

1.1.3.1 Shape selectivity models ................................ 12

1.1.3.2 Experimental observations of shape selectivity .............................................. 15

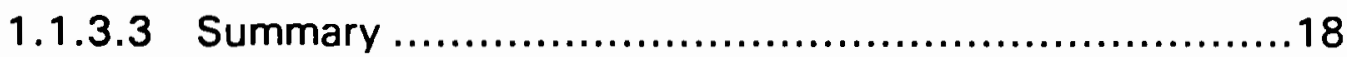

\subsubsection{COKE FORMATION AND DEACTIVATION OF} ZEOLITES

1.1.4.1 The nature of the coke ...................................20

1.1.4.2 The effects of channel structure .........................20

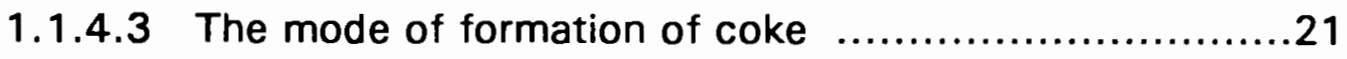

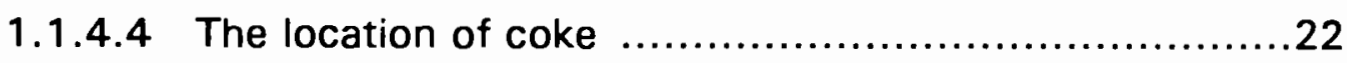

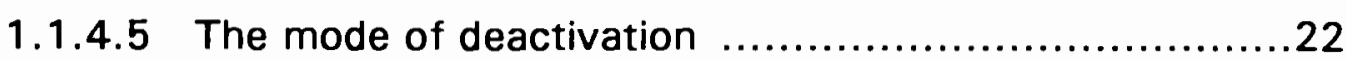




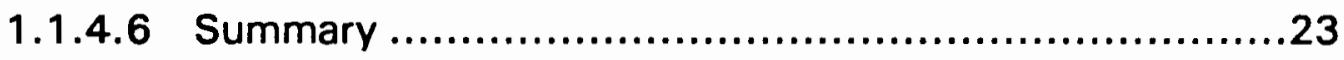

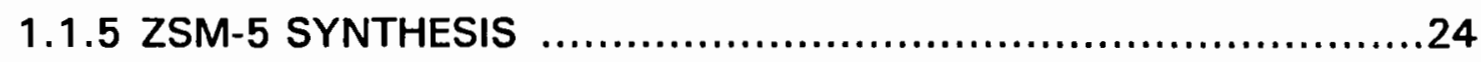

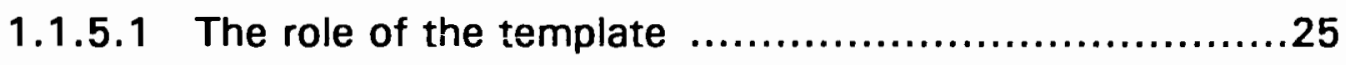

1.1.5.2 The influence of $\mathrm{pH}$.........................................25

1.1.5.3 The effect of aluminium content .......................25

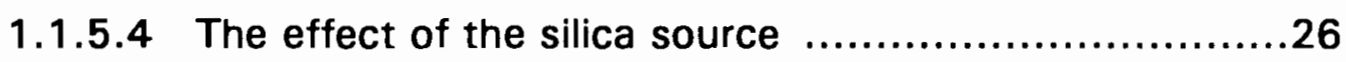

1.1.5.5 The effect of the alkali metal cation .......................26

1.1.6 THE ELIMINATION OF THE EXTERNAL ACIDITY OF ZEOLITES .........................................................27

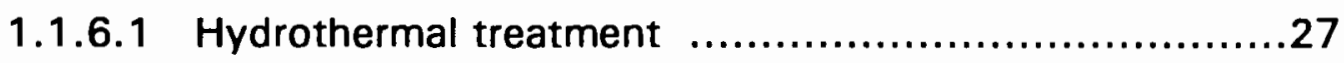

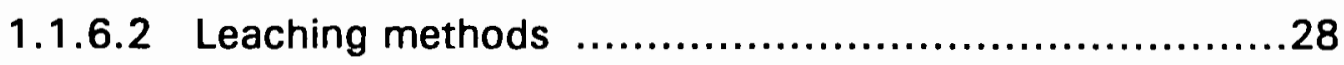

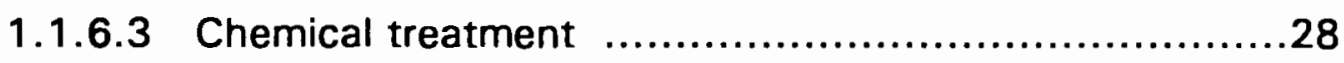

1.1.6.4 Chemical vapour deposition ..............................29

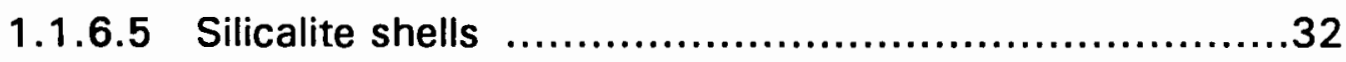

1.2 TEMPERATURE PROGRAMMED DESORPTION FROM

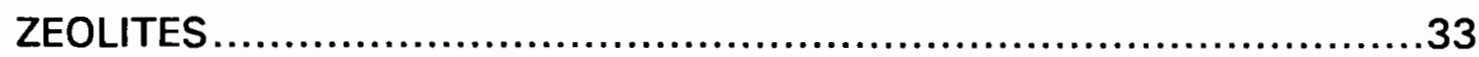

1.2.1 TEMPERATURE PROGRAMMED DESORPTION THEORY ..............34

1.2.1.1 Surface heterogeneity and surface coverage .............38

1.2.1.2 Readsorption and diffusion ..............................38

1.2.1.3 Carrier gas flow rate, bed depth and particle size ....................................................... 39

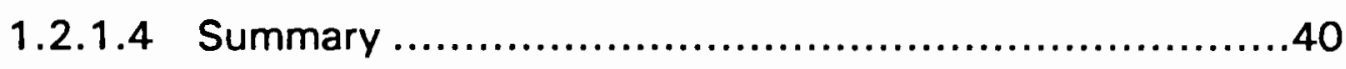

\subsubsection{TEMPERATURE PROGRAMMED DESORPTION FROM}

ZSM-5

\section{EXPERIMENTAL}

2.1 CATALYST SYNTHESIS AND MODIFICATIONS 
2.1.3 INTERMEDIATE TREATMENT ......................................51

2.1.3.1 Washing and drying ...................................51

2.1.3.2 Detemplation ..........................................51

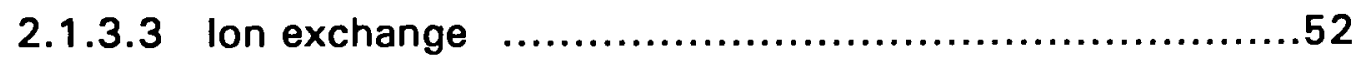

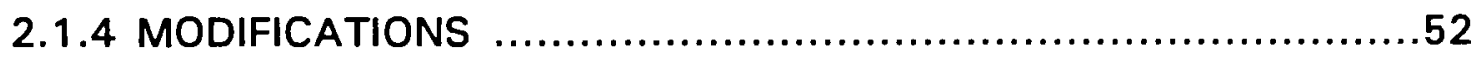

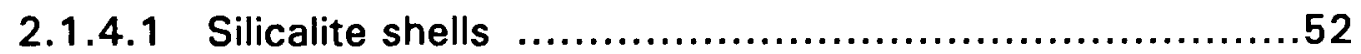

2.1.4.2 Chemical vapour deposition (CVD) ......................53

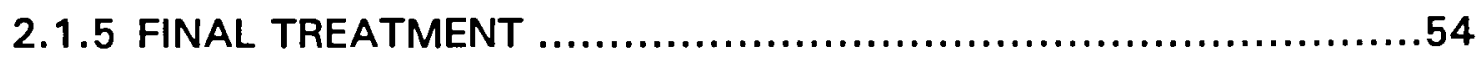

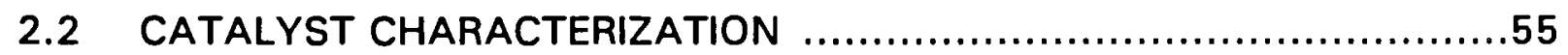

2.2.1 CATALYST STRUCTURE AND MORPHOLOGY $\ldots \ldots \ldots \ldots \ldots \ldots \ldots . \ldots 55$

2.2.1.1 X-ray diffraction (XRD) ..............................55

2.2.1.2 Scanning electron microscopy (SEM) ..................55

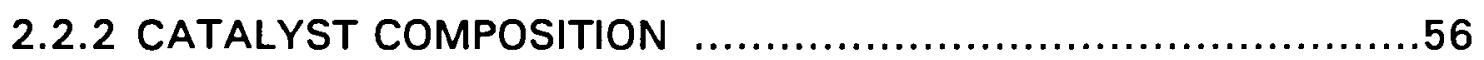

2.2.2.1 Atomic absorption spectroscopy (AAS) ................56

2.2.2.2 Temperature programmed desorption of

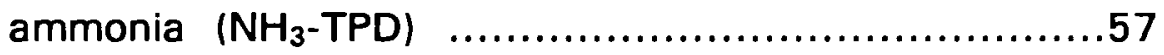

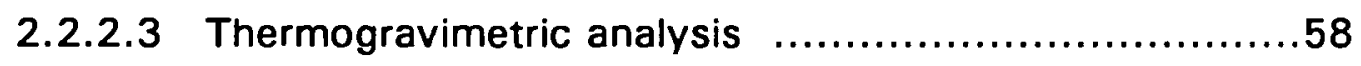

2.3 TEMPERATURE PROGRAMMED DESORPTION STUDIES ................59

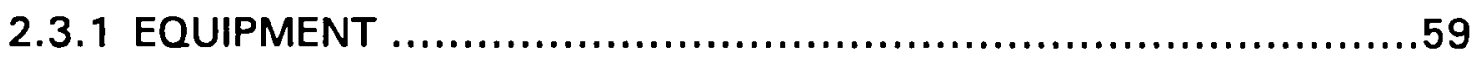

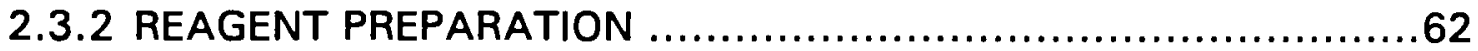

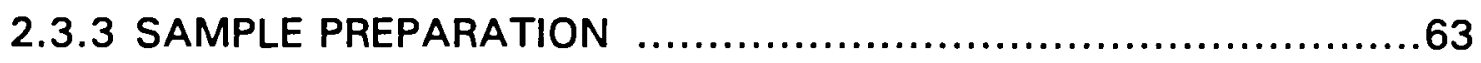

2.3.4 EXPERIMENTAL CONDITIONS AND PROCEDURES $\ldots \ldots \ldots \ldots \ldots . . .63$

2.3.5 SIGNAL DETECTION ...........................................65

2.3.5.1 The mass spectrometer as detector ...................66 


\section{RESULTS}

\subsection{PHYSICAL AND CHEMICAL CATALYST}

CHARACTERIZATION 69

3.1.1 CATALYST STRUCTURE AND MORPHOLOGY .69

3.1.1.1 Relative crystallinity ......................................69

3.1.1.2 Crystallite size and morphology ..........................69

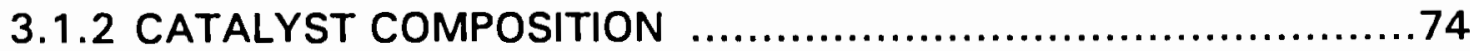

3.1.2.1 Silicon and aluminium content ...........................74

3.1.2.2 Catalyst acidity ........................................... 74

3.1.1.3 Thermogravimetric analysis ..............................75

3.2 TEMPERATURE PROGRAMMED DESORPTION FROM HZSM-5 ...........76

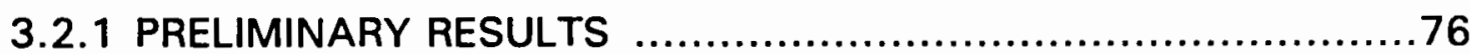

3.2.2 A COMPARISON OF THE DESORPTION SPECTRUM OF THE ADSORBATES INVESTIGATED ......................................78

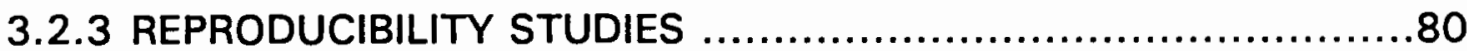

3.2.4 A COMPARISON OF HZSM-5 AND SILICALITE-I ...................83

3.2.5 THE EFFECTS OF CATALYST MASS AND FLOWRATE ............83

3.2.6 THE EFFECTS OF EVACUATION TIME AND

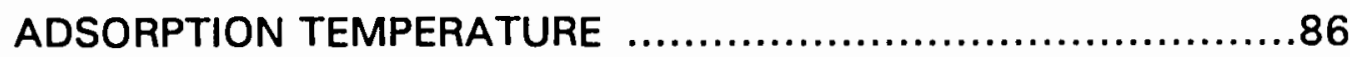

3.2.7 THE STABILITY OF THE ADSORBATE .88

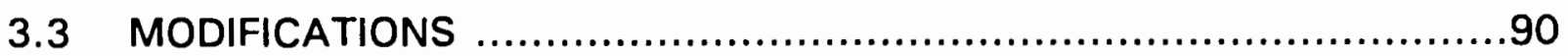

3.3.1 THE EFFECT OF COATING ZSM-5 WITH SILICALITE SHELLS .90 


\section{DISCUSSION}

4.1 DESORPTION FROM THE TOTAL SURFACE OF HZSM-5 95

4.1.1 THE DESORPTION SPECTRUM 95

4.1.1.1 The desorption spectrum of pyridine 95

4.1.1.2 The desorption spectrum of ammonia 96

4.1.2 THE EFFECTS OF CATALYST MASS AND FLOWRATE 96

4.1.3 THE EFFECTS OF ADSORPTION/EVACUATION TEMPERATURE AND EVACUATION TIME

4.2 DESORPTION FROM THE EXTERNAL SURFACE OF HZSM-5 99

4.2.1 THE DESORPTION SPECTRUM OF 4-METHYL QUINOLINE 99

4.2.2 EVIDENCE FOR THE ADSORPTION OF 4-METHYL QUINOLINE ONTO THE EXTERNAL SURFACE ONLY 100

4.3 MODIFICATIONS 102

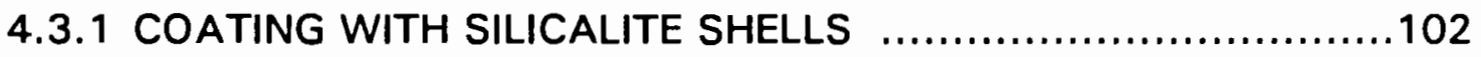

4.3.1.1 Structure of the resulting material ....................... 102

4.3.1.2 Internal acidity of the resulting material .................103

4.3.1.3 External acidity of the resulting material .................105

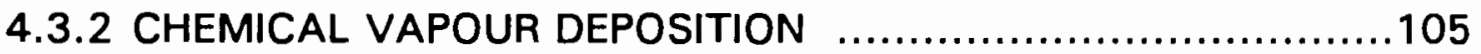

4.3.2.1 Structure of the resulting material ....................... 105

4.3.2.2 Internal acidity of the resulting material ..................106

4.3.2.3 External acidity of the resulting material ...............107

5. CONCLUDING REMARKS 


\section{APPENDICES}

Appendix I: $\quad$ List of chemicals and reagents .............................113

Appendix II: $\quad$ List of equipment ..........................................114

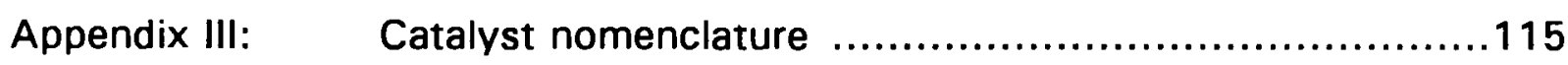

Appendix IV: $\quad$ Sample calculation of AAS results ..........................116

Appendix V: $\quad$ Leak testing .................................................118

Appendix VI: $\quad$ Furnace configuration and temperature ramp ...............119

Appendix VII: $\quad$ Miscellaneous TPD spectra .....................................121

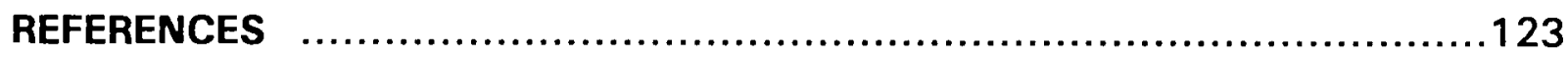




\section{LIST OF FIGURES}

PAGE

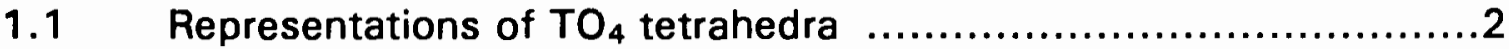

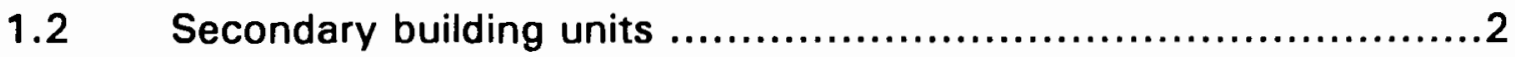

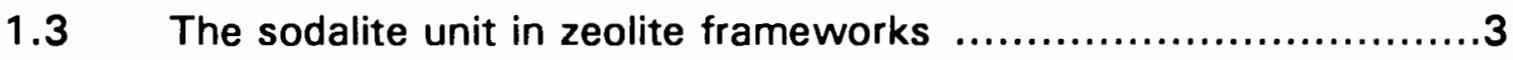

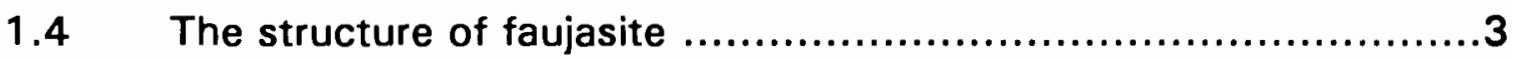

1.5 Stereoscopic representations of zeolite topologies

(a) faujasite, (b) mordenite and (c) ZSM-5 ......................4

1.6 The building blocks of ZSM-5 ...................................

1.7 The skeletal diagram of the (010) plane of the ZSM-5 unit cell, showing the channel opening of the straight channel

1.8 The skeletal diagram of the (100) plane of the ZSM-5 unit cell, showing the channel opening of the sinusoidal channel

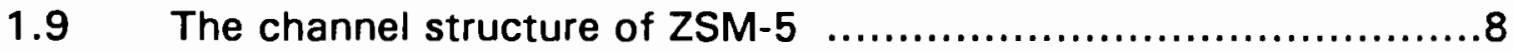

1.10 The formation of the proton form of zeolites .....................9

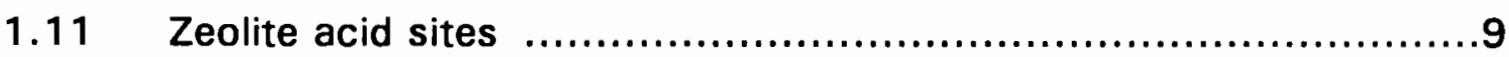

1.12 Intensity of the hydroxyl group stretching frequencies of zeolite $Y$ for different calcination temperatures

1.13 Acid site populations on zeolite $Y$ as a function of

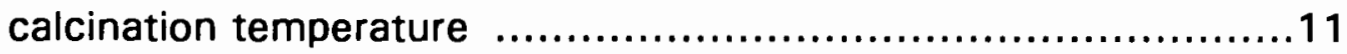

1.14 The formation of Lewis acid sites by dehydroxylation ..............11

1.15 Acid site enhancement via the inductive effect .....................11

1.16 Reactant shape selectivity .......................................13

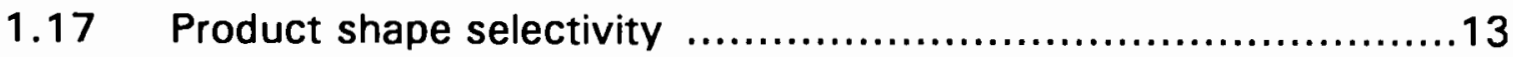

1.18 Diffusion limitations due to steric hindrance $\ldots \ldots \ldots \ldots \ldots \ldots \ldots \ldots \ldots . \ldots 15$

1.19 "Half" channel intersection cavities ................................17

1.20 Schematic representation of the coke distribution on HZSM-5 for (a) low coke content, and (b) high coke content

1.21 Formation of the ZSM-5 building block from a double 5-ring silicate

1.22 Reaction scheme for the Chemical Vapour Deposition of $\mathrm{Si}\left(\mathrm{OCH}_{3}\right)_{4}$ 
2.1 Schematic representation of catalyst synthesis and modifications

2.2 Magnetically stirred autoclave .......................................50

2.3 Schematic of Temperature Programmed Desorption rig for pyridine and 4-methyl quinoline studies

2.4 The TPD cell

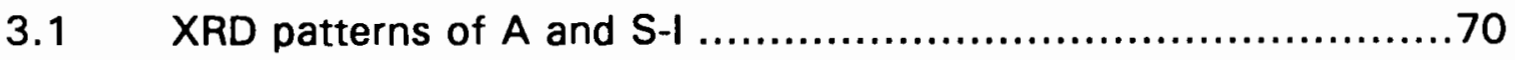

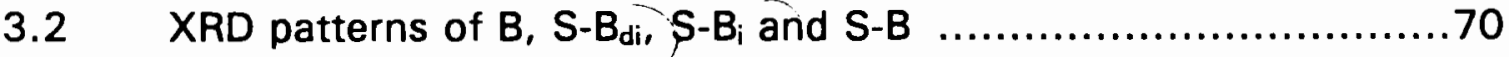

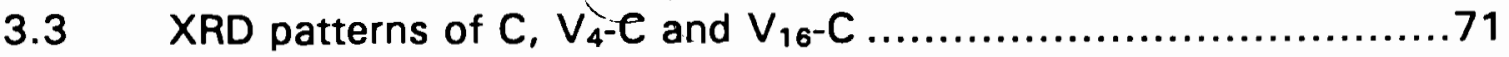

3.4 Simulated XRD pattern of ZSM-5 …..............................71

3.5 Electron micrographs of (a) $A$ and (b) $S-1$.........................72

3.6 Electron micrographs of (a) $C$, (b) $V_{4}-C$ and $(c) V_{16}-C \ldots \ldots \ldots . .72$

3.7 Electron micrographs of (a) $B$, (b) $S-B_{d i}$ (c) $S-B_{i}$ and

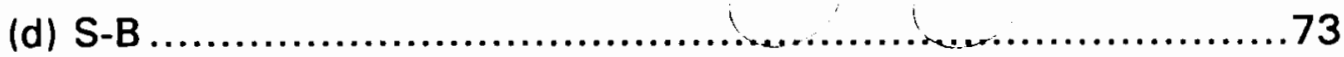

3.8 TPD spectra of (a) $\mathrm{NH}_{3}$, (b) $\mathrm{Py}$ and (c) MQ-4 from HZSM-5 (catalyst A) ....................................................

3.9 Reproducibility of Py-TPD spectra from HZSM-5 (catalyst A)

3.10 Reproducibility of MQ-TPD spectra from HZSM-5 (catalyst A)

3.11 Py-TPD spectra from HZSM-5 and silicalite-I

3.12 MQ-TPD spectra from HZSM-5 and silicalite-I

3.13 The effects of catalyst mass and flowrate on the $\mathrm{NH}_{3}-$ TPD spectrum of HZSM-5 (catalyst A)

3.14 The effect of catalyst mass on the Py-TPD spectrum of HZSM-5 (catalyst A)

3.15 The effect of catalyst mass on the MQ-TPD spectrum of HZSM-5 (catalyst A)

3.16 The effects of adsorption temperature and evacuation time on the Py-TPD spectrum of HZSM-5 (catalyst A)

3.17 The effect of evacuation time on the MQ-TPD spectrum of HZSM-5 (catalyst A)

3.18 The stability of Py upon desorption from HZSM-5 (catalyst A)

3.19 The stability of MO-4 upon desorption from HZSM-5 (catalyst A) 
3.20 PY-TPD spectra of HZSM-5 and ZSM-5 coated with silicalite shells

3.21 The effect of evacuation time on the Py-TPD spectrum S-B

3.22 MQ-TPD spectra of HZSM-5 and ZSM-5 coated with silicalite shells

3.23 Py-TPD spectra of HZSM-5 and ZSM-5 modified by CVD .94

3.24 MQ-TPD spectra of HZSM-5 and ZSM-5 modified by CVD 


\section{LIST OF TABLES}

PAGE

1.1 Channel systems of some representative zeolites .5

1.2 TPD design parameters

2.1 Synthesis conditions and synthesis mixture compositions for primary ZSM-5 syntheses and for silicalite-I

2.2 Synthesis conditions and synthesis mixture compositions for modification using the silicalite shell method

2.3 Synthesis conditions for modification by means of chemical vapour deposition 54

2.4 Gas chromatograph and mass spectrometer settings .66

3.1 Catalyst characterization .75

3.2 The effects of catalyst mass and flowrate on the peak temperature of TPD spectra

3.3 The effects of evacuation times and adsorption temperatures on the peak temperature of TPD spectra $\ldots \ldots \ldots \ldots . .86$

3.4 The effect of coating ZSM-5 with silicalite shells ...................91

3.5 The effect of Chemical Vapour Deposition on ZSM-5 .............93 
NOMENCLATURE

\begin{tabular}{|c|c|}
\hline AAS & Atomic Absorption Spectroscopy \\
\hline CVD & Chemical Vapour Deposition \\
\hline EDTA & Ethylenedinitrilo tetraacetic acid \\
\hline EELS & Electron Energy Loss Spectroscopy \\
\hline GC & Gas Chromatograph \\
\hline HERI & errionite \\
\hline HOFF & offretite \\
\hline HM & mordenite \\
\hline HY (USHY) & zeolite Y (ultrastable) \\
\hline HZSM-5 & Zeolite Socony Mobil \\
\hline MS & Mass Spectrometer \\
\hline MQ-4 & 4-Methyl quinoline \\
\hline n.m.r. & nuclear magnetic resonance \\
\hline Py & Pyridine \\
\hline SBU & Secondary Building Unit \\
\hline SEM & Scanning Electron Microscopy \\
\hline SIM & Selected Ion Mode \\
\hline TEM & Transmission Electron Microscopy \\
\hline TES & Tetraethoxysilane \\
\hline TIC & Total Ion Chromatogram \\
\hline TPA & Tetrapropylammonium \\
\hline TPD & Temperature Programmed Desorption \\
\hline MQ-TPD & $\begin{array}{l}\text { Temperature Programmed Desorption of } \\
\text { 4-Methyl Quinoline }\end{array}$ \\
\hline $\mathrm{NH}_{3}-\mathrm{TPD}$ & $\begin{array}{l}\text { Temperature Programmed Desorption of } \\
\text { ammonia }\end{array}$ \\
\hline Py-TPD & Temperature Programmed Desorption of Pyridine \\
\hline XPS & X-ray Photoelectron Spectroscopy \\
\hline XRD & $X$-ray diffraction \\
\hline
\end{tabular}


CHAPTER 1

\section{INTRODUCTION}





\subsection{ZEOLITES}

Zeolites are 3-dimensional crystalline aluminosilicates consisting of cornerlinked tetrahedra in which small atoms (collectively denoted $\mathrm{T}$ atoms) lie at the centers of the tetrahedra, with oxygen atoms at the corners. The $\mathrm{T}$ sites of all natural zeolites are dominated by $\mathrm{Al}$ and $\mathrm{Si}$ atoms, such that the ratio $\mathrm{O} /(\mathrm{Al}+\mathrm{Si})=2$ [Barrer, 1982], but chemically related atoms such as $G a, G e$ and $P$ can be incorporated in synthetic zeolites. The substitution of aluminium atoms into the silicon based structure results in a net negative charge on the zeolite framework. This is compensated for by the presence of charge balancing cations, typically $\mathrm{Na}, \mathrm{K}, \mathrm{Mg}, \mathrm{Ca}$ and $\mathrm{Ba}$. The unit cell formula is given by

$$
M_{p} D_{q}\left(A l_{p+2 q} S_{r} O_{2 p+4 q+2 r}\right) \cdot s H_{2} \mathrm{O} \quad[\text { Smith, 1979] }
$$

where $M$ and $D$ represent monovalent and divalent cations respectively. The arrangement of the tetrahedral units in the macroscopic crystal results in the formation of open channels in the zeolite structure. Different arrangements yield the various zeolite types. It is this intracrystalline porosity which confers on zeolites their remarkable properties.

In addition to the cations needed to neutralize the framework charge, there is room in the channels and cavities for salts and water molecules in the zeolite bulk. The open frameworks of zeolites also provide an environment in which cations and water have a high degree of mobility, resulting in good ionexchange properties and the capacity for reversible hydration. Indeed, the name zeolite with its Greek origins of "boiling stone" is derived from the latter property. 


\subsubsection{THE STRUCTURE OF ZEOLITES}

\subsubsection{The primary building unit}

The primary building units of zeolites are the tetrahedra, as shown in Figure 1.1.

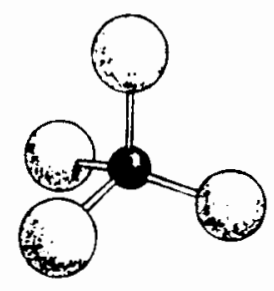

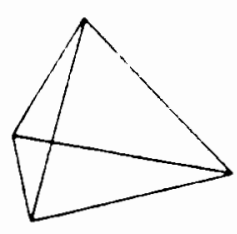

h

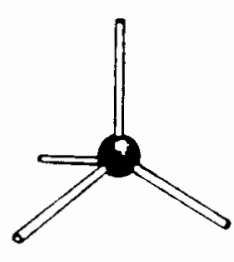

c

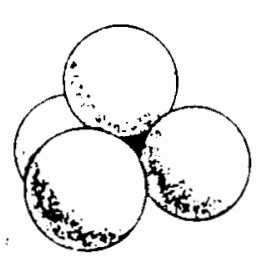

d

FIGURE 1.1: Representations of $\mathrm{TO}_{4}$ tetrahedra

\subsubsection{The secondary building units}

In order to facilitate the description and systematization of the vast diversity of zeolite topologies, Meier [1968] suggested the use of 8 secondary structural units based on simple groupings of linked tetrahedra. The number of these socalled secondary building units (SBU's) was later increased to 16 as shown in Figure 1.2 [Meier and Olson, 1992]. All zeolites can be reduced to combinations of secondary building units.

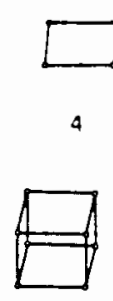

4-4

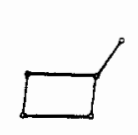

4-1

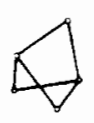

$4-1$

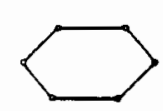

6

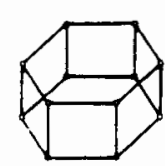

$6-6$

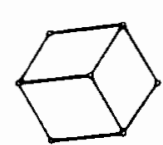

$6 \cdot 1$

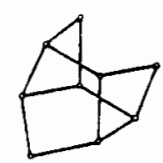

4-4-1
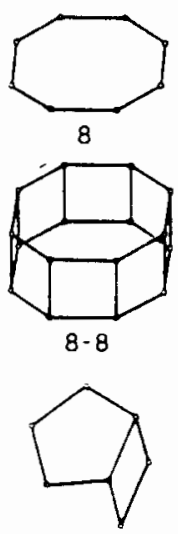

5. 2

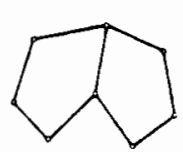

5. 3

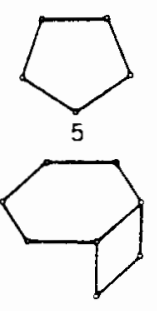

6- 2
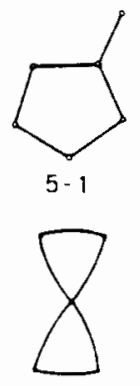

Spiro - 5

FIGURE 1.2: Secondary building units [Meier and Olson, 1992] 
The $T$ atoms in Figure 1.2 are represented by the corners or apices. The $O$ atoms are not shown, but would lie approximately at the midpoints of the lines joining the $T$ atoms.

\subsubsection{Building blocks}

The SBU's may be combined to form building blocks. An example of such a building block is the sodalite unit, depicted in Figure 1.3, which is found in faujasite zeolites, $X$ and $Y$. The sodalite unit is a truncated cubo-octahedron composed of 24 silicon and aluminium ions in tetrahedral coordination with oxygen atoms. These sodalite units are linked together via their hexagonal faces by so-called hexagonal prisms yielding the faujasite structure shown in Figure 1.4.

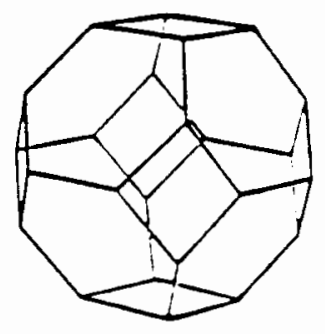

FIGURE 1.3: The sodalite unit in zeolite frameworks

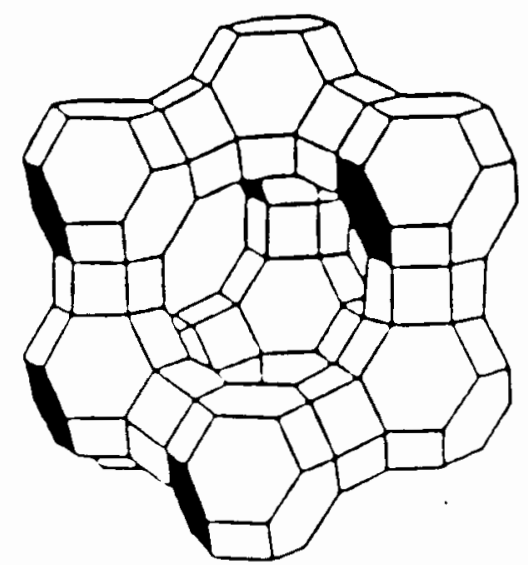

FIGURE 1.4: The structure of faujasite 
This arrangement of sodalite units and hexagonal prisms results in the formation of large, almost spherical cavities interconnected by distorted 12 sided windows. This cavity is referred to as the supercage. In this manner a network of channels and cages is formed. Similarly, in other zeolites, such networks exist, although not all zeolites will have cavities. Also, the channel network may consist of straight parallel channels as in mordenite, or of an intersecting network as in ZSM-5. Figure 1.5 shows the topology of several well-known zeolites.

(a)
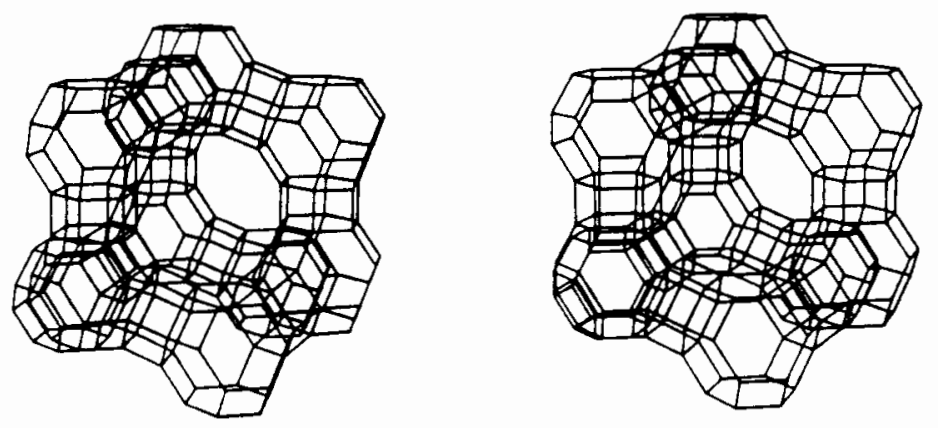

(b)
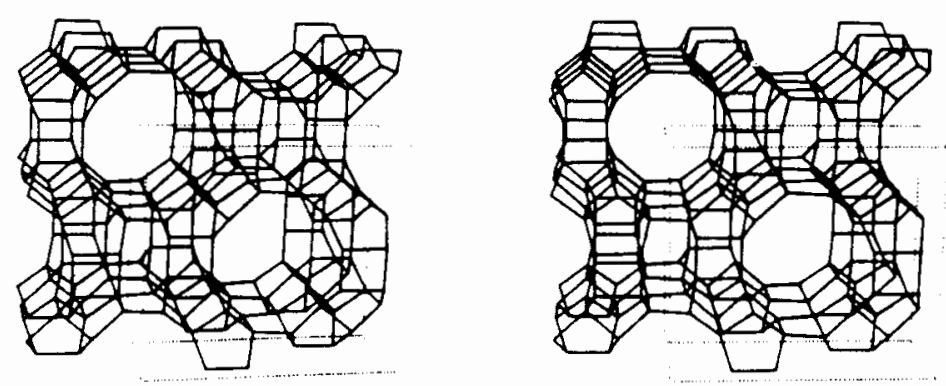

(c)
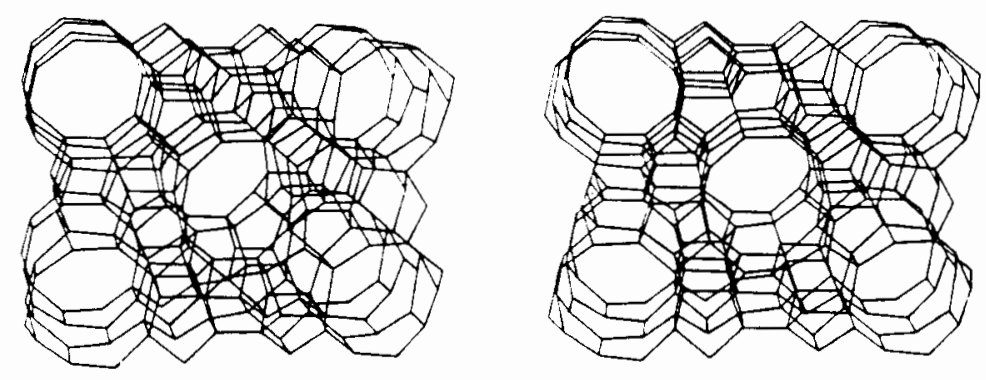

FIGURE 1.5: Stereoscopic representations of zeolite topologies (a) faujasite, (b) mordenite and (c) ZSM-5 [Meier and Olson, 1992] 


\subsubsection{Zeolite groups}

The structural characteristic of greatest interest for catalysis is the channel system, which is described for some zeolites in Table 1.1. Depending on the largest channel, zeolites are characterized as small, medium or large pore zeolites if they contain apertures made by rings of 8, 10 or 12 linked tetrahedra respectively [Haag and Chen, 1987]. Small pore zeolites, which include chabazite and erionite, adsorb only straight-chain molecules such as $n$-paraffins and $n$-olefins. Medium pore zeolites, such as ZSM-5, ZSM-11, ZSM-22 and ZSM-23, are of most interest to the design of shape-selective catalysts. Synthetic faujasites, zeolite $X$ and $Y$, and mordenite are large pore zeolites.

The channel system may be one-dimensional (ZSM-22 and ZSM-48), twodimensional (ferrierite) or three-dimensional (ZSM-5). Multidimensional channels often intersect one another, but this is not always the case. The interconnecting channels may be straight (ZSM-11) or tortuous $(Z S M-5)$. The connectivity of the channel system has major consequences for diffusion and ageing characteristics.

TABLE 1.1: Channel systems of some representative zeolites [Haag and Chen, 1987]

\begin{tabular}{llll}
\hline TYPE & NAME & $\begin{array}{c}\text { RING SIZE OF } \\
\text { CHANNELS }\end{array}$ & $\begin{array}{c}\text { LARGEST CHANNEL } \\
\text { SIZE (A) }\end{array}$ \\
\hline SMALL & Linde type A & $8-8-8$ & 4.1 \\
PORE & Chabazite & $8-8-8$ & $3.6 \times 3.7$ \\
& Erionite & $8-8$ & $3.6 \times 5.2$ \\
MEDIUM & ZSM-22 & 10 & $4.5 \times 5.5$ \\
PORE & ZSM-23 & 10 & $4.5 \times 5.6$ \\
& ZSM-48 & 10 & $5.3 \times 5.6$ \\
& Ferrierite & $10-8$ & $4.3 \times 5.5$ \\
& ZSM-5 & $10-10$ & $5.4 \times 5.6$ \\
ZSM-11 & $10-10$ & $5.1 \times 5.5$ \\
PORGE & ZSM-12 & 12 & $5.7 \times 6.1$ \\
& Linde type L & 12 & 7.1 \\
& Mazzite & 12 & 7.4 \\
& Mordenite & $12-8$ & $6.7 \times 7.0$ \\
& Offretite & $12-8-8$ & 6.4 \\
& Faujasite & $12-12-12$ & 7.4 \\
\hline
\end{tabular}




\subsubsection{The zeolite ZSM-5}

ZSM-5 synthesis was first reported by researchers at Mobil [Argauer and Landolt, 1972]. It is a medium pore zeolite belonging to the pentasil group. The unit cell formula of the sodium form of ZSM-5 is shown below, with $n$ typically having a value of 3 or less (but not greater than 27) [Kokotailo et al., 1978].

$$
\mathrm{Na}_{n} \mathrm{Al}_{n} \mathrm{Si}_{96-n} \mathrm{O}_{192} \cdot 16 \mathrm{H}_{2} \mathrm{O} \quad \mathrm{n}<27
$$

The framework of ZSM-5 consists of linked tetrahedra which may be considered to join to form eight 5-membered rings, as shown in Figure 1.6a (SBU $=5-1$ ). The units are connected through edges to form chains as shown in Figure 1.6b. These chains are connected to form sheets and the linking of sheets leads to a three dimensional framework structure. The sheets parallel to the (010) and (100) planes are shown in Figure 1.7 and Figure 1.8 respectively.

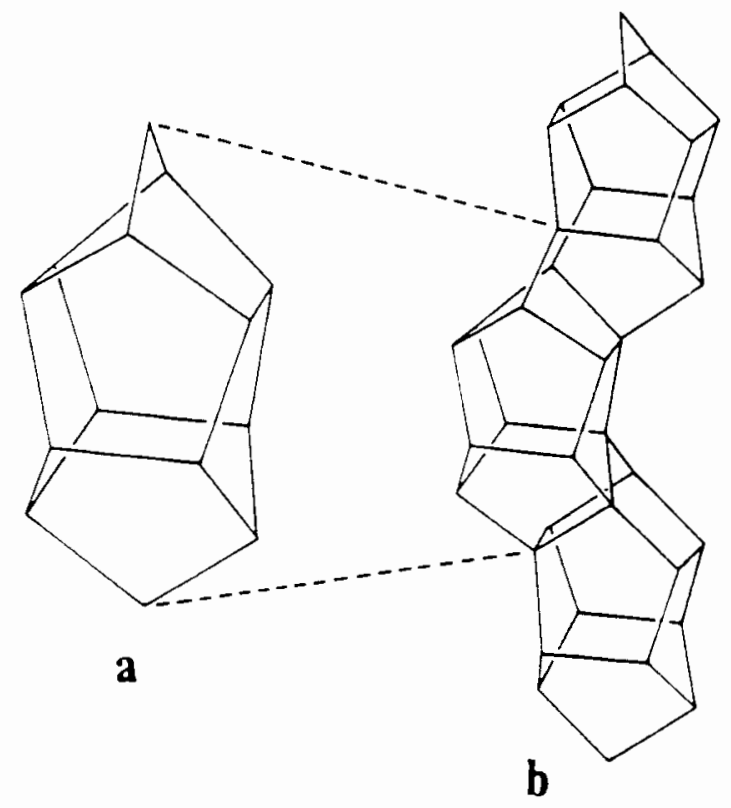

FIGURE 1.6: The building blocks of ZSM-5 


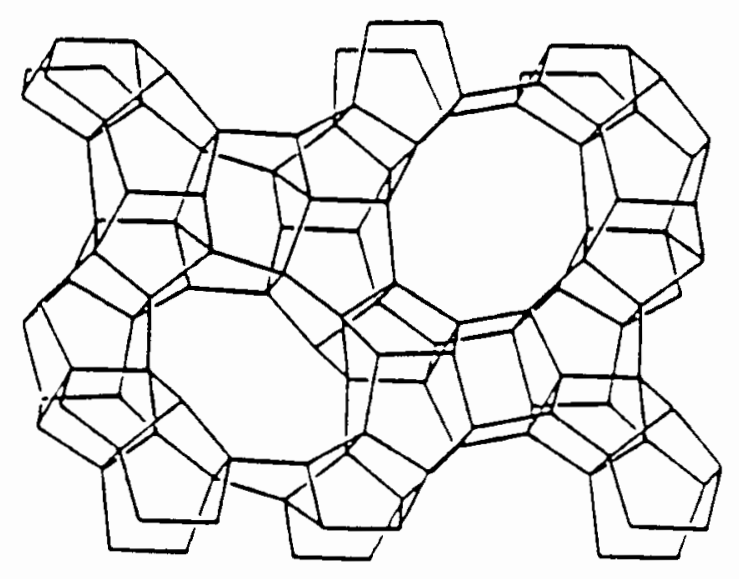

FIGURE 1.7: The skeletal diagram of the 1010) plane of the ZSM-5 unit cell, showing the channel opening of the straight channel

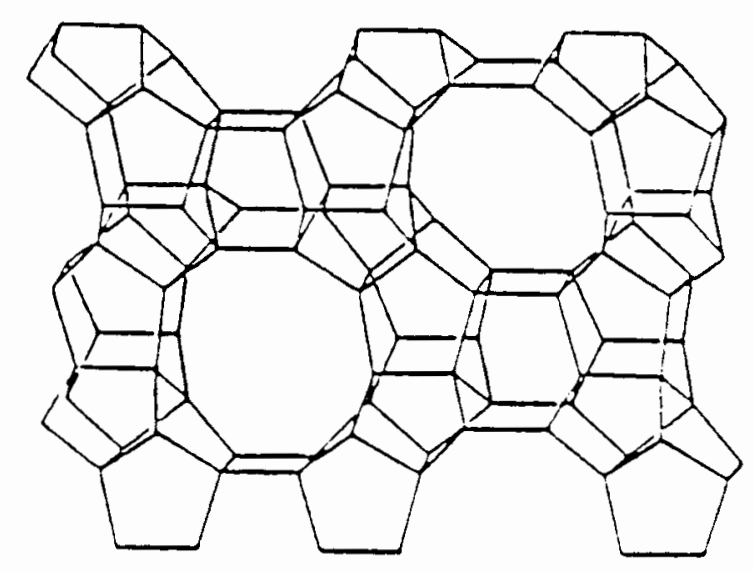

FIGURE 1.8: The skeletal diagram of the (100) plane of the ZSM-5 unit cell, showing the channel opening of the sinusoidal channel

The ZSM-5 framework contains two intersecting channel systems, one sinusoidal running parallel to the $(010)$ plane and the other straight and parallel to the $(100)$ plane, as indicated by Figure 1.9. The elliptical 10-membered ring openings (10 Al or $\mathrm{Si}$ atoms) controlling the channels can be seen clearly in 
Figure 1.7 and Figure 1.8. The sinusoidal channels have a diameter of $5.1 \times$ 5.5 Ångstrom, whereas the straight channels have a diameter of $5.3 \times 5.6$ Ångstrom [Meier and Olson, 1992].

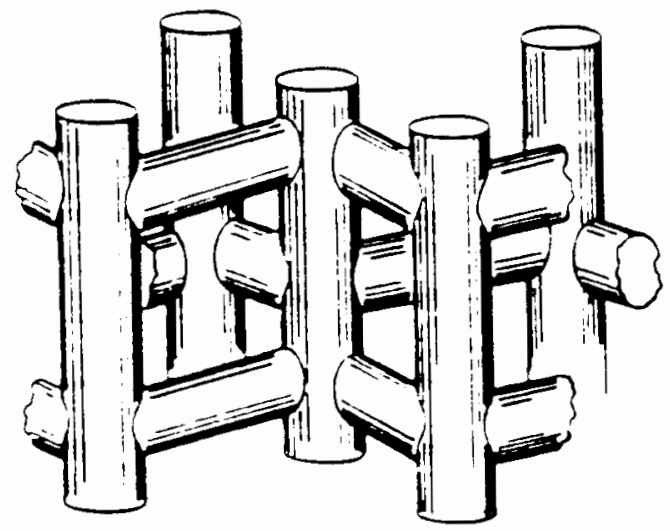

FIGURE 1.9: The channel structure of ZSM-5

It has been shown from X-ray diffraction studies that as-synthesized ZSM-5 crystallizes with orthorhombic symmetry and has lattice constants $a=20.1$, $b=19.9$ and $c=13.4$ Ångstrom [Meier and Olson, 1992]. However, monoclinic symmetry has also been observed [De Vos Burchart et al., 1993]. 


\subsubsection{THE ACIDITY OF ZEOLITES}

In Section 1.1.1 it was mentioned that zeolites are composed of tetrahedrally bound silicon and aluminium ions, joined by bridging oxygen ions. The tetrahedral coordination of the aluminium ion induces a negative framework charge for each aluminium ion. This charge is neutralized by the presence of exchangeable cations. It is this charge balancing phenomenon that is responsible for the acidity and activity of zeolites.

Zeolites are commonly synthesized in the sodium form, and the sodium cations are replaced by ammonium cations. Uytterhoeven et al. [1965] showed that on heating ammonium-exchanged zeolites ammonia is released, thereby yielding the active protonic form, as shown in Figure 1.10.

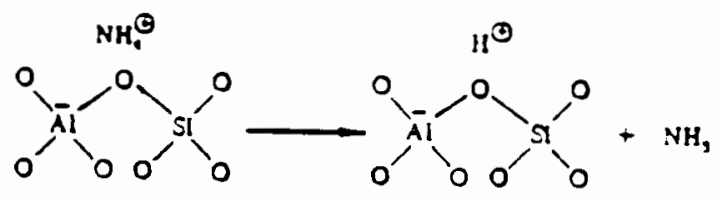

FIGURE 1.10: The formation of the proton form of zeolites

The right hand side of the equation in Figure 1.10 represents a classical Brönsted acid. Uytterhoeven et al. [1965] further proposed that the equilibrium shown in Figure 1.11 is also established.

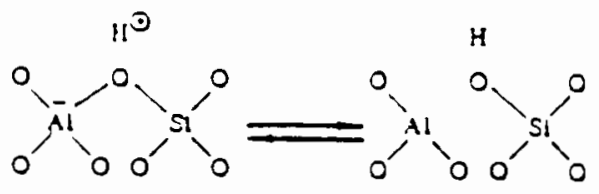

FIGURE 1.11: Zeolite acid sites 
Ward [1967] investigated the nature of the active sites on proton exchanged zeolite $Y$, and observed three hydroxyl group stretching bands in the infrared spectrum of zeolite $Y$ at 3742,3643 and $3540 \mathrm{~cm}^{-1}$. This is in agreement with Uytterhoeven et al. [1965]. The $3742 \mathrm{~cm}^{-1}$ band probably represents $\mathrm{Si}-\mathrm{OH}$ terminal groups (similar to those on silica) or they may be associated with amorphous impurities in the structure [Ward, 1967]. The bands at 3643 and $3540 \mathrm{~cm}^{-1}$ represent hydroxyl groups at different crystallographic locations.

Ward [1967] noted that the maximum intensity of the hydroxyl group bands of zeolite $Y$ is reached at calcination temperatures of $350^{\circ} \mathrm{C}$. From this temperature to $500{ }^{\circ} \mathrm{C}$ the intensities remain constant, after which they decrease (Figure 1.12). The $3742 \mathrm{~cm}^{-1}$ band intensity increases to a maximum at a calcination temperature of $640^{\circ} \mathrm{C}$ before decreasing.

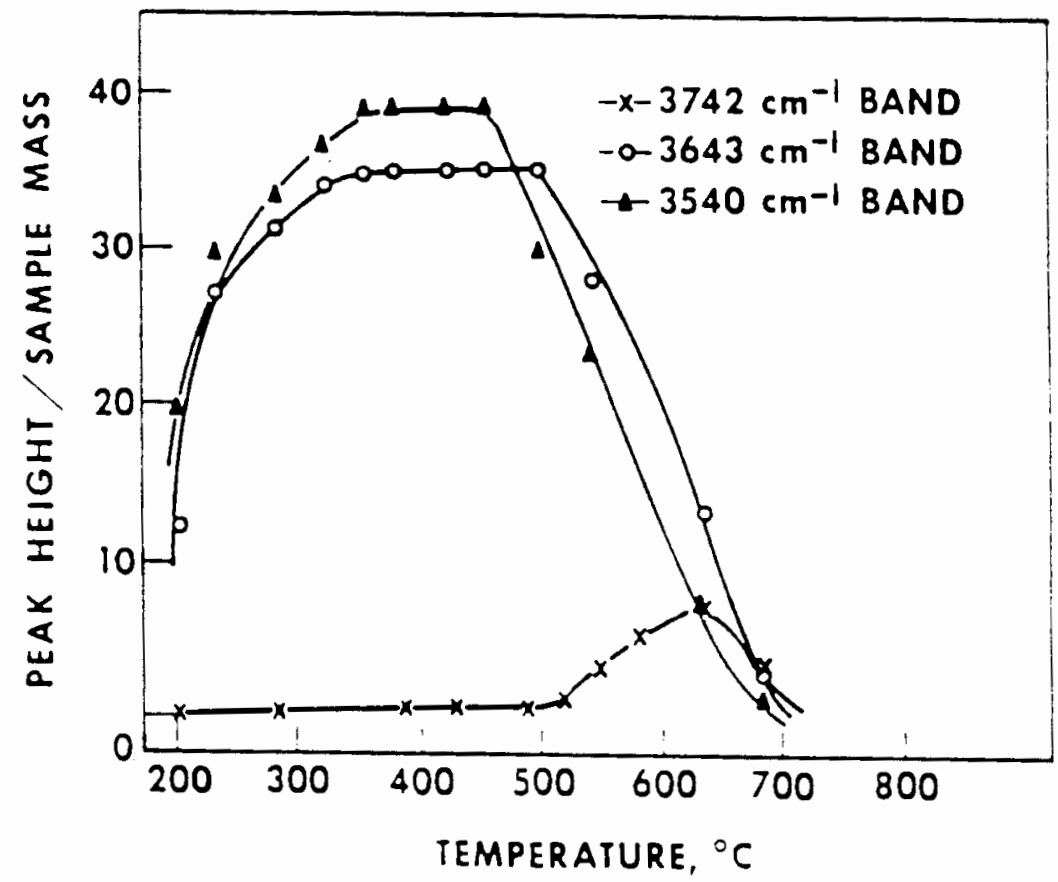

FIGURE 1.12: Intensity of the hydroxyl group stretching frequencies of zeolite $Y$ for different calcination temperatures [Ward, 1967).

Ward [1967] concluded that the hydroxyl groups, functioning as Brönsted acid sites, are largely responsible for catalytic activity. While Brönsted acidity decreases rapidly above calcination temperatures of $500^{\circ} \mathrm{C}$, the concentration 
of Lewis acid sites is small below $475{ }^{\circ} \mathrm{C}$, but increases rapidly at higher temperatures (Figure 1.13).

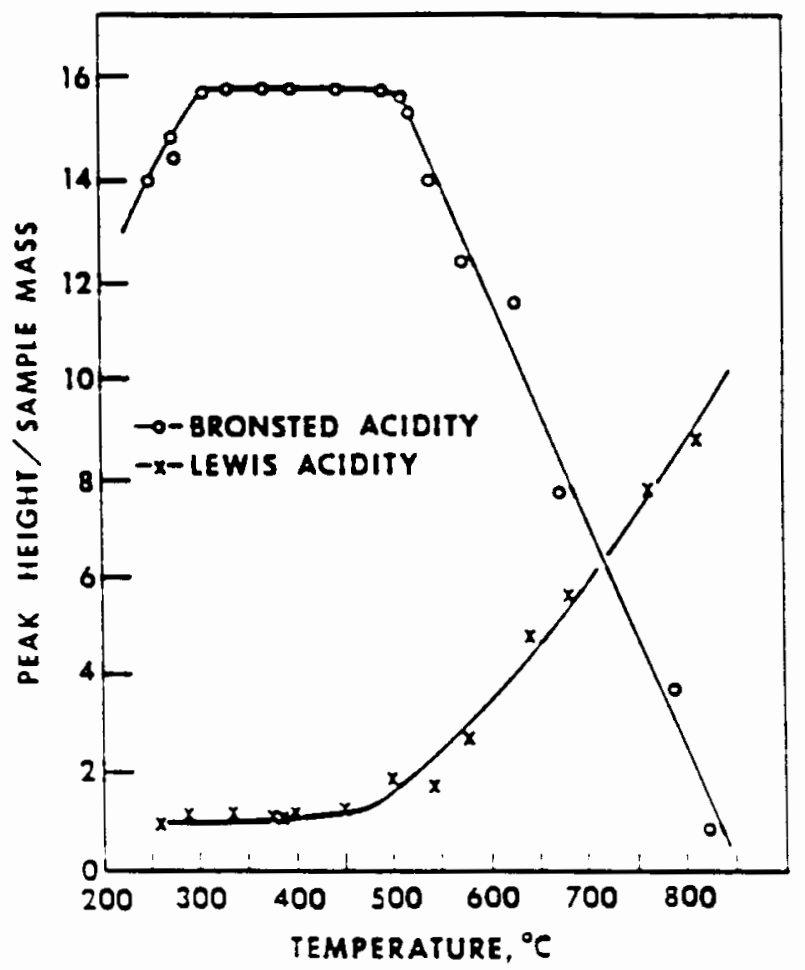

FIGURE 1.13: Acid site populations on zeolite $Y$ as a function of calcination temperature IWard, 1967]

Ward [1967] and Uytterhoeven et al. [1965], suggested that if the Brönsted acid sites are hydroxyl groups, then a conversion to Lewis acid sites should occur with increasing temperature, according to Figure 1.14, such that dehydroxylation of the zeolite occurs.

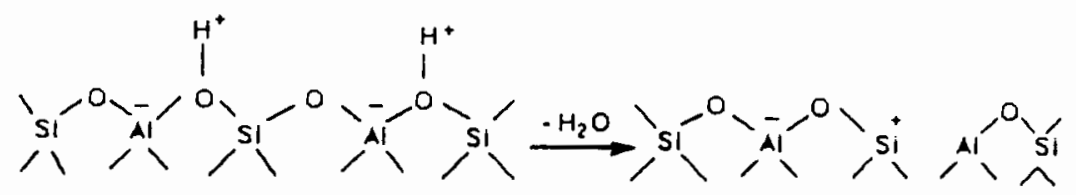

FIGURE 1.14: The formation of Lewis acid sites by dehydroxylation 
Lunsford [1968] pointed out that while Brönsted acidity is decreasing in the 500 - $600{ }^{\circ} \mathrm{C}$ temperature range, the catalytic activity for toluene cracking was found to increase. Lunsford proposed that partial dehydroxylation of the catalyst at elevated temperatures could lead to the formation of defect sites of the type shown in Figure 1.15. He suggested that these sites could act inductively on the local hydroxyls to form strong acids.

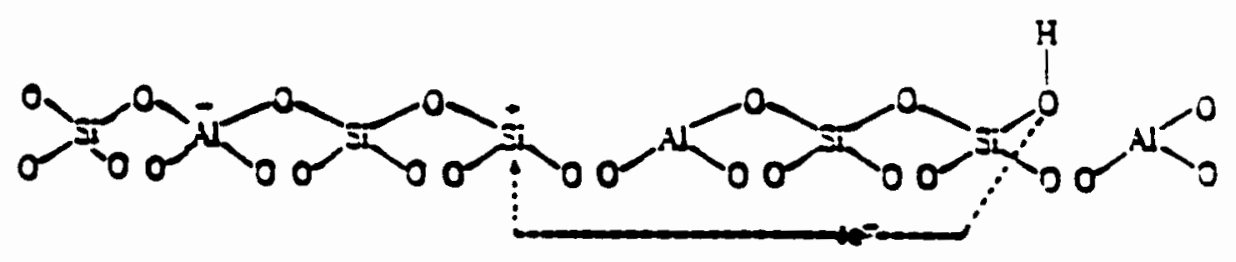

FIGURE 1.15: Acid site enhancement via the inductive effect [Lunsford, 1968]

\subsubsection{SHAPE SELECTIVITY IN ZEOLITES}

\subsubsection{Shape selectivity models}

If the majority of the catalytic sites are confined in the channel structure and if the channels are small, the fate of the reactant molecules and the probability of forming product molecules are determined mostly by molecular dimension and configuration. Only molecules whose dimensions are less than a critical size can enter the channels, have access to internal catalytic sites, and react there. Furthermore, only molecules which can leave appear in the final product. Bulkier molecules will form only on the relatively few catalytic sites on the external surface of the zeolite crystals. Catalysts displaying such properties are said to be shape selective. Csicsery [1979] distinguished between three types of shape selectivity:

In reactant shape selectivity (Figure 1.16) some of the molecules in a reactant mixture are too large to diffuse through the catalyst channels to reach active sites. 


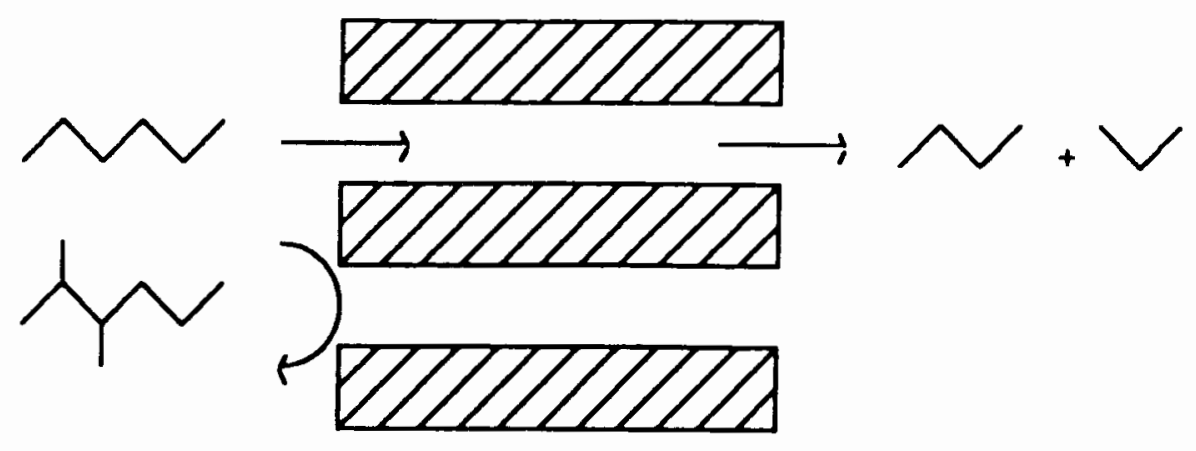

FIGURE 1.16: Reactant shape selectivity

In product shape selectivity (Figure 1.17) only product molecules with sufficiently small dimensions can diffuse out of the channels and appear as products.

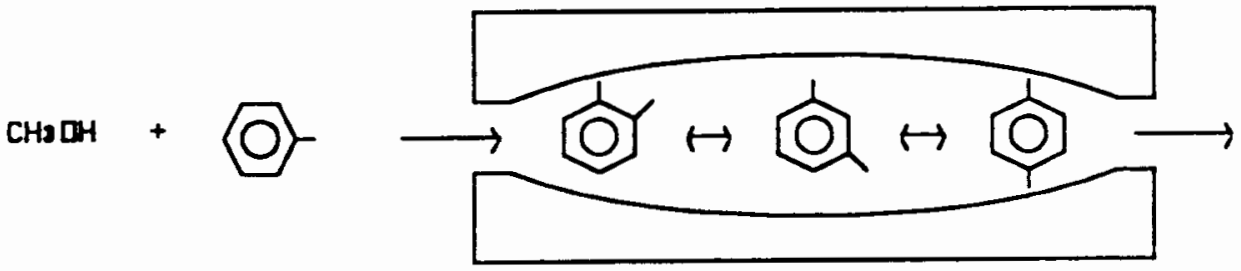

FIGURE 1.17: Product shape selectivity

In restricted transition state shape selectivity certain reactions are prevented because the corresponding transition state requires more space than is available in the cavities or channeis of the catalyst.

Reactant and product selectivities are mass transfer limited and are therefore affected by crystallite size, whereas transition state selectivity is not. 
An additional concept of secondary shape selectivity was introduced by Santilli and Zones [1990]. When, as in the above cases, shape selectivity is a result of direct interactions between molecules and a channel system, the term primary shape selectivity is applied. In zeolite catalysis, secondary shape selectivity occurs when one type of molecule affects the behaviour of another type in a way which does not occur in a less hindered environment. Molecules can interfere with each other in unrestricted environments. Two examples of this are: (i) a molecule with a higher boiling point will preferentially adsorb onto the catalyst surface, and (ii) a highly polar molecule will adsorb on a polar catalytic surface instead of a non-polar molecule. Secondary shape selectivity occurs when one molecule interferes with the reactivity of another because of steric constraints imposed by the channels. As opposed to boiling point and electrostatic effects, secondary shape selectivity is a phenomenon which does not happen in an unhindered environment. Santilli and Zones [1990] state that it is likely that several types of secondary shape selectivity exist, such as reactant, product and transition state secondary shape selectivity, and that these could be caused by both reactants and products.

Choudhary and Akolekar [1989] suggested a shuttlecock-shuttlebox model for the sorbate-zeolite channel system to explain how the dimensions and configurations of molecules can influence the selectivity. They noted that although molecules may have similar critical diameters, the relative penetrability and diffusivity of bulkier molecules could vary dramatically. They also noted that molecules with a critical diameter greater than the channel diameter could diffuse through the channels, sometimes with relative ease. Penetration of bulkier molecules into the zeolite channel is expected to take place only when the molecule enters the channel opening in an orientation in which its compression to the size of the channel is accomplished with relative ease. Otherwise its sorption is either totally rejected or expected to occur with a low probability, because of a much greater steric hindrance experienced by the molecule. Similarly, diffusion of the molecules in the channels is favoured in the direction in which the resistance to movement of the compressed group of the diffusing molecule is at a minimum, as shown in Figure 1.18. 


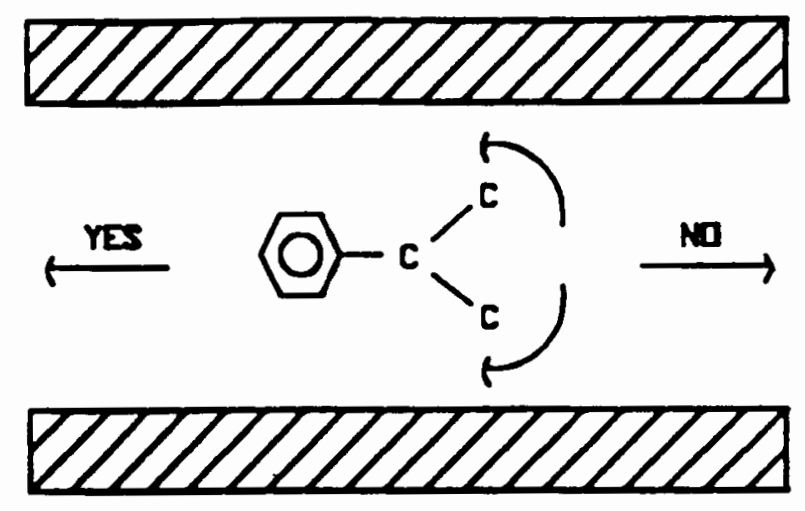

FIGURE 1.18: Diffusion limitations due to steric hindrance

Derouane [1986] suggests that molecular shape selective effects are not necessarily restricted to the intracrystalline volume of the zeolites, although that would clearly favour their occurrence. He suggests that molecular shape selectivity should occur whenever a catalyst selects or prefers specific reactants or products on the basis of their size and shape in order to match its own active site steric requirements. The external surface of zeolites offers channel openings and cut channels (half cavities) due to their framework structure. Derouane proposes that such hilly environments will facilitate the preferential selection and reaction of certain molecules, depending on their stereochemistrv and their ability to optimize their Van der Waals interaction with the framework. or their capacity to "nest". Such external surface molecular shape selective effects are more likely to be observed for bulky molecules, small crystais and crystals with restricted access to their interior (coked or modified crystats).

\subsubsection{Experimental observations of shape selectivity}

Haag et al. [1982] carried out a number of catalytic cracking reactions over ZSM-5. They compared the cracking of various hydrocarbon compounds over small crystal and large crystal ZSM-5, by calculating the rate constant and 
effectiveness factor in each case. They were able to make several interesting conclusions:

(i) At conventional cracking temperatures $\left(323-523{ }^{\circ} \mathrm{C}\right)$, the cracking rates for both paraffins (alkanes) and monomethyl paraffins are independent of crystal size. This means there are no mass transport or diffusional effects.

(ii) Dimethyl paraffins are affected by diffusional resistances, as the reaction rates drop significantly in larger crystals. This means that dimethyl paraffins, or bulkier molecules, have difficulty in diffusing through the channels of the catalyst.

(iii) At the same temperatures, the cracking rates of olefins (alkenes) are 2 to 3 orders of magnitude greater than those of paraffins. This was ascribed due to transition state shape selectivity, as the transition state complex of paraffins is thought to be much bulkier than that of olefins, and may thus have more difficulty in forming.

(iv) Due to the high reaction rates of olefins and monomethyl olefins, mass transport effects arise in large crystals due to diffusional resistances.

(v) The total length of the molecular chain has a minor effect on the diffusivity (and hence the reaction rate), whereas the diffusivity drops by a factor of $10^{4}$ from linear to dimethyl paraffin structures.

These observations correspond both to Csiscery's classification of shape selective effects in zeolites and Choudhary and Akolekar's model described in Section 1.1.3.1.

An experimental example of secondary shape selectivity is the cracking of $\mathrm{nC} 6$ and $\mathrm{nC} 16$ over ZSM-5 and SSZ-16 investigated by Santilli and Zones [1990]. Both catalysts crack $\mathrm{nC} 6$ and $\mathrm{nC} 16$, but when a $50 / 50$ mixture (by volume) of reactants is used over ZSM-5, nC6 has little or no effect on $\mathrm{nC} 16$ conversion, but $\mathrm{nC} 16$ greatly retards the $\mathrm{nC} 6$ conversion. Here, because $\mathrm{nC} 16$ has a much higher boiling point than $\mathrm{nC} 6$, selective adsorption of $\mathrm{nC} 16$ in the zeolite channels is the likely cause for the inhibition of nC6 cracking, and the phenomenon is not a shape selective effect. On SSZ-16, nC16 causes a slight 
increase in nC6 conversion, whereas nC6 completely eliminates $\mathrm{nC} 16$ conversion. As $\mathrm{nC} 6$ is both smaller and lower boiling than $\mathrm{nC} 16$, this is a steric effect in which case the nC6 together with the SSZ-16 channel keep nC16 from reacting.

Experimental observations of the nesting effect on the external surface described by Derouane [1986] have been claimed by Fraenkel et al. [1984]. Fraenkel et al. [1984 and 1986] and Fraenkel and Levy [1989a and 1989b] further speculate that the external Brönsted acid sites are located in "half" channel intersection cavities. These "half" cavities are characterized by largerthan-10-ring openings (Figure 1.19).

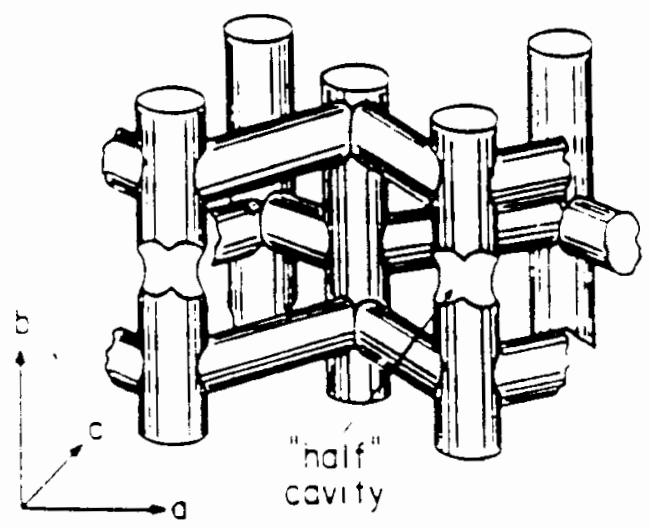

FIGURE 1.19: "Half" channel intersection cavities [Fraenkel et al., 1984]

The medium size channels of ZSM-5 allow diffusion of linear hydrocarbons and small aromatic molecules, such as $p$-xylene and toluene, but restrict the motion of larger molecules. Fraenkel et al. [1984] propose that there are two types of catalytic sites on ZSM-5. The first type is located inside the crystal, corresponding to $100 \% p$-selectivity in xylene production or isomerization. The other resides on the external surface of the zeolite, and is not shape-selective (ie. it gives the thermodynamic equilibrium mixture). Any xylene product composition obtained over ZSM-5 would thus be analysed as the sum of the two contributions: that of the selective and that of the unselective sites. These findings have been disputed by Neuber and Weitkamp [1989]. Neuber and Weitkamp suggested that the observed effects could be rationalized in terms of 
diffusional restrictions inside the channels rather than in terms of shape selective sieving effects on the external surface.

The effects of cation exchange and poisoning have been investigated by Choudhary and Akolekar [1991]. H.Na-ZSM-8 and H.Na-ZSM-5 show an increase in shape selectivity for xylene isomerization and toluene disproportionation with increasing $\mathrm{Na}$ content due to an increase in the diffusional resistance with increasing $\mathrm{Na}$ exchange. Similarly, poisoning of these catalysts with pyridine results in an increase in shape selectivity for the above mentioned reactions, also due to increased diffusional resistances.

\subsubsection{Summary}

The internal surface of ZSM-5 certainly plays a major role in shape selective catalysis. The effect of the external surface is less certain. Larger molecules, either in the reaction or product mixtures, will have greater diffusional resistances inside the channels than smaller molecules. Therefore the acid sites on the external surface will play a greater role in the reaction of large molecules than molecules that readily diffuse through the channels. Therefore, even though the number of acid sites on the external surface is small compared to the total number of acid sites, these easily accessible and non-shape selective acid sites may provide a high turnover rate for non-shape selective reactions. This will be most noticeable for small crystallite sizes, as these crystals will have the largest ratio of external/internal surface area. 


\subsubsection{COKE FORMATION AND DEACTIVATION OF ZEOLITES}

Deactivation of catalysts is of considerable importance in catalysis because many catalysts show a loss of activity with time. The loss in activity of zeolites may be caused by [Bhatia et al., 1989-90]:

(i) The formation of coke, which will accumulate on the surface and/or block the channels,

(ii) The selective adsorption of undesirable agents, especially basic compounds, which poison the active sites,

(iii) Sintering, which changes the structure and the surface area of the catalyst.

Poisoning by bases and structural rearrangements brought on by sintering can be controlled by feed purification or appropriate choice of reaction conditions. All reactions of organic compounds on solid acid catalysts are accompanied by the formation of heavy by-products which form a hydrogen-deficient deposit, viz. coke, on the surface and result in deactivation. The deactivation rate depends on the relative rate of formation of these by-products, which can be very different from one catalytic system (catalyst + reaction + reaction conditions) to another [Guisnet and Magnoux, 1989; Magnoux et al., 1987; Bhatia et al., 1989-90]. The deactivation rate depends also on the mode of deactivation.

The formation of coke is a shape selective reaction. This concept was first introduced by Rollmann [1977]. He suggests that coke formation and deactivation rates are intrinsic properties of the channel structure. Cycloparaffin pre-cursors, and hence coke, cannot readily form in the restrictive pore system of shape selective catalysts. Large pore catalysts offer little restriction to coke formation and deactivation becomes significant. Rollmann and Walsh [1979] further suggest that while catalyst composition and crystal size can influence coke formation, these are secondary effects. Not all coke is formed in the intracrystalline pore system, but intracrystalline coke formation is a shape selective reaction directly controlled by the zeolite channel structure. Therefore not all zeolites have the same propensity to coke. 
The nature of the coke, the effect of the zeolite structure, the location of the coke and the modes of coke formation and deactivation have been studied widely [Guisnet and Magnoux, 1989; Rollmann, 1977; Magnoux et al., 1987; Anderson et al., 1989b; Karge, 1991]. This is briefly summarized in Sections 1.1.4.1 to 1.1 .4 .5 .

\subsubsection{The nature of the coke}

Karge [1991] describes several methods by which coke has been analysed. Using this approach, coke can be divided into two types [Guisnet and Magnoux, 1989; Karge, 1991], namely soft (or soluble, non-graphitic) coke and hard (or insoluble, graphitic) coke. Soft coke consists mainly of paraffinic, olefinic and polyolefinic species $(\mathrm{H} / \mathrm{C}$ ratio $>1$ ), whereas hard coke consists predominantly of alkylaromatics and polyaromatics $(H / C$ ratio $<1)$. According to Guisnet and Magnoux [1989] soluble coke molecules are intermediates in the formation of insoluble coke. They conclude that insoluble coke is not formed at low coke content, and that the aromaticity of the soluble coke increases with the coke content.

Schulz et al. [1987] and Magnoux et al. [1987] report that the coke found in the channels of HZSM-5 consists mainly of alkylated 2-ring aromatics, although the exact nature of the coke may depend on the feed [Bhatia et al., 1989-90]. In the case of HY bulky aromatic rings (more than 3 rings) can be found in the supercages [Magnoux et al., 1987; Bhatia et al., 1989-90].

The coke on HZSM-5, H-OFF and USHY was studied by Gallezot et al. [1988] using TEM and EELS. The external coke formed on HZSM-5 and H-OFF gave an EELS spectrum not much different from that of coronene, indicating that the coke is made up of graphite-like polyaromatic molecules. The external coke formed on USHY consists of linear polyaromatic filaments protruding from the channels.

\subsubsection{The effects of channel structure}

As has been mentioned in Section 1.1.4, the zeolite structure influences the formation of coke, and hence deactivation, because coke formation is a shape 
selective reaction [Rollmann, 1977; Rollmann and Walsh, 1979]. It is difficult to evaluate with precision the effect of channel structure on coking rate since it is impossible to obtain the same acidity for zeolites with different channel structures. The coking rate is greater when:

(i) The space available for its formation (in cavities or channel intersections) is greater, and

(ii) The intermediates to coke formation diffuse more slowly out of the channels.

\subsubsection{The mode of coke formation}

The coke formation on zeolites probably occurs through cracking of paraffins and olefins, oligomerization of the olefins, transformations through hydrogen transfer into monoaromatics, alkylation of these monoaromatics and cyclization and hydrogen transfer to polyaromatics [Guisnet and Magnoux, 1989]. The channel structure can have a significant effect in these steps:

(i) Steric constraints can limit the reaction occurring through intermediates having a size comparable to that of the space available near the acid sites (shape selective effects), and

(ii) Because of limitations in the diffusion of reactive components or of their trapping within zeolite cages, these compounds participate in the formation of coke (diffusional effects).

Bulow et al. [1987] investigated the cracking of $n$-hexane and mesitylene on HZSM-5. Coke deposits formed from $n$-hexane cracking were distributed homogeneously throughout the crystal, while coke deposits formed from mesitylene cracking were deposited on or near the external surface. Hence bulky molecules such as mesitylene promote coke formation on the external surface, while smaller molecules, at least initially, promote coke formation in the channels. Anderson et al. [1989b] report that deacidification of the external surface of HZSM-5 with $\mathrm{SiCl}_{4}$ reduces the amount of aromatic residue held externally, especially at higher temperatures. 


\subsubsection{The location of coke}

An important problem related to the coking of zeolites is the formation and location of the coke deposits, namely in the channels, in the cavities or on the external surface. Most researchers believe that coke is initially formed in the channels of HZSM-5 and later on the external surface [Anderson et al., 1989b; Bibby et al., 1986; Bulow et al., 1987 for example]. Magnoux et al. [1987] also propose that initial coke formation occurs in the channels and cavities of HM and $\mathrm{HY}$ before coke is formed on the external surface.

The amount of coke deposited on HZSM-5 before external coke is detected varies. Bibby et al. [1986] report values of $14-18 \mathrm{wt} \%$ before the onset of external coke formation, whereas Behrsing et al. [1989] report a value of 6 wt\%. However, Anderson et al. [1989b] report that migration of coke from the channels to the external surface occurs as the temperature is raised. Hence the amount of coke on the external surface may depend on the reaction and/or reaction conditions. This is in agreement with Bhatia et al. [1989-90]. Bibby et al. [1986] also state that coke continues to form during thermal cracking reactions on the hot catalyst bed, even after complete deactivation. Furthermore, the amount of coke formed was found to be in excess of the pore volume, with ratios of external coke to internal coke ranging from 5 - 14 for different particle sizes.

\subsubsection{The mode of deactivation}

Magnoux et al. [1987] investigated the deactivation modes of HM, HY and HZSM- 5 during $n$-heptane cracking. Coke formation, initially very rapid on HM and $H Y$, is very slow on HZSM-5. As mentioned in Section 1.1.4.4, coke is formed initially in the channels and cavities, and then on the external surface. The modes of deactivation are described below [Magnoux et al., 1987].

(i) On $\mathrm{HM}$, deactivation is mainly due to pore blockage.

(ii) On HY small polyaromatics are initially formed on the strongest sites, until diffusion becomes slow and the bulky molecules block the entry to the cavities. Then the coke content increases at a slower rate as new coke molecules are formed, but also due to the growth of existing coke deposits, both in the channels and on the external surface. 
(iii) For HZSM-5 deactivation is initially due to coverage of acid sites located at channel intersections by small ( 1 or 2 ring) aromatics. Later on, bulkier polyaromatics form extremely slowly on external acid sites or from acid sites located near the external surface, thereby blocking the channels.

\subsubsection{Summary}

The smaller aromatic molecules formed in the channels of HZSM-5 can diffuse out of the channels with relative ease due to the intersecting channel system of this zeolite. Thus HZSM-5 does not deactivate extensively due to coke formation in its channels. However, when coke formation on the external surface becomes dominant, the poly-aromatic molecules on the external surface block access to the channels. It is this coverage of the external surface which causes the deactivation of HZSM-5, as indicated by Figure 1.20.

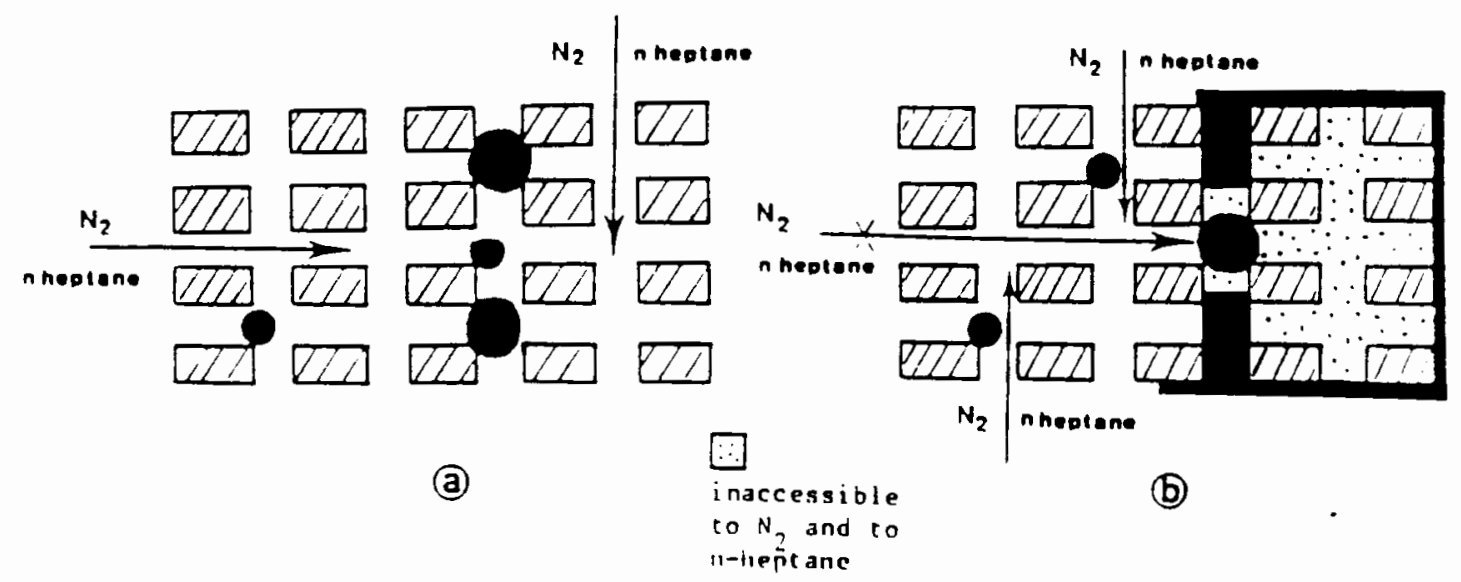

FIGURE 1.20: Schematic representation of the coke distribution on HZSM-5 for (a) low coke content, and (b) high coke content [Magnoux et al., 1987] 


\subsubsection{ZSM-5 SYNTHESIS}

The synthesis of ZSM-5 was patented by Argauer and Landolt [1972] in the early seventies. The synthesis method essentially follows the gel method. Zeolites, with the possible exception of silicalites, are synthesized in an oxide system containing $\mathrm{H}_{2} \mathrm{O}-\mathrm{SiO}_{2}-\mathrm{Al}_{2} \mathrm{O}_{3}$-(alkali, alkaline earth, organic cation) at temperatures below $200^{\circ} \mathrm{C}$ and at autothermal pressures [Sand, 1980].

Si n.m.r. studies [Boxhoorn et al., 1983] have provided evidence for the presence of the double five ring silicate shown in Figure 1.21. With a relatively small number of breaking and formation of Si-O bonds, the building block for ZSM-5 can be obtained [Kokotailo et al., 1978]. Provided the $\mathrm{pH}$ conditions are high enough ( $>10.5$ for the presence of $\left.\mathrm{Al}(\mathrm{OH})_{4}{ }^{-}\right)$it has been proposed that an intermediate aluminosilicate species may be formed via a condensation reaction [Roozeboom et al., 1983]. These species could give rise to aluminium analogues of the siliceous ZSM-5 building blocks shown in Figure 1.21.
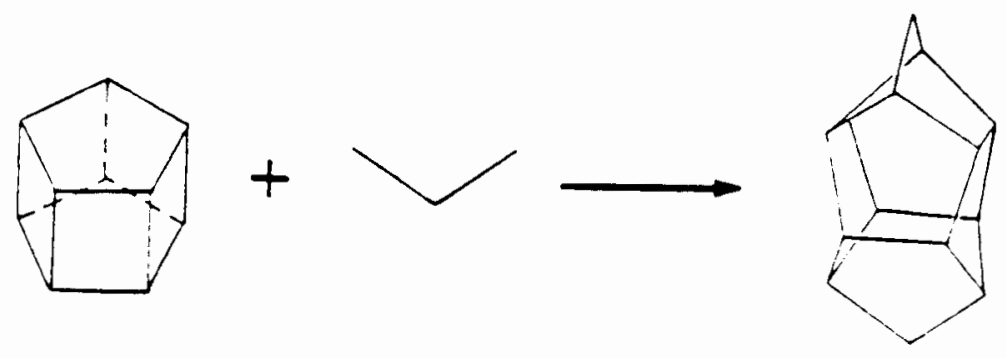

Figure 1.21: Formation of the ZSM-5 building block from a double 5-ring silicate

The main variables of the gel method for zeolite synthesis are:

- the organic cation or template

- the $\mathrm{pH}$ of the synthesis mixture

- the aluminium content

- the nature of the silicon source

- the alkali metal cation

These variables and their influence on catalyst characteristics are briefly discussed in the following sections. 


\subsubsection{The role of the template}

Gabelica et al. [1983a] report that tetrapropylammonium (TPA) ions which are used as a template during ZSM-5 synthesis form complexes with aluminosilicate and silicate species, subsequently replicating the framework via stereospecific interaction.

It has been suggested that a maximum of one TPA cation occupies each channel intersection. The number of channel intersections per unit cell in ZSM-5 is 4 . Indeed, it was shown by Nagy et al. [1983] that the number of TPA cations (3.3 - 3.8 per unit cell) approaches this value. Rollmann [1983] showed that $\mathrm{TPA}+/ \mathrm{SiO}_{2}$ ratios greater than 0.05 are required for complete zeolite pore filling and correspondingly good synthesis yields. This corresponds to 3 - 4 TPA molecules per unit cell.

\subsubsection{The influence of $\mathrm{pH}$}

While the nucleation and growth rates normally increase with increasing $\mathrm{pH}$, at very high $\mathrm{OH}^{-}$concentrations $\left(\mathrm{pH}\right.$ values above 11-12), the $\mathrm{OH}^{-}$species attached to the aluminosilicate groups undergo ionization and prevent further polymerization. Nucleation starts to compete with growth. The formation of small particles is observed, mainly due to a secondary nucleation of the ingredients released from the dissolution of the larger units [Derouane and Gabelica, 1986; Szostak, 1989). At lower $\mathrm{pH}$ values ( $\mathrm{pH}$ values below 9 ) the dissolution process is essentially absent and large crystals are formed. The $\mathrm{OH}^{-} / \mathrm{SiO}_{2}$ ratio most strongly influences the composition and degree of polymerization of the aluminosilicate unit, and thus crystallite size.

\subsubsection{The effect of aluminium content}

It has been observed that the crystallization rate and crystallite size decrease for increased Al content [Van der Gaag, 1985]. The incorporation of Al into the structure is disruptive, and thus the more Al present in the synthesis gel the more difficult it becomes to be incorporated into the structure. This then leads to the growth of smaller crystals. 
Another factor which may influence the crystallite size is the effect of agitation. This may have the effect of increasing the homogeneity of the synthesis mixture and hence of the aluminium contained in the synthesis gel. Agitation may result in smaller crystals.

\subsubsection{The effect of the silica source}

Derouane et al. [1981] reported that the use of polymeric silica as silica source, and with low Si/Al ratios, a small number of nuclei were formed via liquid phase ion transportation. This produced large crystals with inhomogeneous aluminium distributions. Many small crystals were formed when monomeric silica was used as silica source and when the Si/Al ratio was higher. Crystallization proceeded via solid phase hydrogel transformations. The aluminium distribution was found to be more homogeneous. It was proposed that the two mechanisms were essentially dependent on the silica source and the relative concentrations of the reactants.

\subsubsection{The effect of the alkali metal cation}

Gabelica et al. [1983b] have reported that the nucleation process is affected by the properties of the alkali cation. Depending on their size, they can have a structure forming effect ( $\mathrm{Li}, \mathrm{Na}$ ), or a structure breaking effect ( $K, \mathrm{Rb}, \mathrm{Cs}$ ). Structure forming alkali cations such as $\mathrm{Li}$ or $\mathrm{Na}$ resulted in the rapid crystallization of many, but small polycrystalline aggregates. On the other hand, when a structure breaking alkali cation was added to the synthesis mixture, large crystals were formed. 


\subsubsection{THE ELIMINATION OF THE EXTERNAL ACIDITY OF ZEOLITES}

From Sections 1.1.3 and 1.1.4 it has become clear that the external surface of zeolites, especially in ZSM-5, can play a major role in non-shape selective reactions and in the coke induced deactivation of these zeolites. Bhatia et al. [1989-90] state that, "for shape selectivity to occur, essentially all the catalytic active sites must be in the interior of the pores. The exterior area of the zeolite crystals is only about $1 \%$ of the total, but if diffusion limitations are significant, it may be necessary to poison or inactivate exterior sites so they do not contribute excessively to the reaction." Anderson et al. [1989b] state that "retained products may function as possible precursors to coke formation and deactivation of the catalyst. Deacidification of the external surface would reduce the amount of aromatic residue held externally."

There are several methods of altering the acidity of zeolites. This section discusses some of these methods, the main emphasis being placed on the methods which are most likely to eliminate selectively the external acidity with a minimum of change to the bulk of the zeolite.

\subsubsection{Hydrothermal treatment}

The activity of HZSM-5 can be increased by mild steaming treatments [Nayak and Choudhary, 1984; Zholobenko et al., 1990; Andersen, 19911. Nayak and Choudhary [1984] and Lago et al. [1986] report a decrease in total acidity for steamed HZSM-5 from TPD-studies, due to the dealumination of the catalyst and the formation of extraframework Al species. XPS studies [Nayak and Choudhary, 1984] show an increase in the concentration of Al on the surface of the zeolite. Enrichment of the surface with Al has also been found for zeolite $Y$ by Akporiaye et al. [1986]. Furthermore, steaming causes the formation of mesopores [Szostak, 1991]. Therefore hydrothermal treatment is not suitable for the selective dealumination of the external surface. 


\subsubsection{Leaching methods}

Acid leaching is a dealumination method which is often used in conjunction with other methods, such as steaming. The extraframework Al species are removed from the zeolite using this method [Scherzer, 1984]. Steaming followed by acid leaching tends to leave HZSM-5 and HM with an Al deficient surface, but leaves HY with a near uniform distribution [Szostak, 1991]. However, according to Anderson et al. [1989a] and Handreck and Smith [1990] this method is not suitable for selective external surface dealumination.

The use of EDTA to dealuminate HY was first reported by Kerr [1968]. This method results in Al deficient surfaces [Dwyer et al., 1981], but also in the formation of mesopores [Akporiaye et al., 1986; Szostak, 1991]. However, bulk dealumination, at least for large pore zeolites such as HY, does occur.

\subsubsection{Chemical treatment}

Beyer and Belenykaja [1980] were the first to report on the bulk dealumination of zeolites using $\mathrm{SiCl}_{4}$. They were able to increase the Si/Al ratio of $\mathrm{NaY}$ from 2.5 to 50 without the destruction of the zeolite structure, using temperatures ranging from $457-557{ }^{\circ} \mathrm{C}$. It is believed that $\mathrm{Al}$ atoms were replaced by $\mathrm{Si}$ atoms according to the following reaction:

$$
\mathrm{M}_{1 / \mathrm{n}}\left[\mathrm{AlO}_{2} \cdot\left(\mathrm{SiO}_{2}\right)_{x}\right]+\mathrm{SiCl}_{4} \ldots>1 / \mathrm{nMCl}_{\mathrm{n}}+\mathrm{AlCl}_{3}+\left[\left(\mathrm{SiO}_{2}\right)_{x+1}\right]
$$

where $M$ is the charge balancing cation (in this case $\mathrm{Na}$ ).

Martens et al. [1990] showed this is in fact a 2-step reaction. Beyer and Belenykaja [1980] noted that $\mathrm{AlCl}_{3}$ and $\mathrm{NaCl}$ species blocked the channels, but these could be removed by acid leaching.

Namba et al. [1986] investigated the dealumination of $\mathrm{Na}-\mathrm{ZSM}-5$ using $\mathrm{SiCl}_{4}$. They noted that the structure was not destroyed and that the external acid sites were removed more selectively than the internal acid sites. Furthermore, the rate of 1,3,5-triisopropylbenzene (too large to enter the channels) cracking was found to be lower on $\mathrm{SiCl}_{4}$ dealuminated HZSM-5 than on the parent HZSM-5. $\mathrm{SiCl}_{4}$ dealumination also improved the shape selective alkylation of 1,2,4- 
trimethylbenzene with methanol. Cracking of cumene resulted in less coke formation on $\mathrm{SiCl}_{4}$ dealuminated $\mathrm{HZSM}-5$.

It was shown by Anderson et al. [1989a] that the lowest temperature, time and $\mathrm{SiCl}_{4}$ partial pressure in their studies $\left(600{ }^{\circ} \mathrm{C}, 1 \mathrm{~min}, 1.04 \mathrm{kPa}\right.$ respectively) resulted in the best surface dealumination for HZSM-5. However, they noted that for large extents of surface dealumination, bulk dealumination will take place. On the other hand, for minimal bulk dealumination, surface dealumination will be incomplete. These findings have also been confirmed by Handreck and Smith [1990], who reported that dealumination using $\mathrm{SiCl}_{4}$, followed by acid leaching, did not remove aluminium selectively from the crystalline surface.

$\left(\mathrm{NH}_{4}\right)_{2} \mathrm{SiF}_{6}$ has been used to dealuminate zeolite $\mathrm{Y}$ [Akporiaye et al., 1986; Neuber et al., 1988; Skeels and Breck, 1984]. This method does not dealuminate the external zeolite surface preferentially, but in fact produces the most homogeneous Al dispersion [Szostak, 1991] when compared to EDTA and steam dealumination. This method does not result in the formation of mesopores [Akporiaye et al., 1986]. Liu and $\mathrm{Xu}$ [1989] claim that $\mathrm{NH}_{4} \mathrm{BF}_{4}$ gives a more crystalline product compared to $\left(\mathrm{NH}_{4}\right)_{2} \mathrm{SiF}_{6}$, and that this is achieved without boron insertion into the framework.

\subsubsection{Chemical vapour deposition}

The use of chemical vapour deposition (CVD) to cover the external surface with silicon alkoxides has been investigated by Niwa and co-workers. Silicon alkoxides were chosen for their size and were not expected to enter the channels of the zeolite. Niwa et al. [1984b] have reported on the deposition of $\mathrm{Si}\left(\mathrm{OCH}_{3}\right)_{4}$ (kinetic diameter $0.89+-0.02 \mathrm{~nm}$ ) at $320^{\circ} \mathrm{C}$ on $\mathrm{HM}$. The amount of deposition was controlled by varying the partial pressure and deposition time. The weight gain was measured using a microbalance.

Niwa et al. [1988] report that during deposition at ambient temperatures, decomposition products (methanol, dimethyl ether) are adsorbed by the zeolite. These can be desorbed by raising the temperature. At higher deposition temperatures lower hydrocarbons were observed, possibly due to methanol conversion on HM. The catalyst was calcined in oxygen after the deposition, as 
some carbonaceous material had formed [1984a]. The reaction mechanism proposed by Niwa et al. [1988] is shown in Figure 1.22. First, the alkoxide reacts with the hydroxyl on the external surface to yield the anchored trimethoxide and methanol. Secondly, the trimethoxide is hydrolyzed by the remaining water in the system to form hydroxyl groups, which react further with the gaseous alkoxide or the vicinal trimethoxide. A polymeric silica layer consisting of siloxane bonds is obtained.
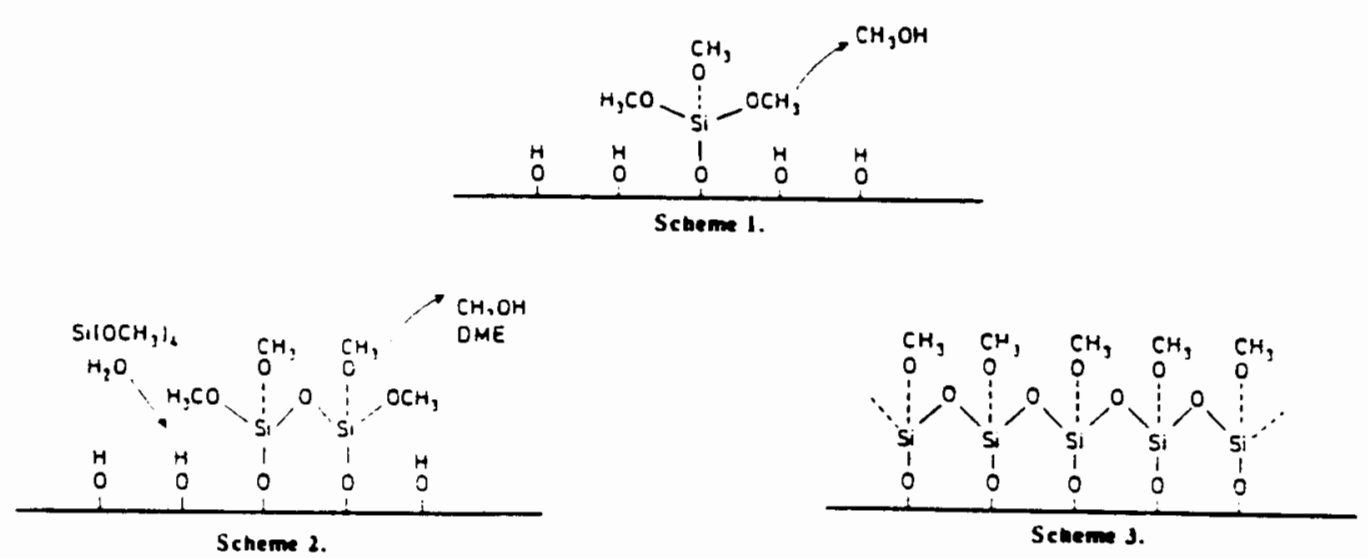

FIGURE 1.22: Reaction scheme for the Chemical Vapour Deposition of Si(OCH$)_{4}$ [Niwa et al., 1988]

A similar modification has been reported by Richter et al. [1991], who used 12tungstosilicic acid. They claim that the Keggin unit $\left(\mathrm{SiW}_{12} \mathrm{O}_{40}\right)^{4}$ cannot penetrate the ZSM-5 channel system but becomes deposited on the external surface. However, thermal decomposition of the acid yields $\mathrm{WO}_{3}$ at high loading accompanied by a loss of acid sites in the channel system. This is not exclusively caused by further dealumination but has to be partially attributed to site blocking by $\mathrm{WO}_{3}$. Obviously, the decomposition of the acid involves mobile species of smaller sizes which are able to migrate into the interior of the zeolite.

Niwa et al. [1988] employed various silanes, viz. Si(OMe $)_{4}, \mathrm{Si}(\mathrm{OMe}) \mathrm{Me}_{3}$ and $\mathrm{SiMe}_{4} . \mathrm{Si}(\mathrm{OMe})_{4}$ was found to be the most reactive. The methoxy group must be present for successful deposition of the silane. Furthermore, it was found that $\mathrm{Si}(\mathrm{OMe})_{4}$ is more reactive than $\mathrm{Si}(\mathrm{OEt})_{4}$ [Niwa et al., 1989].

$\mathrm{NH}_{3}$-TPD studies of HM [Niwa et al., 1984a] and HZSM-5 [Niwa et al., 1986] indicated that neither the peak maximum temperature nor the amount desorbed changed for the samples modified by $\mathrm{Si}\left(\mathrm{OCH}_{3}\right)_{4}$ deposition. Similarly, The $\mathrm{H}_{2} \mathrm{O}$ 
and $\mathrm{N}_{2}$ adsorption capacity and adsorption rate remained unchanged, whereas for $\sigma$ - and $p$-xylene the adsorption rate decreased significantly [Hibino et al., 1991; Niwa et al., 1986; Niwa et al., 1984a] for the modified samples. These findings confirmed the conservation of zeolite adsorption capacity (ie. $\mathrm{Si}\left(\mathrm{OCH}_{3}\right)_{4}$ deposition did not affect the internal acid sites), but also implied that the channel openings were narrowed by the deposition of the silane. This was also shown by Niwa et al. [1984b], who found that the rates of hexane, 2-methyl pentane and 2,2-dimethyl butane sorption on modified HM were suppressed by $\mathrm{Si}\left(\mathrm{OCH}_{3}\right)_{4}$ deposition, especially for the branched molecules.

SEM studies indicated no differences between modified and unmodified catalysts. XPS showed an increase in the Si content of the surface layer of modified samples [Niwa et al., 1984a]. IR studies revealed $\mathrm{C}-\mathrm{H}$ stretching vibrations at 2950 and $2850 \mathrm{~cm}^{-1}$, which were removed by calcination in $\mathrm{O}_{2}$ at $400{ }^{\circ} \mathrm{C}$ [Niwa et al., 1986]. Hydroxyl bands at 3740 and $3600 \mathrm{~cm}^{-1}$ were altered upon deposition. The intensity of the $3600 \mathrm{~cm}^{-1}$ band was restored upon desorption of the decomposition products of the CVD process. This indicated that the internal Brönsted acid sites were not altered by the deposition. The $3740 \mathrm{~cm}^{-1}$ band was not restored completely upon desorption of the decomposition products of the CVD process, indicating that the isolated $\mathrm{Si}-\mathrm{OH}$ existing on the external surface was altered by the deposition process.

Various reactions have been applied to investigate the effects of silane deposition. The cracking of $\mathrm{C}_{8}$-paraffins on HM [Niwa et al., 1984b] showed that the cracking of octane remains unaffected, whereas 2,2,4-trimethyl pentane is unreactive on modified samples. Methanol conversion on modified HZSM-5 [Niwa et al., 1986] showed a decrease in large (aromatic) molecules and a corresponding increase in that of small olefins. Details of the aromatic product distribution reveal a remarkable change towards the smaller isomers with increasing deposition, indicating greatly enhanced shape selectivity due mainly to pore narrowing but also due to deacidification of the external surface. The lifetime was not enhanced by the deposition. The results of studies of the alkylation and disproportionation of toluene and the isomerization of $\sigma$-xylene on HZSM-5 [Hibino et al., 1991], showed similar increases in the fraction of the $p$ isomer selectivity, the $p$-xylene selectivity reaching $98 \%$ in some catalysts. In the case of 1,3,5-triisopropyl benzene cracking, which cannot enter the channels of HZSM-5, the conversion was virtually completely suppressed with high levels of deposition. 


\subsubsection{Silicalite shells}

A US patent by Rollmann [1980] reports on the silicalite-l coating of ZSM-5 by reintroduction of the ZSM-5 crystals into an aluminium-free synthesis mixture. This is said to yield ZSM-5 crystals with an Al-rich core with an Al-free shell with an isostructural configuration. Handreck and Smith [1990] investigated this method of coating the external surface and concluded that this method did not restrict access to the channels of the zeolite. However, the possible presence, in the final product, of acidic amorphous silica that has the potential to catalyze reactions in a non-shape selective manner may place a limit on the overall effectiveness of this method.

Warzywoda et al. [1991] investigated seeding Al-free ZSM-5 crystallizations with Al-free crystals to study the role of the seed crystal in promoting the synthesis of a subsequent batch. They noted that very little growth was observed, but that new populations were observed to form both around the seeds and on the seed surface. Jacobs and Martens [1987] note that for successful seeding the template-to-silica ratio should be kept low when large amounts of seeds are used.

Lee et al. [1993] report that the inactivation of the acid sites on the external surface by coating the crystals increases the $p$-selectivity in toluene alkylation, without narrowing of the channels. In this case Na-ZSM-5 was used as seeds. $X R D$ patterns of coated crystals showed reduced intensities of the peaks near $7.9^{\circ}$ and $23.1^{\circ} 2 \theta$. Crystal sizes could not be compared quantitatively by SEM pictures only, as a catalyst with a shell-to-core weight ratio of $1: 1$ is only expected to be 1.26 times larger than the seed. $\mathrm{NH}_{3}$-TPD showed decreased peak intensities and the peak maximum temperatures were also lower for the coated samples. Both these observations were probably due to the reduction in the number of acid sites per unit weight of catalyst, because the modified catalysts consisted of both ZSM-5 and silicalite-I phases. 


\subsection{TEMPERATURE PROGRAMMED DESORPTION FROM ZEOLITES}

The temperature programmed desorption technique is commonly ascribed to Amenomiya and Cvetanovic [1963a], who reported this technique in 1963 using an ethylene-alumina system. The technique involves the desorption of a probe, previously adsorbed under controlled conditions, from a catalyst into an inert carrier gas, by raising the temperature of the catalyst linearly and measuring the amount of probe desorbed using a suitable detector.

Numerous catalysts have been investigated using this method, such as alumina [Amenomiya and Cvetanovic, 1963a; Amenomiya and Cvetanovic, 1963b; Amenomiya and Cvetanovic, 1963c; Amenomiya et al., 1964], silica-alumina [Amenomiya and Cvetanovic, 1970; Schwarz et al., 1978], zeolite $X$ [Kiskinova et al., 1981], mordenite [Kapustin et al., 1988] and ZSM-5 [Kofke et al., 1988; Topsoe et al., 1981; Hidalgo et al., 1984]. The probes which have been used include ammonia [Amenomiya et al., 1964; Post and Van Hooff, 1984; I wamoto et al., 1986], pyridine [Schwarz et al., 1978; Topsoe et al., 1981; Parrillo et al., 1990], alkenes [Amenomiya and Cvetanovic, 1963a; Kofke and Gorte, 1989], alcohols [Kofke et al., 1988; Kofke et al., 1989] and other amines [Post and Van Hooff, 1984; Pope, 1990; Parrillo et al., 19901. The detectors used have included infrared [Topsoe et al., 1981; Parrillo et al., 1990], flame ionization [Nayak and Choudhary, 1983] and thermal conductivity [Amenomiya and Cvetanovic. 1963a] detectors, and mass spectrometers [Schwarz et al., 1978; Kofke et al., 1988; Parrillo et al., 1990].

The desorption spectrum is a plot of desorption rate versus temperature, and consists of one or more peaks which identify specific sites on the catalyst surface. Using suitably calibrated thermal conductivity detectors, flame ionization detectors, mass spectrometers or titration methods, the amount of desorbed material can be determined and, in the case of bases desorbed from acid catalysts, this can be related to the number of acid sites on the catalyst surface. In principle, a distribution of acid site strength with respect to temperature can be obtained. Desorption activation energies can also be obtained [Cvetanovic and Amenomiya, 1972], but valid interpretation of the data is essential. 
The peak shape and the position of the peak maximum have been investigated thoroughly, and are functions of readsorption of the probe molecule onto the channel walls [Gorte, 1984; Cvetanovic and Amenomiya, 1967; Rieck and Bell, 1984], diffusion [Gorte, 1984; Jones and Griffin, 1981], particle size [Tronconi and Forzatti, 1985], bed depth [Rieck and Bell, 1984], carrier gas flowrate [Rieck and Bell, 1984], surface heterogeneity [Amenomiya and Cvetanovic, 1963c] and surface coverage [Schwarz et al., 1978; Kiskinova et al., 1981]. The activation energy for desorption can be calculated by using different heatir.g rates, assuming first order desorption and that large pore diffusional effects are absent [Cvetanovic and Amenomiya, 1972]. Usually, the rate limiting step in porous catalysts is the diffusion of the probe out of the catalyst (due to readsorption) [Gorte, 1982; Demmin and Gorte, 1984; Jones and Griffin, 1983]. Gorte [1982] and Demmin and Gorte [1984] have proposed a set of design parameters, in the form of dimensionless groups, by which it is possible to carry out TPD experiments under conditions which will ensure sound data interpretation.

\subsubsection{TEMPERATURE PROGRAMMED DESORPTION THEORY}

A mathematical model of temperature programmed desorption has been described by Cvetanovic and Amenomiya [1967 and 1972]. They assumed a linear heating rate, first order desorption kinetics, an energetically homogeneous surface and no diffusional or readsorption effects. The following expressions were terived:

$$
\left(k_{d}\right)_{m}=A \exp \left(-E_{d} / R T_{\max }\right)=b E_{d} / R T_{\max }^{2}
$$

where,

$$
\begin{aligned}
& \left\langle k_{d}\right\rangle_{m}=\text { desorption rate constant } \\
& A \quad=\text { pre-exponential factor } \\
& E_{d}=\text { desorption activation energy } \\
& R \quad=\text { gas constant } \\
& T_{\max }=\text { temperature of peak maximum } \\
& b \quad=\text { heating rate }
\end{aligned}
$$

Equation 1.1 can be rewritten as:

$$
2 \ln T_{\max }-\ln b=E_{d} / R T_{\max }+\ln \left(E_{d} / A R\right)
$$


From Equation 1.2 it can be seen that the desorption activation energy can be obtained by plotting ( 2 In $T_{\max }$ - In b) versus $1 / T_{\max }$. It should be noted that when the variation of the heating rate, $b$, is small, the accuracy of this method will be low.

The peak shape can, in principle, provide values of $E_{d}$, but only for homogeneous surfaces without readsorption, as in such cases the peak shape is uniquely defined by the ratios $E_{d} / T_{\max }$ [Cvetanovic and Amenomiya, 1972]. However, due to dispersion in the lines linking the sample cell to the detector, significant peak broadening may still occur before the desorbed adsorbate reaches the detector.

As previously mentioned Gorte [1982] and Demmin and Gorte [1984] have proposed a set of design parameters, in the form of dimensionless groups, by which it is possible to carry out TPD experiments under conditions which will ensure sound data interpretation. The design parameters are listed in Table 1.1.

Complications due to lag times in the sample cell (Group 1 in Table 1.1), resulting in long residence times, should be avoided. Diffusional limitations in the catalyst channels (Group 2) can be minimized by using low heating rates. Concentration gradients in the catalyst particles will be significant when Group 3 is greater than 0.05 . Low flowrates will result in smaller concentration gradients in the catalyst particles. When Group 3 is greater than 10 the flowrate may be considered infinite since the mass transfer process is then diffusion limited. Group 4 determines the extent of back-mixing in the packed bed. When Group 5 is greater than unity readsorption will be important even for infinite flowrates. When flowrates are low enough so that no gradients are present in the particles, the importance of readsorption is determined by Group 6. These parameters are often much greater than 1 , especially in porous materials, indicating that readsorption can often significantly increase the observed peak temperature.

When conducting experiments under conditions for which the criteria for cell (convective) and channel (diffusive) lag times are satisfied, yet with flowrates high enough to generate concentration profiles within the channels, then valid comparisons of TPD spectra can still be made if constant heating rates, catalyst masses, carrier gas flowrates and initial surface coverages are used in all cases. Also, since the peak temperature may be raised due to readsorption, when the 
magnitude of the Group 3 parameter exceeds 10 (infinite flowrate, diffusion limited), both the TPD peak shape and temperature will remain unaffected by changes in the flowrate. Under these conditions comparisons of TPD spectra will be more meaningful than if fluctuations in the carrier gas flowrate would affect the desorption peaks. This does not allow for the determination of absolute values of adsorption energies, but relative values may still be obtained from the peak temperatures.

The parameters proposed by Demmin and Gorte [1984] have been derived assuming first-order desorption kinetics and the bed is modelled as a CSTR. Jones and Griffin [1983] considered the case of Langmuir adsorption kinetics, since this is more appropriate than the assumption that desorption for readsorption) is independent of surface coverage. They assumed the TPD process to be diffusion limited. For desorption from a flat surface (ie. no readsorption) the TPD spectrum exhibits essentially a Gaussian distribution [Jones and Griffin, 1983; Gorte, 1982; Demmin and Gorte, 1984; Herz et al., 1982]. If readsorption occurs the TPD spectrum is skewed towards higher desorption temperatures [Jones and Griffin, 1983; Gorte, 1982; Demmin and Gorte, 1984]. Jones and Griffin [1983] showed that, for higher initial coverages, there is an increase in the desorption rate on the leading edge llow temperature side) of the TPD spectrum. The higher fraction of occupied sites meant that diffusing molecules are less likely to be "restrained" by readsorption, especially at the start of desorption. Also, as a result of readsorption and because of saturation effects associated with Langmuir adsorption kinetics, the peak maximum temperature shifts to lower values as the initial coverage is increased.

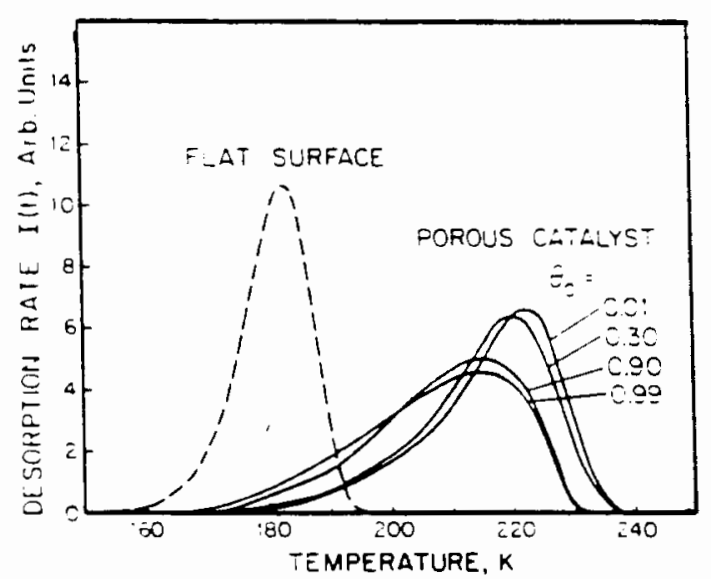

Figure 1.23: Simulated TPD spectra [Jones and Griffin, 1983] 
TABLE 1.2: TPD design parameters [Demmin and Gorte, 1984]

\begin{tabular}{|c|c|c|c|c|}
\hline & Parameter & Definition & Observed Effect & Ideal requirement \\
\hline 1. & $\frac{\varepsilon_{B} V_{\beta}}{Q\left(T_{f}-T_{0}\right)}$ & $\begin{array}{l}\text { Residence time } \\
\text { of carrier gas }\end{array}$ & Convective lag & $\begin{array}{l}\text { Must be }<0.01 \text { for } \\
\text { negligible lag }\end{array}$ \\
\hline 2. & $\frac{\varepsilon_{p r^{2} \beta}}{D_{p}\left(T_{f}-T_{0}\right)}$ & $\begin{array}{l}\text { Time constant for } \\
\text { diffusion out of } \\
\text { an individual } \\
\text { particle }\end{array}$ & Diffusive lag & $\begin{array}{l}\text { Must be }<0.01 \text { for } \\
\text { negligible lag }\end{array}$ \\
\hline 3. & $\frac{O r}{4 \pi^{2} N D_{p}}$ & $\begin{array}{l}\text { Ratio of carrier gas } \\
\text { flowrate to rate of } \\
\text { diffusion }\end{array}$ & $\begin{array}{l}\text { Particle concentra- } \\
\text { tion gradients }\end{array}$ & $\begin{array}{l}\text { Must be }<0.05 \text { for } \\
\text { negligible gradient }\end{array}$ \\
\hline 4. & $\frac{\mathrm{OL}^{2}}{V D_{B}}$ & $\begin{array}{l}\text { Ratio of carrier gas } \\
\text { flowrate to axial } \\
\text { mixing }\end{array}$ & $\begin{array}{l}\text { Bed concentration } \\
\text { gradients }\end{array}$ & $\begin{array}{l}\text { Must be }<0.1 \text { for } \\
\text { valid CSTR model }\end{array}$ \\
\hline 5. & $\frac{a p s F_{r^{2}}}{\pi^{2} D_{p}}$ & $\begin{array}{l}\text { Ratio of adsorption } \\
\text { rate to diffusion } \\
\text { rate }\end{array}$ & $\begin{array}{l}\text { Readsorption at } \\
\text { infinite flow- } \\
\text { rate }\end{array}$ & $\begin{array}{l}\text { Must be }<1 \text { for } \\
\text { negligible } \\
\text { readsorption }\end{array}$ \\
\hline 6. & $\frac{a \rho s F V\left(1-\varepsilon_{B}\right)}{0}$ & $\begin{array}{l}\text { Ratio of adsorption } \\
\text { rate to carrier gas } \\
\text { flowrate }\end{array}$ & $\begin{array}{l}\text { Readsorption at } \\
\text { low flowrate }\end{array}$ & $\begin{array}{l}\text { Must be }<1 \text { for } \\
\text { negligible } \\
\text { readsorption }\end{array}$ \\
\hline
\end{tabular}

where,

\begin{tabular}{|c|c|c|}
\hline $\boldsymbol{\sigma}$ & $=$ & particle surface area $\left(\mathrm{cm}^{2} / \mathrm{g}\right)$ \\
\hline$\beta$ & $=$ & heating rate $(\mathrm{K} / \mathrm{sec})$ \\
\hline$D_{B}$ & $=$ & bed dispersion coefficient $(\mathrm{cm} / \mathrm{sec})$ \\
\hline$D_{\mathbf{p}}$ & $=$ & particle dispersion coefficient $\left(\mathrm{cm}^{2} / \mathrm{sec}\right)$ \\
\hline$\varepsilon_{\mathrm{B}}$ & $=$ & bed porosity \\
\hline$\varepsilon_{\mathrm{p}}$ & $=$ & particle porosity \\
\hline $\mathrm{F}$ & $=$ & $(\mathrm{RT} / 2 \pi \mathrm{M})^{1 / 2}(\mathrm{~cm} / \mathrm{sec})$ \\
\hline $\mathrm{L}$ & $=$ & bed length $(\mathrm{cm})$ \\
\hline M & $=$ & molar mass $(g / m o l)$ \\
\hline $\mathrm{N}$ & $=$ & number of particles in the bed \\
\hline$\rho$ & $=$ & particle density $\left(\mathrm{g} / \mathrm{cm}^{3}\right)$ \\
\hline Q & $=$ & carrier gas flowrate $\left(\mathrm{cm}^{3} / \mathrm{sec}\right)$ \\
\hline $\mathbf{r}$ & $=$ & radius of particles $(\mathrm{cm})$ \\
\hline $\mathrm{R}$ & $=$ & ideal gas constant $\left(\mathrm{g} \mathrm{cm}^{2} / \mathrm{mol} \mathrm{sec} 2 \mathrm{~K}\right)$ \\
\hline $\mathbf{s}$ & $=$ & sticking coefficient \\
\hline $\mathrm{T}$ & $=$ & temperature $(\mathrm{K})$ \\
\hline$T_{f}$ & $=$ & final temperature $(\mathrm{K})$ \\
\hline$T_{0}$ & $=$ & initial temperature (K) \\
\hline V & $=$ & bed volume $\left(\mathrm{cm}^{3}\right)$ \\
\hline
\end{tabular}


As mentioned earlier, the peak shape and peak maximum temperature, $T_{\text {max }}$ can be altered by a number of factors. The most important of these are surface heterogeneity, surface coverage, readsorption and diffusion, but carrier gas flowrate, bed depth and particle size also affect either the peak shape or the peak maximum temperature.

\subsubsection{Surface heterogeneity and surface coverage}

Amenomiya and Cvetanovic [1963c] proposed that if the activation energy of desorption and the peak maximum temperature are constant, only the peak size would change depending on the amount of material adsorbed. However, by decreasing the amount of propylene adsorbed on alumina, the peak maximum temperature increased. They noticed that the leading edge (low temperature side) of the peak was gradually removed, whereas the trailing edge (high temperature side) remained unchanged. They concluded propylene was preferentially adsorbed onto strong sites, and these results indicated surface heterogeneity, or a range of activation energies of desorption (assuming no readsorption). Amenomiya et al. [1964] showed similar results for the desorption of ammonia from alumina.

When it is assumed that no readsorption occurs during temperature programmed desorption, the position of $T_{\max }$ is independent of initial surface coverage, if all adsorption sites are homogeneous. On heterogeneous surfaces the adsorbate will adsorb preferentially on the strongest acid sites, in which case $T_{\max }$ will increase with decreasing surface coverage. Such a shift in $T_{\max }$ has therefore been regarded to indicate a potential existence of surface heterogeneity. However, even with homogeneous adsorption sites there will be a similar shift if readsorption occurs [Cvetanovic and Amenomiya, 1967].

\subsubsection{Readsorption and diffusion}

Readsorption is intrinsic to the adsorption system being studied and can often not be eliminated by changing experimental parameters. The possibility of readsorption in porous catalysts should always be considered since it can raise $T_{\max }$ by several hundred degrees. The extent to which readsorption influences 
the peak position and shape was studied using a model developed by Rieck and Bell [1984], and was found to be comparable to Gorte's findings [Gorte, 1982].

When the desorption of the adsorbate is greater than its diffusion out of the channels of the catalyst, then adsorbate partial pressure builds up inside the catalyst. This can cause a lag in the detection of the desorbing adsorbate [Gorte, 1982]. The desorption is no longer the rate-limiting process, and the measured flux of molecules leaving the sample is determined by the rate of diffusion out of the catalyst channels, as modified by readsorption on the channel walls [Jones and Griffin, 1983]. These effects can be reduced by judicious choice of experimental conditions. However, for microporous solids, especially zeolites and molecular sieves, it may not be possible to eliminate these effects totally.

Readsorption should be considered especially when reaction is occurring along with desorption [Gorte, 1982]. The many desorption and readsorption processes imply that TPD with reaction will not be much different from running a reaction at the instantaneous pressure and temperature of the desorption. Thus only questions about the reaction, which cannot be answered by reaction studies, should be addressed using TPD.

\subsubsection{Carrier gas flowrate, bed depth and particle size}

An increase in carrier gas flowrate results in a peak shift to lower temperatures and sharper peaks [Rieck and Bell, 1984]. Such effects have been reported by Fletcher [1984]. With increasing flowrate, the concentration of the adsorbate in the voids between the particles decreases, thereby increasing the concentration gradient within the particle and decreasing the concentration at the center of the particle. This accelerates the rate of desorption while suppressing the rate of readsorption, thus shifting the peak temperatures to lower values. Hence, equilibrium readsorption prevails when a carrier gas is used to sweep away the desorbing adsorbate.

Rieck and Bell [1984] also showed that an increase in particle size increased the peak temperature. However, an increase in carrier gas flowrate would result in a point where the peak position and shape would no longer be sensitive to flowrate, as the desorption process would be dominated by intraparticle mass 
transfer. These findings correspond to those obtained by Tronconi and Forzatti [1985].

An increase in catalyst mass, or bed depth, may result in axial gradients along the bed [Rieck and Bell, 1984]. This will affect the desorption rate in a similar way to changes in the flowrate. A decrease in catalyst mass will tend to lower $T_{\text {max }}$. Should axial gradients be present, most models used are no longer appropriate as the bed is usually modelled as a CSTR.

\subsubsection{Summary}

The importance of the need for detailed information has been highlighted in the preceding sections when wishing to analyze TPD spectra. The influence of the various experimental parameters is pronounced, and makes comparisons difficult if the experimental parameters are not identical. It is therefore difficult to make claims about the strength of the acid sites of different catalysts, as indicated by $T_{\text {max }}$, based solely on TPD data. Especially when comparing modified catalysts, a change in $T_{\max }$ may not be due to a change in acid strength, but rather due to a change in one or more experimental parameters. However, $T_{\max }$ and the peak shape may still be instructive indications of changes to the system. The amount of adsorbate desorbed from the catalyst is also an instructive parameter obtained from TPD studies.

\subsubsection{TEMPERATURE PROGRAMMED DESORPTION FROM ZSM-5}

Topsoe et al. [1981] studied the acidic properties of ZSM-5 type zeolites by infrared spectroscopy and temperature programmed desorption. Ammonia was adsorbed at $20^{\circ} \mathrm{C}$ until saturated, then eluted at $20^{\circ} \mathrm{C}$ before increasing the temperature linearly. They observed three peaks with maxima in the regions $60-100^{\circ} \mathrm{C}, 150-200^{\circ} \mathrm{C}$ and $420-500^{\circ} \mathrm{C}$, named $\alpha, \beta$ and $\gamma$ respectively. They proposed that the $\gamma$-peak was associated with the adsorption of $\mathrm{NH}_{3}$ on strong Brönsted and/or Lewis acid sites, and that these sites would probably be located at the channel intersections. The IR band at $3605 \mathrm{~cm}^{-1}$ (Si-OH-Al groups) was 
found to be characteristic of these sites. The $\beta$-peak was ascribed to silanol (Si$\mathrm{OH}$ ) groups of weaker Brönsted acid strength, corresponding to an IR band at $3720-3740 \mathrm{~cm}^{-1}$, or with adsorption of $\mathrm{NH}_{3}$ on $\mathrm{Na}$ counterions. The $a$-peak was thought to be due to nonzeolitic material and did not seem to have any catalytic function.

These results were confirmed by, amongst others, Hidalgo et al. [1984]. $\mathrm{NH}_{3}$ was adsorbed and evacuated at $100^{\circ} \mathrm{C}$. TPD spectra showed two peaks at $147{ }^{\circ} \mathrm{C}$ (low temperature desorption peak - LTD peak) and $324{ }^{\circ} \mathrm{C}$ (high temperature desorption peak - HTD peak) respectively, but a third peak was observed at lower temperatures when $\mathrm{NH}_{3}$ was adsorbed at $20{ }^{\circ} \mathrm{C}$. The IR band at $3605 \mathrm{~cm}^{-1}$ was also ascribed to $\mathrm{Si}-\mathrm{O}-\mathrm{Al}$ groups, corresponding to the HTD peak. They did, however, suggest that the low temperature desorption peak $\left(147^{\circ} \mathrm{C}\right.$ ) is also in some way related to the IR band at $3605 \mathrm{~cm}^{-1}$ (Si-O-Al groups). Indeed, Iwamoto et al. [1986] suggested that the LTD peak of $\mathrm{NH}_{3}$ results from physisorbed or very weakly chemisorbed molecules, but not from $\mathrm{NH}_{3}$ bonded to weak acid sites. Furthermore, Pope [1990] suggested that, unlike other larger amines, more than one $\mathrm{NH}_{3}$ molecule can be adsorbed strongly per acid site. A peak at higher temperatures $\left(677^{\circ} \mathrm{C}\right.$ and above) was found to be due to dehydroxylation of the zeolite [Hidalgo et al., 1984; Iwamoto et al., 1986].

Post and Van Hooff [1984] investigated $\mathrm{NH}_{3}$-TPD and $n$-hexane cracking on HZSM-5 and silicalite-I (which is isostructural to ZSM-5, but has no acidity). They observed a LTD peak and a HTD peak from HZSM-5, but only a LTD peak from silicalite-l. The acidity of silicalite-I arises from Si-OH groups at the crystal surface. Furthermore, since silicalite-I shows no activity for $n$-hexane cracking, only the HTD peak from HZSM-5 is of catalytic interest. Hunger et al. [1990] increased the $\mathrm{NH}_{3}$ dosage gradually, and noticed that the HTD peak appeared first, and the LTD peak appeared only when the dosage was increased. This implies that the adsorbate is adsorbed preferentially onto the strong acid sites, as indicated by the HTD peak. This is in agreement with the findings of Cvetanovic and Amenomiya [1967].

It has been pointed out that the use of certain amines may give unreliable results for the measurement of acid site concentration due to the reactivity of the molecules upon heating, or the exclusion of two molecules present at adjacent sites [Pope, 1990]. Parrillo et al. [1990] examined the desorption of 
simple amines (methyl-, ethyl-, $n$-propyl-, isopropyl- and $t$-butylamine) as well as pyridine. For each adsorbate a well defined adsorption state corresponding to a coverage of one molecule per aluminium atom could be identified by using TPDTGA. Amine molecules adsorbed in excess of one molecule per site desorbed unreacted at much lower temperatures. This excess is thus equivalent to a LTD peak. With the exception of methylamine and pyridine, the 1:1 complexes formed by each amine reacted completely to desorb as ammonia and alkene products (equivalent to a HTD peak). Pyridine desorbed intact above $423{ }^{\circ} \mathrm{C}$. Infrared spectroscopy was used to demonstrate that the stoichiometric complexes formed for each amine were protonated and associated with the hydroxyls at the aluminium sites in the zeolite. These results imply that the acid sites in HZSM-5 are simple Brönsted sites. Very similar results were obtained by Kofke et al. [1988] using simple alcohols and by Kofke and Gorte [1989] using simple alkenes as adsorbates.

Kofke et al. [1989] studied the temperature programmed desorption of 2propanol and 2-propanamine on HZSM-5, HZSM-12 and HM. On all three zeolites 1:1 adsorption complexes with similar reactivities were formed. The complexes decompose at the same temperatures and form the same products on all three zeolites. For this reason Kofke et al. [1989] claimed that the acid sites formed by isolated aluminium atoms in the zeolite lattice are chemically equivalent, independent of the structure of the lattice.

However, the influence of acid site strength, number of acid sites and zeolite structure seems to be uncertain. Hidalgo et al. [1984] reported the peak maximum temperature of $\mathrm{HZSM}-5$ to be essentially independent of $\mathrm{Si} / \mathrm{Al}$ ratio. Kapustin et al. [1988] reported a decrease in peak maximum temperature with increasing Si/Al ratio. They also compared peak maximum temperatures for HZSM-5 and HM, having similar heats of adsorption, and deduced that the structure influenced peak maximum temperatures, which is contrary to the findings of Kofke et al. [1989]. For this reason they concluded that the peak maximum temperature could not be used for comparisons of the acid site strengths of different zeolites. Iwamoto et al. [1986], in agreement with Kapustin et al. [1988], found that the aluminium content influenced the peak maximum temperature, but found that the structure had no effect, which is in agreement with Kofke et al. [1989]. 
These apparently contradictory findings of various studies may be explained when one considers the potentially overwhelming influence of experimental conditions (catalyst mass, carrier gas flowrate, heating rate, etc) on the resulting spectra. Furthermore, it seems likely that changes in Si/Al ratios and the use of different zeolites will result in changes to the competitive interaction between the desorption and readsorption phenomena. Hence this will result in changes to the peak maximum temperature of the desorption spectrum.

Evidence for readsorption in HZSM-5 has been reported by Kapustin et al. [1988]. They noticed that an increase in carrier gas flowrate or a decrease in catalyst mass resulted in lower values of $\mathrm{T}_{\text {max }}$ of the $\mathrm{NH}_{3}$-TPD spectrum. $A$ decrease in $T_{\max }$ was also observed by Hunger et al. [1990] for a decrease in catalyst mass. This is in agreement with the models of Demmin and Gorte [1984] and Rieck and Bell [1984].

It was also shown by Hidalgo et al. [1984] and Anderson et al. [1979] that the peak maximum temperature of the HTD peak decreased with increased cation exchange, whereas that of the LTD peak remained relatively unchanged. This implies that a increase in ion exchange results in a corresponding loss of acidity.

Although ammonia is used more commonly as adsorbate, the use of pyridine has also been reported [Parrillo et al., 1990; Topsoe et al., 1981; Sharma et al., 1993]. Sharma et al. [1993] have reported that pyridine has a smaller particle diffusion coefficient than $\mathrm{NH}_{3}$, due to its greater size. This resulted in higher values of the peak maximum temperature for pyridine. Similar observations in peak maximum temperature for $\mathrm{NH}_{3}$ and pyridine have been made by Parrillo et al. [1990]. Topsoe et al. [1981] reported that pyridine desorption helps the dehydroxylation of the zeolite. The desorption of pyridine from a Brönsted site results in the loss of a $\mathrm{H}_{2} \mathrm{O}$ molecule and thus the formation of a Lewis site.

Post and Van Hooff [1984] used a probe which is too large to enter the channels to study the external surface of HZSM-5. When triethylamine (TEA) was used instead of $\mathrm{NH}_{3}$, again both a LTD peak $\left(180^{\circ} \mathrm{C}\right)$ and a HTD peak (490 ${ }^{\circ} \mathrm{C}$ ) were observed on HZSM-5, but only a LTD peak was observed on silicalite-I. However, since TEA is likely to react upon desorption (as shown for many amines by Parrillo et al. [1990]), the LTD and HTD peak could also be due to the desorption of the different reaction products. Since a TCD was used in these studies as detector, it would not have been possible to differentiate 
between these two possibilities. Furthermore, it is unlikely that a LTD peak should exist on HZSM-5 or on silicalite-I (indicating physisorbed material) if the adsorbate is adsorbed onto the external surface. Other adsorbates which have been used to probe the eternal surface of HZSM-5 include ethyldiisopropylamine [Pope, 1990], various nitrogen containing (poly-)aromatic compounds [Rollmann, 1991], and 4-methyl quinoline [Anderson et al., 1979]. However, no desorption spectra have been reported in these studies. 


\subsection{RESEARCH OBJECTIVES}

From the preceding sections, it can be seen that the external surface of ZSM-5 is accessible to molecules of all sizes. The external surface behaves in a nonshape selective manner. Furthermore, coke formation on the external surface has a greater deactivating effect than coke formation in the zeolite channels. It would thus be of great benefit to study the effects of eliminating the external acidity of ZSM-5.

Of the methods that have been used to dealuminate zeolites, the methods that are most likely to eliminate the external acidity, without affecting the internal acidity, are the methods that form a coat around the crystals. Thus in this study the two methods which have been investigated are (a) coating the ZSM5 crystals with a silicalite shell, and (b) chemical vapour deposition.

The analytical tool chosen to determine the success of eliminating the external acidity, is temperature programmed desorption. Ammonia (critical diameter = $2.4 \AA$ ) and pyridine (critical diameter $=5.1 \AA$ ) are used as adsorbates that will be able to enter the channels of ZSM-5, and 4-methyl quinoline (critical diameter $=7.3 \AA$ ) is used to probe the external surface. The detector chosen for these studies is a mass spectrometer, by virtue of its flexibility in monitoring all desorbing species simultaneously for the duration of the experiment.

The objectives of this study are:

(i) To modify ZSM-5 by coating the crystals with silicalite shells, by changing the post-synthesis treatment of the parent crystals (intermediate treatment), while keeping the modification procedure the same.

(ii) To modify ZSM-5 by chemical vapour deposition, by varying the amount of tetraethoxysilane deposited onto the catalyst.

(iii) To study the adsorption and desorption of bases from the internal and external surfaces of unmodified ZSM-5 using temperature programmed desorption techniques. 
(iv) To investigate the success and the effects of eliminating the external acidity of ZSM-5 by means of coating the crystals with silicalite shells using temperature programmed desorption techniques.

(v) To investigate the success and the effects of eliminating the external acidity of ZSM-5 by means of chemical vapour deposition using temperature programmed desorption techniques. 
CHAPTER 2

EXPERIMENTAL 



\subsection{CATALYST SYNTHESIS AND MODIFICATIONS}

This section deals with the synthesis and modifications of the catalyst in question, namely ZSM-5. A list of all reagents and chemicals used can be found in Appendix I. The complete synthesis procedure consists of several steps. A schematic representation of this is given by Figure 2.1. The primary synthesis is the synthesis of the unmodified, or parent, ZSM-5. Before the catalyst is modified the catalyst may be treated in several ways. This is the intermediate treatment (consisting of washing and drying, detemplation or ion exchanging), after which modification takes place. The catalyst can be modified (i) by coating the parent crystals with a silicalite shell, which is achieved by reimmersing the parent crystals in an Al-free synthesis mixture, or (ii) by chemical vapour deposition, which is achieved by passing a silicon alkoxide over the parent crystals. Final treatment (consisting of washing and drying, detemplation and ion exchange) ensures that the catalyst is ready for use.

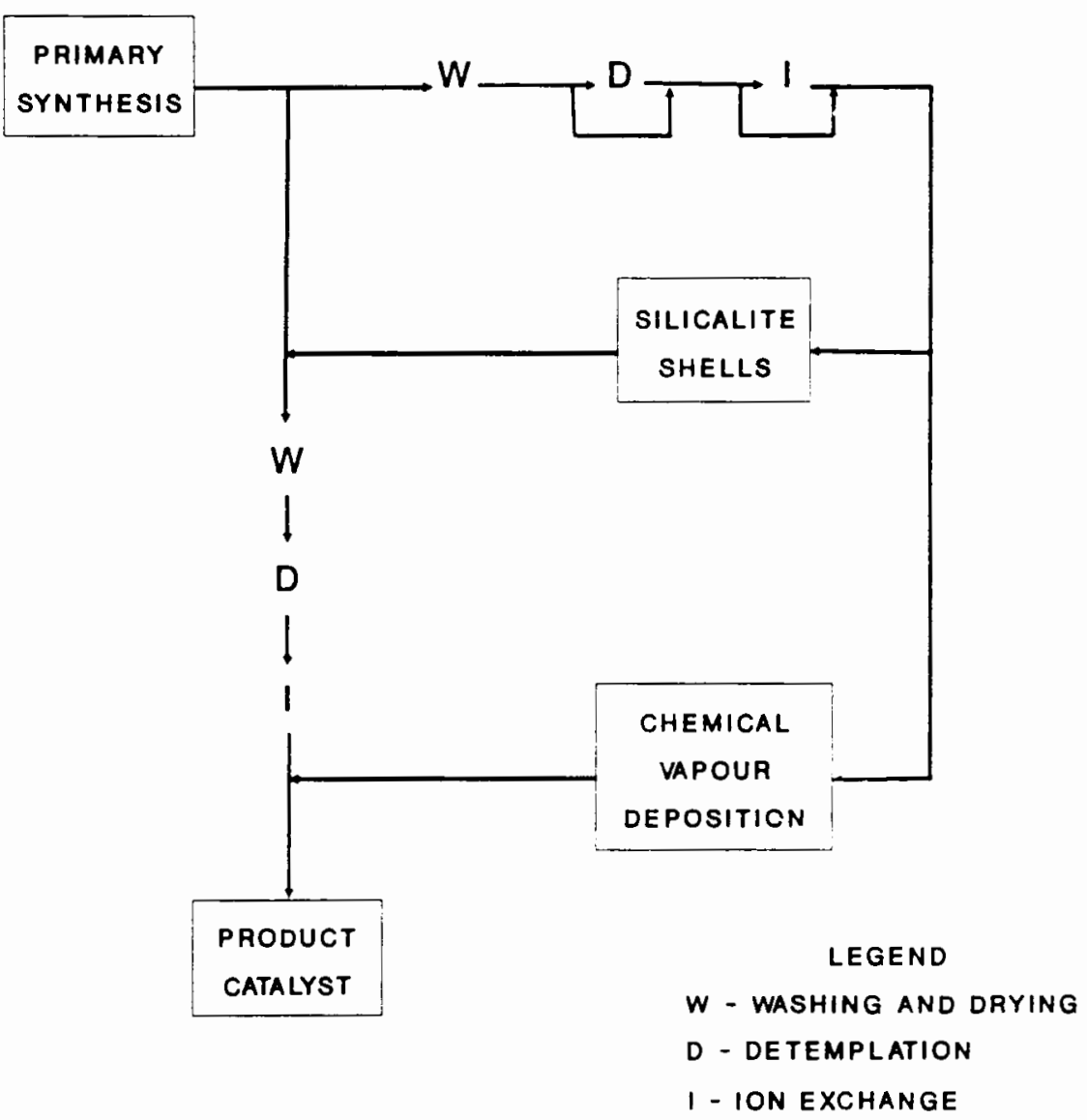

FIGURE 2.1: Schematic representation of catalyst synthesis and modifications 


\subsubsection{CATALYST NOMENCLATURE}

The catalysts are named according to the following code:

$$
\mathrm{M}_{\mathrm{t}}-\mathrm{P}_{\mathrm{di}}
$$

where $\quad-\mathbf{M}$ is the modification step.

S - modification using silicalite shells

$\mathbf{V}$ - modification using chemical vapour deposition

- $t$ is a number indicating the time, in hours, during which chemical vapour deposition took place (Not applicable to the silicalite shell method).

- $P$ is the primary synthesis batch ( $A$ - C)

A - used mainly for catalyst characterization and testing

B - used for modification using silicalite shells

C - used for modification using chemical vapour deposition

- $\mathbf{d}$ indicates that during the intermediate treatment, detemplation did not occur.

- $\mathbf{i}$ indicates that during the intermediate treatment, ion exchange did not occur.

NOTE: $\quad$ S-I is a silicalite-I batch

A fold-out in Appendix III can be used as reference guide to the catalyst nomenclature.

\section{examples}

1. A This is unmodified ZSM-5, batch $A$.

2. S-Bdi This is the primary ZSM-5 of batch $B$, not detemplated and not ionexchanged during the intermediate treatment, which is modified using the silicalite shell method.

3. $\mathrm{V}_{4}-\mathrm{C} \quad$ This is the primary batch $\mathrm{C}$, detemplated and ion exchanged (not indicated), modified using the chemical vapour deposition method for $4 \mathrm{~h}$. 


\subsubsection{PRIMARY SYNTHESIS}

The synthesis method for ZSM-5 is based on US Patent 3,702,886 by Argauer and Landolt (1972). The synthesis method for the primary, or parent syntheses, yields a ZSM-5 material with an approximate $\mathrm{Si} / \mathrm{Al}$ ratio $=35$ and is described in this section. Table 2.1 shows the synthesis conditions for the primary syntheses. The synthesis conditions for silicalite-I are also included in Table 2.1.

TABLE 2.1: Synthesis conditions and synthesis mixture compositions for primary ZSM-5 syntheses and for silicalite-I

\begin{tabular}{lcrrrr}
\hline CATALYST & & A & B & C & S-I \\
\hline temperature & $\left({ }^{\circ} \mathrm{C}\right)$ & 167 & 156 & 165 & 161 \\
time & $(\mathrm{h})$ & 72 & 72 & 72 & 72 \\
& & & & & \\
$\mathrm{H}_{2} \mathrm{O}$ & $(\mathrm{g})$ & 100.1 & 100.1 & 100.1 & 100.0 \\
$\mathrm{TPA}-\mathrm{Br}$ & $(\mathrm{g})$ & 25.18 & 25.18 & 25.19 & 25.18 \\
Ludox & $(\mathrm{g})$ & 31.85 & 31.82 & 31.84 & 31.83 \\
$\mathrm{Al}(\mathrm{OH})_{3}$ & $(\mathrm{~g})$ & 0.4751 & 0.4751 & 0.4756 & - \\
$\mathrm{NaOH}$ & $(\mathrm{g})$ & 1.87 & 1.87 & 1.87 & 1.87 \\
& & & & & \\
\hline
\end{tabular}

NOTE: Catalyst $\mathrm{S}-\mathrm{I}$ is silicalite-I

The synthesis of ZSM-5 occurs in the following manner:

- Obtain the following quantities of materials:

\begin{tabular}{|c|c|c|}
\hline (i) & TPA-Br & $25.18 \mathrm{~g}$ \\
\hline (ii) & $\mathrm{NaOH}$ & 1.87 \\
\hline (iii) & $\mathrm{H}_{2} \mathrm{O}$ & 100.0 \\
\hline (iv) & Ludox & 31.84 \\
\hline (v) & $\mathrm{AllOH})_{3}$ & 0.4751 \\
\hline
\end{tabular}

- Dissolve the full charge of TPA-Br in approx. $1 / 3 \mathrm{H}_{2} \mathrm{O}$ in a Teflon autoclave beaker.

(Solution A)

- Dissolve the full $\mathrm{NaOH}$ charge and the full $\mathrm{Al}(\mathrm{OH})_{3}$ charge in a minimum of $\mathrm{H}_{2} \mathrm{O}$ (approx. $2 \mathrm{ml}$ ) in a $50 \mathrm{ml}$ glass beaker by gently heating the mixture to its boiling point.

(Solution B)

- Add Solution B to Solution A.

(Solution C) 
- Add the full Ludox charge to Solution $C$. (Solution D)

- Rinse used beakers with remaining $\mathrm{H}_{2} \mathrm{O}$ and add this to Solution D. Stir the mixture.

- Place Solution $D$ in the magnetically stirred autoclave (Figure 2.2). Add a Teflon coated stirrer bar. Seal the autoclave.

- Heat the autoclave to $160^{\circ} \mathrm{C}$ at $1{ }^{\circ} \mathrm{C} / \mathrm{min}$ and maintain the temperature for $72 \mathrm{~h}$.

- Cool the autoclave at $1^{\circ} \mathrm{C} / \mathrm{min}$ to room temperature.

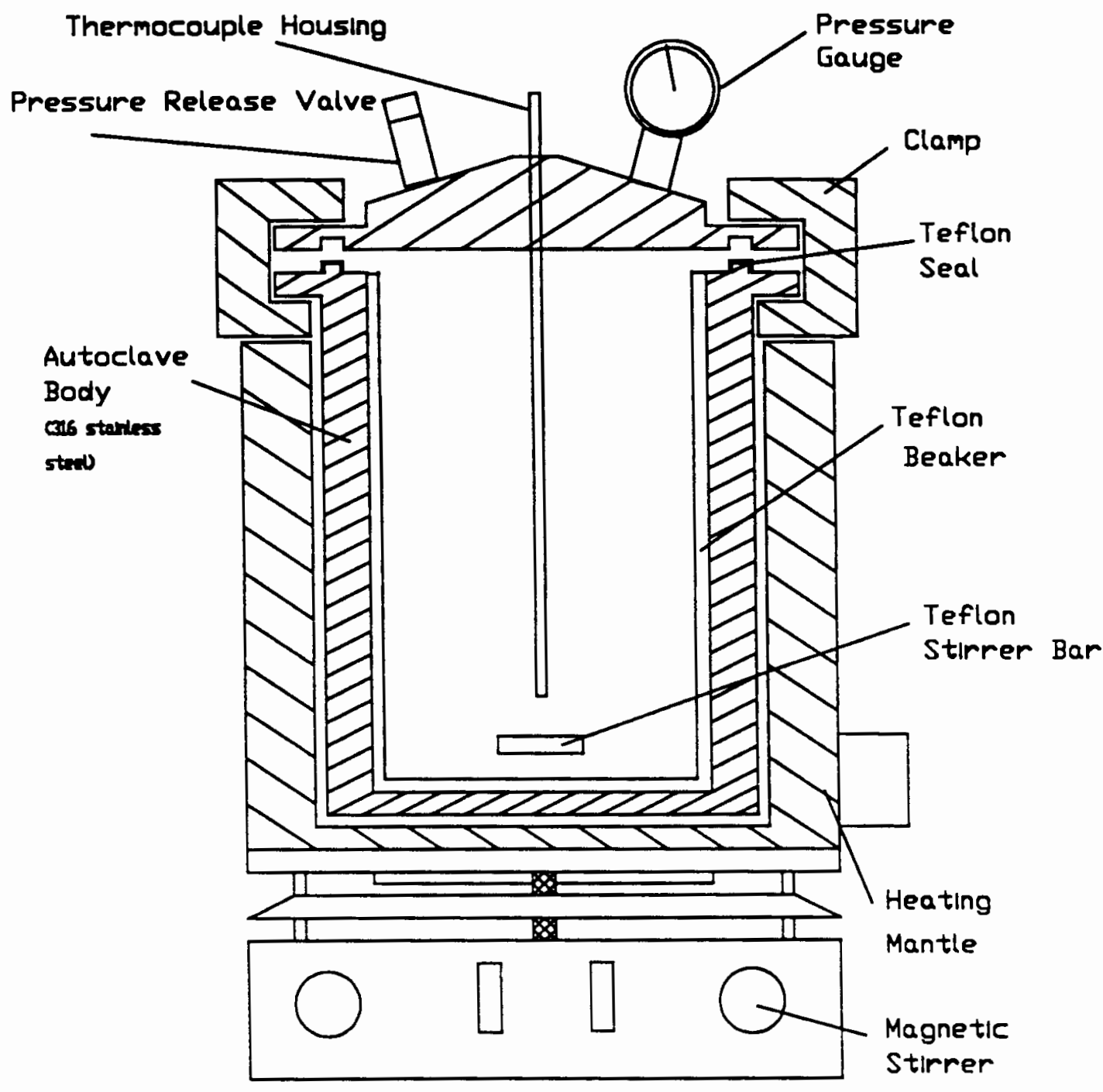

Internal dimensions of Teflon Beaker

Height - $90 \mathrm{~mm}$

Dlameter- $60 \mathrm{~mm}$

FIGURE 2.2: Magnetically stirred autoclave 


\subsubsection{INTERMEDIATE TREATMENT}

After the synthesis of the catalyst, the catalyst is treated in several ways. Not all treatments are carried out in all cases, as indicated by Figure 2.1.

\subsubsection{Washing and drying}

After the synthesis of the catalyst, the catalyst is washed and dried in the following manner. This step a/ways occurs.

- Transfer the synthesized catalyst from the Teflon autoclave beaker into a $200 \mathrm{ml}$ glass beaker. Allow the catalyst to settle out. (Step 1)

- Discard the supernatant liquor. Fill the beaker with distilled or deionized water. Mix the catalyst with the water. Allow the catalyst to settle out. (Step 2)

- Repeat Step 2 three times.

- Discard the supernatant liquor. Place the catalyst in an oven to dry at $80-90^{\circ} \mathrm{C}$ for $16 \mathrm{~h}$.

\subsubsection{Detemplation}

The catalyst is detemplated in the following manner. This step does not always occur when the catalyst is to be modified.

- Place the catalyst in a tubular stainless steel reactor, $300 \mathrm{~mm}$ long, 16 $\mathrm{mm}$ I.D.

- Pass $\mathrm{N}_{2}$ over the catalyst at $500^{\circ} \mathrm{C}$ at a flowrate of $60 \mathrm{ml} / \mathrm{min}$ for $6-8 \mathrm{~h}$.

- Pass air over the catalyst at $500^{\circ} \mathrm{C}$ at a flowrate of $60 \mathrm{ml} / \mathrm{min}$ for $16 \mathrm{~h}$. 


\subsubsection{Ion exchange}

The catalyst is ion exchanged in the following manner. This step does not always occur when the catalyst is to be modified, but must be preceded by detemplation.

- Prepare a 1 liter $2 \mathrm{M} \mathrm{NH}_{4} \mathrm{NO}_{3}$ solution using distilled or deionized water.

- Place this solution, together with a Teflon coated stirrer bar, in a glass culture vessel (flat bottomed vessel similar to autoclave body of

Figure 2.2 with glass top and reflux condenser) on a hotplate.

- Add the detemplated catalyst to the solution.

- Attach a reflux condenser to the glass culture vessel.

- Agitate the solution and heat until boiling gently for $24 \mathrm{~h}$ under reflux conditions.

- Wash and dry the solution as described in Section 2.1.3.1.

\subsubsection{MODIFICATIONS}

\subsubsection{Silicalite shells}

To obtain a silicalite shell around the ZSM-5 crystals, the catalysts are reimmersed into a secondary synthesis mixture. This mixture contains no $\mathrm{Al}(\mathrm{OH})_{3}$, but is otherwise of the same composition as described in Section 2.1.2. Hence the procedure is similar to that described in Section 2.1.2, with the addition that the parent ZSM-5 crystals are added last (ie. to solution $D$ in Section 2.1.2). The relative amounts of ZSM-5 seeds and secondary synthesis mixture can be varied. Here, the relative amounts of ZSM-5 seeds and secondary synthesis mixture is such that approximately $1.5 \mathrm{~g}$ silicalite-l is expected to form per gram of ZSM-5 added as seed crystal. In some cases samples are not detemplated or ion exchanged prior to reimmersion into the secondary synthesis mixture, but all undergo final treatment (Section 2.1.5). The modification synthesis time is 3 days at $160^{\circ} \mathrm{C}$. 
TABLE 2.2: Synthesis conditions and synthesis mixture compositions for modification using the silicalite shell method

\begin{tabular}{|c|c|c|c|c|}
\hline \multicolumn{2}{|l|}{ CATALYST } & S-Bdi & $\mathrm{S}-\mathrm{Bi}$ & $S-B$ \\
\hline \multirow{3}{*}{\multicolumn{2}{|c|}{$\begin{array}{l}\text { primary synthesis } \\
\text { intermediate treatment } \\
\text { detemplation } \\
\text { ion exchange }\end{array}$}} & $B$ & B & B \\
\hline & & no & yes & yes \\
\hline & & no & no & yes \\
\hline temperature & $\left({ }^{\circ} \mathrm{C}\right)$ & 164 & 156 & 159 \\
\hline time & (hrs) & 72 & 72 & 72 \\
\hline $\mathrm{H}_{2} \mathrm{O}$ & $(g)$ & 50.04 & 31.31 & 31.25 \\
\hline TPA-Br & (g) & 12.60 & 7.87 & 7.87 \\
\hline Ludox & (g) & 15.96 & 9.93 & 9.95 \\
\hline $\mathrm{Al}(\mathrm{OH})_{3}$ & $(g)$ & & - & - \\
\hline $\mathrm{NaOH}$ & (g) & 0.936 & 0.590 & 0.585 \\
\hline ZSM-5 & $(g)$ & 4.0 & 2.5 & 2.5 \\
\hline
\end{tabular}

\subsubsection{Chemical vapour deposition (CVD)}

Modification by means of chemical vapour deposition (CVD) is achieved in the following manner:

- Place the required amount of catalyst (typically $2.5 \mathrm{~g}$ ) in a tubular quartz TPD cell of the vacuum line (described in Section 2.3.1).

- Pass $\mathrm{N}_{2}$ or air over the catalyst at $450^{\circ} \mathrm{C}$ at a flowrate of $30 \mathrm{ml} / \mathrm{min}$ for $16 \mathrm{~h}$.

- Cool the catalyst in situ to the deposition temperature, and evacuate the sample for $2 \mathrm{~h}$.

- Expose the sample to tetraethoxysilane (TES), kept at $0^{\circ} \mathrm{C}$ using an ice bath, for the required deposition time.

- Evacuate the sample (typically for $0.5 \mathrm{~h}$ ) to remove gaseous deposition products.

- Repeat the deposition and evacuation steps.

- Pass air over the catalyst at $500^{\circ} \mathrm{C}$ at a flowrate of $45 \mathrm{ml} / \mathrm{min}$ for $16 \mathrm{~h}$. 
Catalysts modified in this manner do not undergo final treatment as described in Section 2.1.5, as these catalysts have been previously washed, dried, detemplated and ion-exchanged.

TABLE 2.3: Synthesis conditions for secondary syntheses by means of chemical vapour deposition

\begin{tabular}{lccc}
\hline CATALYST & & $\mathrm{V}_{4}-\mathrm{C}$ & $\mathrm{V}_{16}-\mathrm{C}$ \\
\hline $\begin{array}{l}\text { primary synthesis } \\
\text { intermediate treatment }\end{array}$ & $\mathrm{C}$ & $\mathrm{C}$ \\
$\quad \begin{array}{c}\text { detemplation } \\
\text { ion exchange }\end{array}$ & & yes & yes \\
& & yes & yes \\
temperature & $\left(^{\circ} \mathrm{C}\right)$ & 320 & 400 \\
$\quad$ deposition time & (h) & 1 & 4 \\
$\quad$ evacuation time & (h) & 0.5 & 0.5 \\
$\quad$ number of cycles & (h) & 4 & 4 \\
total dep. time & (h) & 4 & 16 \\
ZSM-5 & (g) & 2.5 & 2.5 \\
& & & \\
\hline
\end{tabular}

\subsubsection{FINAL TREATMENT}

Catalysts modified by reimmersion into a secondary synthesis mixture to form silicalite shells (ie. all catalysts designated S-...) need to be treated before use. Three processes are required, discussed previously, namely:

(i) washing and drying

(Section 2.1.3.1)

(ii) detemplation

(Section 2.1.3.2)

(iii) ion exchange

(Section 2.1.3.3)

Catalysts modified by chemical vapour deposition (ie. all catalysts designated V.....) do not undergo the above treatments. 


\subsection{CATALYST CHARACTERIZATION}

\subsubsection{CATALYST STRUCTURE AND MORPHOLOGY}

\subsubsection{X-ray diffraction (XRD)}

A Philips $X$-ray Diffractometer is used to obtain $X$-ray diffraction spectra using Cu-Ka radiation. The samples were kept at ambient conditions prior to analysis. Relative crystallinities are obtained by adding the peak heights of the three largest peaks in the range $22-25^{\circ} 2 \theta$ [Hardenberg et al., 1992] and normalizing these with respect to the most crystalline sample. The following parameters are used for the Diffractometer:

- voltage
- current
- range
- preset
- time constant
- $2 \theta /$ step
- $2 \theta$ range
- slits

$40 \mathrm{kV}$

$30 \mathrm{~mA}$

$10^{4}$

2000 counts/sec

1 sec

0.1

$6-40^{\circ}$

$1^{\circ}$

\subsubsection{Scanning electron microscopy (SEM)}

A Cambridge $\$ 200$ scanning electron microscope is used to obtain crystallite sizes. The following parameters are used:

- accelerating voltage

- aperture

- tilt angle

- resolution

- working distance
$15 \mathrm{keV}$

30

$39^{\circ}$

10

$10-15 \mathrm{~mm}$

The sample is mounted on a stub with a carbon and glue mixture, and coated with AuPd. Care is taken to select representative micrographs of the sample, 
and although this characterization method may not be truly representative of the whole sample, it is unlikely that the micrographs will vary substantially within the same sample.

\subsubsection{CATALYST COMPOSITION}

\subsubsection{Atomic absorption spectroscopy (AAS)}

Zeolite aluminium, silicon and sodium contents are determined by atomic absorption spectroscopy. A Varian Spectra AA-30 spectrometer, attached to a DS 15 data station is used to obtain the measurements. Ion exchanged samples were used for these analyses.

Samples are prepared in the following manner:

- Place a 300 to $400 \mathrm{mg}$ sample in a Parr bomb.

- Add $5 \mathrm{ml} 40 \% \mathrm{HF}$ (cold) to the sample.

- Add $5 \mathrm{ml} \mathrm{HCl}$ to the sample.

- Place the Parr bomb in an oven at $100{ }^{\circ} \mathrm{C}$ for $35 \mathrm{~min}$.

- Cool the solution to room temperature.

- Add $50 \mathrm{ml}$ saturated boric acid to the solution.

- Make up to $500 \mathrm{ml}$ with $\mathrm{H}_{2} \mathrm{O}$ in a volumetric flask.

The aluminium standards are prepared in the following manner:

- For a concentration range of $0,10,25,50$ and $75 \mu \mathrm{g} / \mathrm{ml}$, place $0,1.0$, 2.5, 5.0 and $7.5 \mathrm{ml}$ of 1000 PPM Al standard solution in $100 \mathrm{ml}$ volumetric flasks for each standard concentration.

- Add $1 \mathrm{ml} \mathrm{HF}$ to each flask.

- Add $1 \mathrm{ml} \mathrm{HCl}$ to each flask.

- Add $10 \mathrm{ml}$ boric acid to each flask.

- Make up to $100 \mathrm{ml}$ with $\mathrm{H}_{2} \mathrm{O}$.

Standards for silicon and sodium are prepared in a similar fashion. 
The following standards are used:

$\begin{array}{lllllll}-\mathrm{Al} & 0 & 10 & 25 & 50 & 75 & \mu \mathrm{g} / \mathrm{ml} \\ -\mathrm{Si} & 0 & 50 & 100 & 200 & 300 & \mu \mathrm{g} / \mathrm{ml} \\ -\mathrm{Na} & 0 & 0.5 & 1.0 & 1.5 & & \mu \mathrm{g} / \mathrm{ml}\end{array}$

A sample calculation of the AAS results can be found in Appendix IV.

\subsubsection{Temperature programmed desorption of ammonia $\left(\mathrm{NH}_{3}-\mathrm{TPD}\right)$}

To obtain quantitative data of the number of acid sites, as measured by mmol of $\mathrm{NH}_{3}$ per gram of catalyst, $\mathrm{NH}_{3}$-TPD studies are carried out using the apparatus and procedures described below. This standard TPD system does not permit the use of adsorbates other than $\mathrm{NH}_{3}$. Section 2.3 describes the apparatus and procedures used for TPD studies in which $\mathrm{NH}_{3}$, pyridine and 4-methyl quinoline are used as adsorbates. The apparatus described in Section 2.3 is not suitable for quantitative measurements.

$\mathrm{NH}_{3}$-TPD spectra are recorded in the range $100-600^{\circ} \mathrm{C}$. The sample is placed in a tubular quartz reactor $(300 \mathrm{~mm}$ long, $14 \mathrm{~mm}$ I.D.), which can be heated by a suitable furnace. Air and $\mathrm{He}$ are available as carrier gases. $\mathrm{A} \mathrm{NH}_{3} / \mathrm{He}$ mixture is used to adsorb $\mathrm{NH}_{3}$ onto the sample. The signal is detected by a suitably calibrated TCD. The furnace is driven by computer which is also used to store data. Back titration is used to confirm the results obtained using the TCD.

The following procedure is used:

- Place $0.25 \mathrm{~g}$ of catalyst in a quartz TPD cell.

- Calcine the sample in air at $500^{\circ} \mathrm{C}$ at a flowrate of $60 \mathrm{ml} / \mathrm{min}$ for $4 \mathrm{~h}$.

- Cool the sample to $100{ }^{\circ} \mathrm{C}$ for $\mathrm{NH}_{3}$ adsorption.

- Pass $\mathrm{NH}_{3} / \mathrm{He}\left(5 \mathrm{~mol} \% \mathrm{NH}_{3}\right.$ ) over the sample for $1 \mathrm{~h}$ at $60 \mathrm{ml} / \mathrm{min}$ at $100^{\circ} \mathrm{C}$. 
- Flush the sample for $24 \mathrm{~h}$ with $\mathrm{He}$ at a flowrate of $60 \mathrm{ml} / \mathrm{min}$ at the adsorption temperature to remove the bulk of the physisorbed $\mathrm{NH}_{3}$.

- Ramp the furnace linearly at $10^{\circ} \mathrm{C} / \mathrm{min}$ from the adsorption temperature to $600{ }^{\circ} \mathrm{C}$ in $\mathrm{He}$ at a flowrate of $60 \mathrm{ml} / \mathrm{min}$.

\subsubsection{Thermogravimetric analysis}

The moisture content of the catalyst and $n$-hexane adsorption capacities are determined by thermogravimetric analysis on a Stanton Redcroft STA-780 Series Thermal Analyser. The moisture content can also be used to obtain the dry mass of the sample.

\section{Moisture content}

The samples are kept at ambient conditions prior to the analysis. The moisture content is obtained by heating $25 \mathrm{mg}$ of sample at $10^{\circ} \mathrm{C} / \mathrm{min}$ from $20^{\circ} \mathrm{C}$ to $500{ }^{\circ} \mathrm{C}$ in a $30 \mathrm{ml} / \mathrm{min}$ air stream.

\section{n-Hexane adsorption capacity}

The $n$-hexane adsorption capacity of the sample is obtained as follows:

- Place $25 \mathrm{mg}$ of catalyst in the microbalance.

- Heat the sample at $10^{\circ} \mathrm{C} / \mathrm{min}$ from $20^{\circ} \mathrm{C}$ to $500{ }^{\circ} \mathrm{C}$ in a $30 \mathrm{ml} / \mathrm{min}$ air stream.

- Hold the sample at this temperature for $1 \mathrm{~h}$, then switch the carrier gas flow from air to $N_{2}$, and again hold for $1 \mathrm{~h}$. Cool the sample to $50^{\circ} \mathrm{C}$.

- Direct the carrier gas through a double stage saturator, kept at $0^{\circ} \mathrm{C}$, and adsorb $n$-hexane until no further weight change is observed. 


\subsection{TEMPERATURE PROGRAMMED DESORPTION STUDIES}

The apparatus used for these TPD studies was built for this project. It allows the use of different adsorbates, such as $\mathrm{NH}_{3}$, pyridine (Py) and 4-methyl quinoline (MO-4), to probe different areas on the zeolite surface, but no quantitative measurements can be made (refer to Section 3.2.3 for discussion). Quantitative $\mathrm{NH}_{3}$-TPD measurements are made using the apparatus and procedures described in Section 2.2.2.2.

\subsubsection{EQUIPMENT}

The equipment used for temperature programmed desorption studies consists of a heated TPD sample cell, which can be evacuated by means of a vacuum line. An on-line mass spectrometer is used as detector. Appendix II lists all items of equipment used to build the apparatus. Figure 2.3 shows a schematic of the apparatus used for TPD studies.

The vacuum line

The vacuum line consists of a borosilicate glass vacuum line $(25 \mathrm{~mm}$ diameter $)$. The vacuum is supplied by a rotary pump and an oil-diffusion pump. The vacuum is monitored using a Pirani and a Penning vacuum gauge. Four pairs of glass reservoirs are attached to the vacuum line. Each pair is used to purify and store a liquid adsorbate (such as pyridine or 4-methyl quinoline) or tetraethoxysilane used for chemical vapour deposition. A liquid nitrogen trap is used to trap condensable contaminants and adsorbates before entering the diffusion pump. A quartz TPD cell, or reactor, can be inserted into the vacuum line and can be attached using Cajon fittings. Stopcocks isolate various sections of the vacuum line. Data of leak testing can be found in Appendix $V$.

\section{The furnace}

The configuration of the furnace can be found in Appendix VI. The temperature of the furnace is controlled using a temperature programmer. The thermocouple used to control and monitor the temperature is placed in the thermowell of the TPD cell, thus ensuring that the temperature of the sample is accurately ramped. Appendix VI shows a profile of the temperature ramp. As can be seen from this profile, the sample can be ramped linearly from ambient temperatures to above $1000{ }^{\circ} \mathrm{C}$ using a range of temperature ramps. All the thermocouples and temperature controllers were calibrated prior to use. 


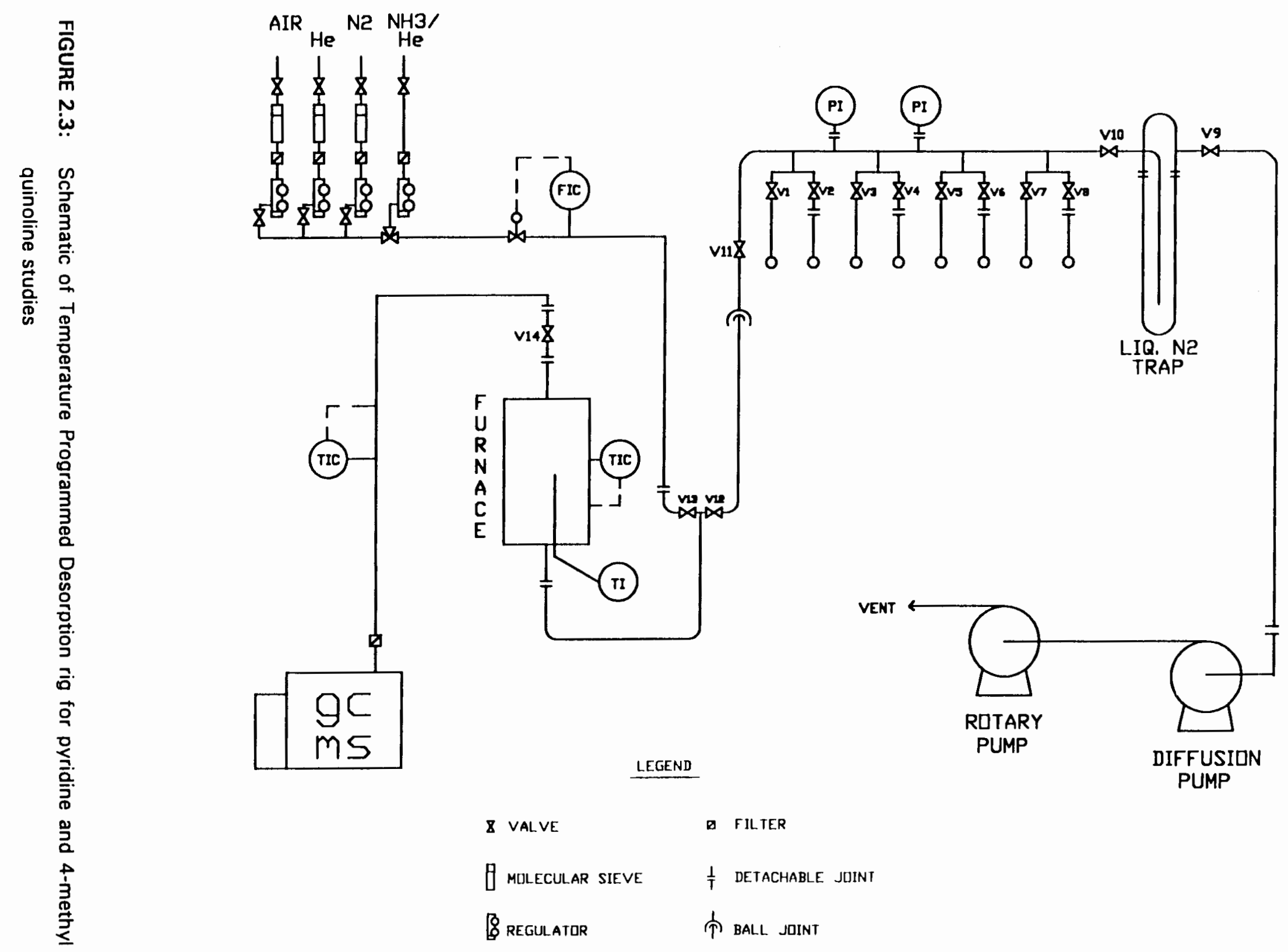


The TPD cell

The TPD cell is a $350 \mathrm{~mm}$ long, $10 \mathrm{~mm}$ I.D. quartz tube, with a $2 \mathrm{~mm} \mathrm{I.D.}$ thermowell, as shown in Figure 2.4.

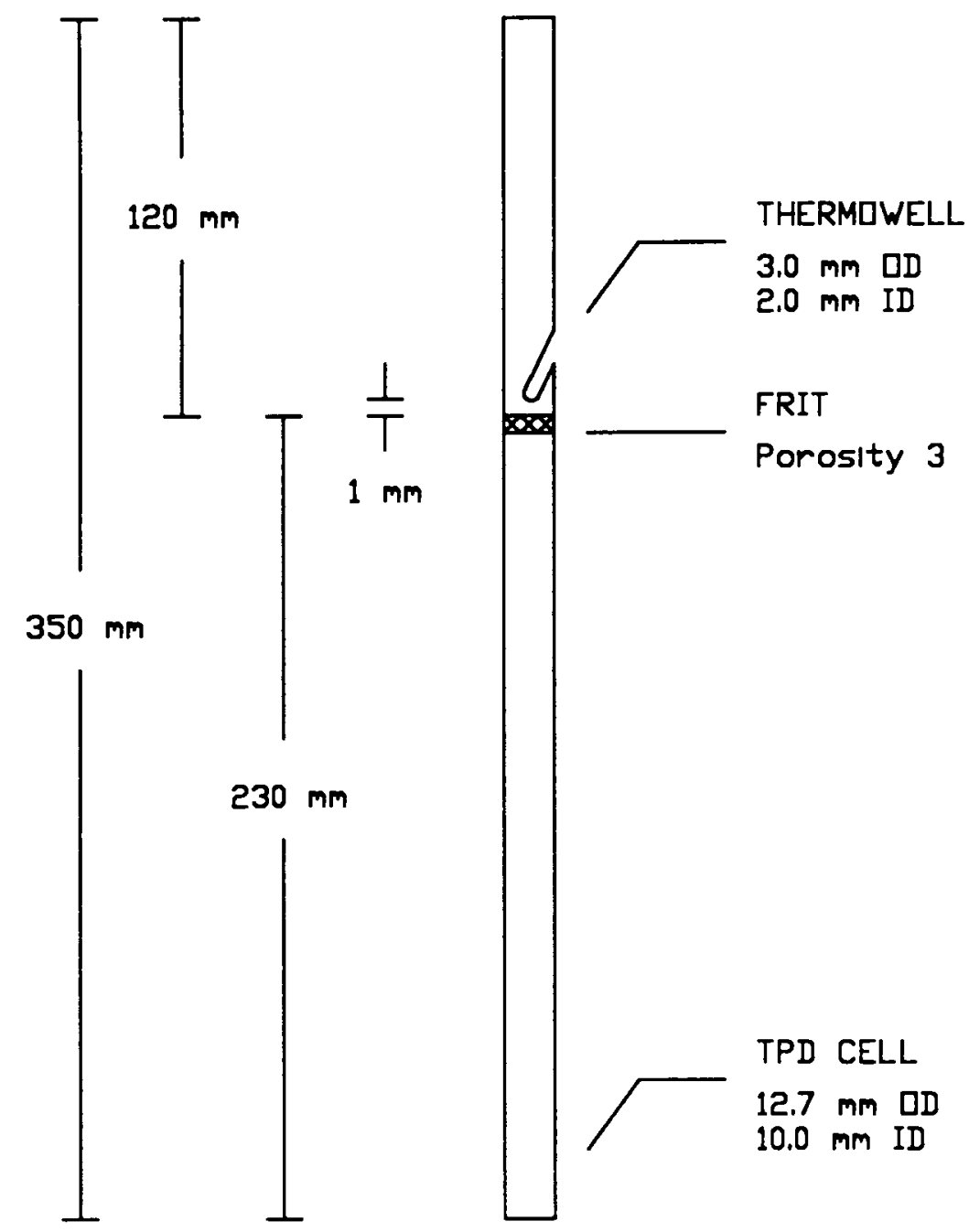

FIGURE 2.4: The TPD cell

The carrier gas transfer lines

Several carrier gases are available for use. Air and $\mathrm{N}_{2}$ are used for calcination purposes, $\mathrm{He}$ is used during the desorption stage and a $\mathrm{NH}_{3} / \mathrm{He}$ mixture (5 mol\% $\mathrm{NH}_{3}$ ) is used to adsorb $\mathrm{NH}_{3}$ onto the catalyst. The gases pass through a 3A molecular sieve and a filter prior to a regulator. The gas flow is monitored and controlled using a mass flow controller common to all carrier gases. The 
mass flow controller was calibrated for He prior to use. The carrier gases pass through a $1 / 8$ inch stainless steel feed line attached to the vacuum line. An 1/8 inch stainless steel tube connects the vacuum line to the GC/MS. This line is heated to prevent condensation in or adsorption onto the walls of the tube by the adsorbates. An in-line filter prevents contamination of the GC/MS.

\section{The detector}

The total flow entering the GC is split. Only a small fraction, typically $1 / 100$ $1 / 250$, enters a $15 \mathrm{~m}$ long, $0.22 \mathrm{~mm}$ I.D. deactivated capillary column. By adjusting the column head pressure the flow to the MS through the capillary column can be regulated. The mass spectrometer is used to monitor the abundance of the ions of the species desorbed from the sample versus temperature.

\subsubsection{REAGENT PREPARATION}

As mentioned before, the carrier gases are dried using $3 \mathrm{~A}$ molecular sieves, and pass through a 2 micron filter before use.

The liquid adsorbates, pyridine and 4-methyl quinoline, are vacuum distilled prior to use, according to the following procedure:

- The adsorbate is placed in one of the detachable reservoirs.

- The adsorbate is heated and evacuated until approximately $1 / 3$ of the material has been distilled and collected in the liquid $\mathrm{N}_{2}$ trap.

- The adsorbate is heated further, but the liquid $N_{2}$ trap is isolated, and a liquid $\mathrm{N}_{2}$ dewar is placed around the twin (non-detachable) reservoir, such that approximately a further $1 / 3$ of the adsorbate is collected in this reservoir. This reservoir contains $3 \mathrm{~A}$ molecular sieves to adsorb water. This fraction is used as the pure adsorbate for the TPD studies.

- The remaining $1 / 3$ can be discarded. 


\subsubsection{SAMPLE PREPARATION}

When the adsorbate to be used is $\mathrm{NH}_{3}$ or pyridine, the catalyst is coated onto quartz particles (70 - 212 micron) before it is placed in the TPD cell. This procedure not only mixes the quartz particles with the catalyst, but also causes the catalyst to stick onto the rough quartz particles. This is done for the following reasons (brackets indicate why this does not apply to MO-TPD studies for practical reasons):

- Because small catalyst samples are used, it ensures that the thermocouple is in the catalyst bed (the large amount of catalyst used for MO-TPD studies ensures that the thermocouple is in the bed).

- The quartz particles act as a heat sink during adsorption and desorption (only a small amount of MQ-4 adsorbs onto the catalyst).

- It prevents the catalyst bed from fluidizing when high carrier gas flowrates are used (low flowrates are used for MO-TPD studies).

The coating of the beads is achieved in the following way:

- Mix the required amounts of $70-212$ micron quartz particles with the catalyst in a porcelain dish (typical particles : catalyst ratio is $20: 1 \mathrm{~g})$.

- Add 2 - $5 \mathrm{ml} \mathrm{H}_{2} \mathrm{O}$ to the mixture.

- Heat the mixture on a hotplate until all the $\mathrm{H}_{2} \mathrm{O}$ evaporates while constantly stirring the mixture.

- Add more $\mathrm{H}_{2} \mathrm{O}$ if required to ensure that all the catalyst is coated onto the quartz particles.

This procedure did not affect the TPD spectra in any way.

\subsubsection{EXPERIMENTAL CONDITIONS AND PROCEDURES}

The experimental conditions and procedures of a typical TPD experiment are described in the section below for each of the adsorbates. Unless otherwise 
stated in the text, these parameters apply. The parameters differ for each adsorbate. For example, the catalyst mass and carrier gas flowrate for MQ-TPD experiments differ from $\mathrm{NH}_{3}$ and Py-TPD experiments in order to obtain detectable signals in the MS. Adsorption temperatures and evacuation times also vary according to the requirements of each system. Conditions for MQ-4 are given in brackets where different to $\mathrm{NH}_{3}$ or $\mathrm{Py}$.

\section{Initial procedures}

- Pump down the vacuum line, excluding the sample cell.

- Place $0.05 \mathrm{~g}$ catalyst, coated onto $1 \mathrm{~g}$ quartz particles, $1.0 \mathrm{~g}$ catalyst without quartz particles for MQ-4), prepared as described in Section 2.3.3, in the TPD cell. Place the cell in the furnace.

- Heat the line connecting the vacuum line to the $\mathrm{GC} / \mathrm{MS}$ to $150{ }^{\circ} \mathrm{C}(280$ ${ }^{\circ} \mathrm{C}$ for $\left.\mathrm{MQ}-4\right)$.

\section{Calcination}

- Calcine the sample in air at $500{ }^{\circ} \mathrm{C}$ at a flowrate of $60 \mathrm{ml} / \mathrm{min}$ for $4 \mathrm{~h}$ (8 $\mathrm{h}$ for $\mathrm{MQ}-4$ ).

- Cool the sample to $\quad-100{ }^{\circ} \mathrm{C}$ for $\mathrm{NH}_{3}$ adsorption

- $200{ }^{\circ} \mathrm{C}$ for Py adsorption

- $100{ }^{\circ} \mathrm{C}$ for MQ-4 adsorption

- Evacuate the sample for $2 \mathrm{~h}$ (to less than $10^{-4} \mathrm{mbar}$ ).

\section{Adsorption}

- In the case of $\mathrm{NH}_{3}$ adsorption, pass $\mathrm{NH}_{3} / \mathrm{He}$ over the sample for $1 \mathrm{~h}$, at a flowrate of $60 \mathrm{ml} / \mathrm{min}$.

- In the case of Py and MQ-4, place an ice bath, kept at $0{ }^{\circ} \mathrm{C}$, around the adsorbate storage reservoir to ensure a constant partial pressure in all runs. Isolate the liquid $\mathrm{N}_{2}$ trap. Expose the sample to the required adsorbate for $1 \mathrm{~h}$ ( $3 \mathrm{~h}$ for MQ-4).

\section{Evacuation/Flushing}

- In the case of $\mathrm{NH}_{3}$, flush the sample for $24 \mathrm{~h}$ in $\mathrm{He}$ at a flowrate of 60 $\mathrm{ml} / \mathrm{min}$ at the adsorption temperature. 
- In the case of Py and MQ-4, evacuate the sample for $23 \mathrm{~h}$ (1/4 $\mathrm{h}$ for MQ-4) at the adsorption temperature. Flush the sample in $\mathrm{He}$ at a flowrate of $60 \mathrm{ml} / \mathrm{min}$ for up to $1 \mathrm{~h}$.

Temperature Programmed Desorption

- Set the GC/MS settings as described in Section 2.3.5.

- In the case of $\mathrm{Py}, \mathrm{cool}$ the sample to $150{ }^{\circ} \mathrm{C}$ to ensure that the temperature ramp is linear before desorption starts. In the case of $\mathrm{NH}_{3}$ and $\mathrm{MQ}-4$ the adsorption temperature is sufficiently low.

- Ramp the furnace at $10^{\circ} \mathrm{C} / \mathrm{min}$ up to a maximum of $1050{ }^{\circ} \mathrm{C}$ in $\mathrm{He}$ at a flowrate of $150 \mathrm{ml} / \mathrm{min}(60 \mathrm{ml} / \mathrm{min}$ for $\mathrm{MQ}-4)$.

\subsubsection{SIGNAL DETECTION}

The data is recorded using a Hewlett Packard 5971A Mass Selective Detector attached to a Hewlett Packard Vectra QS/16S personal computer. The data is recorded in the Selected Ion Mode (SIM). The relative abundance of a selection of the following ions is recorded versus time, as required. The ions printed in bold typeface are the two most abundant ions of each species in the desorption spectrum of these studies.

$\begin{array}{ll}\text { ammonia } & 17,16,15 \\ \text { pyridine } & 79,52,51,50,39,27 \\ \text { 4-methyl quinoline } & 143,128,79,78,52,51,50,15 \\ \text { water } & 18,17,16\end{array}$

Signal recording is initiated after the temperature ramp has commenced in order to correct for the lag time between the sample and the detector $11 \mathrm{~min}$ for $\mathrm{NH}_{3}$ and $\mathrm{Py}, 1.5 \mathrm{~min}$ for $\mathrm{MQ}-4)$. The lag time is due mainly to the $15 \mathrm{~m}$ long $\mathrm{GC}$ column. The signal can be adjusted to account for the split ratio (typically $100 / 1$ - 250/1) prior to the GC column or changes in catalyst mass and carrier gas flowrate. The time scale is converted to a temperature scale. 
The gas chromatograph and mass spectrometer settings typically used in these studies are given in Table 2.4:

TABLE 2.4: Gas chromatograph and mass spectrometer settings

\begin{tabular}{lcrrr}
\hline GC/MS SETTINGS & & $\mathrm{NH}_{3}$ & $\mathrm{PY}$ & $\mathrm{MQ}-4$ \\
\hline & & 150 & 150 & 280 \\
oven temp. & $\left({ }^{\circ} \mathrm{C}\right)$ & 280 & 280 & 280 \\
detector temp. & $\left({ }^{\circ} \mathrm{C}\right)$ & 5 & 5 & 7 \\
column head pressure & $(\mathrm{psi})$ & 147 & 147 & 57 \\
split vent flow & $(\mathrm{ml} / \mathrm{min})$ & 2 & 2 & 2 \\
purge vent flow & $(\mathrm{ml} / \mathrm{min})$ & 0.6 & 0.6 & 0.6 \\
column flow & $(\mathrm{ml} / \mathrm{min})$ & 0.985 & 0.985 & 5.000 \\
dwell time & $\left(\mathrm{sec}^{-1}\right.$ & 0.167 & 0.167 & 0.1 \\
cycle time & $\left(\mathrm{sec}^{-1}\right)$ & $5 \times 10^{7}$ & $5 \times 10^{7}$ & $5 \times 10^{7}$ \\
total ion maximum & & $5 \times 10^{6}$ & $5 \times 10^{6}$ & $5 \times 10^{6}$ \\
ion maximum & & 1682 & 1682 & 1682 \\
EMVolts & & 0 & 0 & 0 \\
solvent delay & $(\mathrm{min})$ & 95 & 90 & 95 \\
max. run time & $(\mathrm{min})$ & & & \\
& & &
\end{tabular}

\subsubsection{The mass spectrometer as detector}

In order to understand the abilities and limitations of the mass spectrometer as a detector for the desorption of an adsorbate from a zeolite, a few remarks are included in this section to elucidate on these matters.

A molecule entering the mass spectrometer is ionized. The ratio of the ions formed is specific to that molecule, which can thus be identified. Data can be collected in the following two manners: (i) as a Total Ion Chromatogram (TIC), which monitors all ions in a specified range, or (ii) in the Selected lon Mode (SIM), which monitors a few selected ions. In this study the TIC was used only to obtain the complete desorption spectrum from the sample. SIM was typically used in all other experiments, as this mode allows more precise monitoring of ions specific to a particular compound. Furthermore, by choosing ions specific to a particular compound, several species can be monitored, even though they 
may desorb simultaneously. This is not always possible using a TCD or FID as detector.

Care must be taken if one ion is a characteristic ion of two different compounds. For example, the three most abundant ions from $\mathrm{H}_{2} \mathrm{O}$ are $m / e=18$, 17 and 16; from $\mathrm{NH}_{3}$ they are $m / e=17,16$ and 15 . Hence, if the desorption of $\mathrm{NH}_{3}$ is monitored from zeolites, it is not advisable to monitor $m / e=17$ only, as desorption of $\mathrm{H}_{2} \mathrm{O}$ from the zeolite is likely to occur, thereby increasing the signal of $m / e=17$. Thus a judicious choice of the ions to be monitored is required. Even so, it is possible that the ions formed by the ionization of one molecule may themselves ionize other molecules when these molecules reach the detector simultaneously [Middleditch, 1979].

By monitoring the relative intensities of several ions characteristic of one molecule (using SIM), it is possible to determine whether a compound has reacted on the zeolite surface prior to reaching the detector. If the relative intensities change, or if they are not the same as for the pure compound, during the course of the desorption process, then a reaction has taken place on the surface of the zeolite. Care must be taken to check which ions are formed due to the ionization in the MS and which ions arise from reaction products.

The mass spectrometer does not have the same sensitivity to all ions. Therefore, even though the concentration of two compounds are the same, the intensity of the signal, or abundance, may in fact vary by several orders of magnitude for different ions. In this study the sensitivity to $\mathrm{H}_{2} \mathrm{O}$ and $\mathrm{NH}_{3}$ ions was found to be far smaller than to $\mathrm{Py}$ ions, probably because $\mathrm{H}_{2} \mathrm{O}$ and $\mathrm{NH}_{3}$ ionize to a much lesser extent than Py. However, the magnitude of the signal can be increased by increasing the concentration of the desorbed species in the carrier gas stream (by increasing the catalyst mass and/or by decreasing the carrier gas flowrate) or by increasing the dwell time (the time period during which the MS "counts" each ion).

Due to the different amounts of adsorbate desorbed for the various probes under investigation, it has been necessary to vary certain experimental parameters in order to acquire the required magnitude of the signal for each of the desorbing species. Therefore it is not always possible to relate the spectra of the different adsorbates directly. 
CHAPTER 3

\section{RESULTS}





\subsection{PHYSICAL AND CHEMICAL CATALYST CHARACTERIZATION}

\subsubsection{CATALYST STRUCTURE AND MORPHOLOGY}

\subsubsection{Relative crystallinity}

XRD patterns of each catalyst are given in Figures $3.1,3.2$ and 3.3. The main difference between ZSM-5 (sample A) and silicalite-I (sample S-I) is the intensity of the reflections at $2 \theta$ values of $7.9^{\circ}$ and $8.8^{\circ}$ (Figure 3.1 ). These two reflections are more intense for sample S-I. From Figure 3.2 it can be seen that samples $\mathbf{S}-\mathbf{B}, \mathbf{S}-\mathrm{B}_{i}$ and $\mathbf{S}-\mathrm{Bdi}_{\mathrm{d}}$ show similar increases in intensity for the reflections at $2 \theta$ values of $7.9^{\circ}$ and $8.8^{\circ}$ compared to sample $B$. On the other hand, a slight decrease in these reflections is observed for samples modified by chemical vapour deposition (Figure 3.3). A simulated XRD pattern of calcined ZSM-5 is shown for comparison in Figure 3.4. The relative crystallinities are listed in Table 3.1. Of the primary synthesis batches, sample $A$ has the lowest relative crystallinity, as calculated by summation of the intensities of the three major peaks between $22-25^{\circ} 2 \theta$. The relative crystallinities of samples $S-B i$ and $S-B$ are lower than that of sample $B$, whereas the relative crystallinity of sample S-Bdi is similar to that of sample B. The relative crystallinities of the samples modified by chemical vapour deposition are similar to sample $C$, although the relative crystallinity of sample $\mathrm{V}_{4}-\mathrm{C}$ is slightly higher. The estimated error for these data is $5 \%$.

\subsubsection{Crystallite size and morphology}

Crystallite sizes were determined from electron micrographs (Figures 3.5, 3.6 and 3.7). The number average crystallite sizes range from $1 \mu \mathrm{m}$ to $3 \mu \mathrm{m}$, except in the case of silicalite-I, which has a crystallite size of $5 \mu \mathrm{m}$. The crystallite sizes of the modified samples, even of those modified by coating the parent crystals with silicalite shells, are not noticeably larger than their parent crystals. A catalyst with a shell-to-core weight ratio of $1.5: 1$ is only expected to be $\mathbf{1 . 3 6}$ times larger than the seed crystal. Also, separate silicalite-I crystals may have formed. No significant deposits of amorphous material were seen in the micrographs at these magnifications. All samples have formed agglomerates with spherical morphologies, with the exception of silicalite-I, which has a twinned crystallite morphology. 


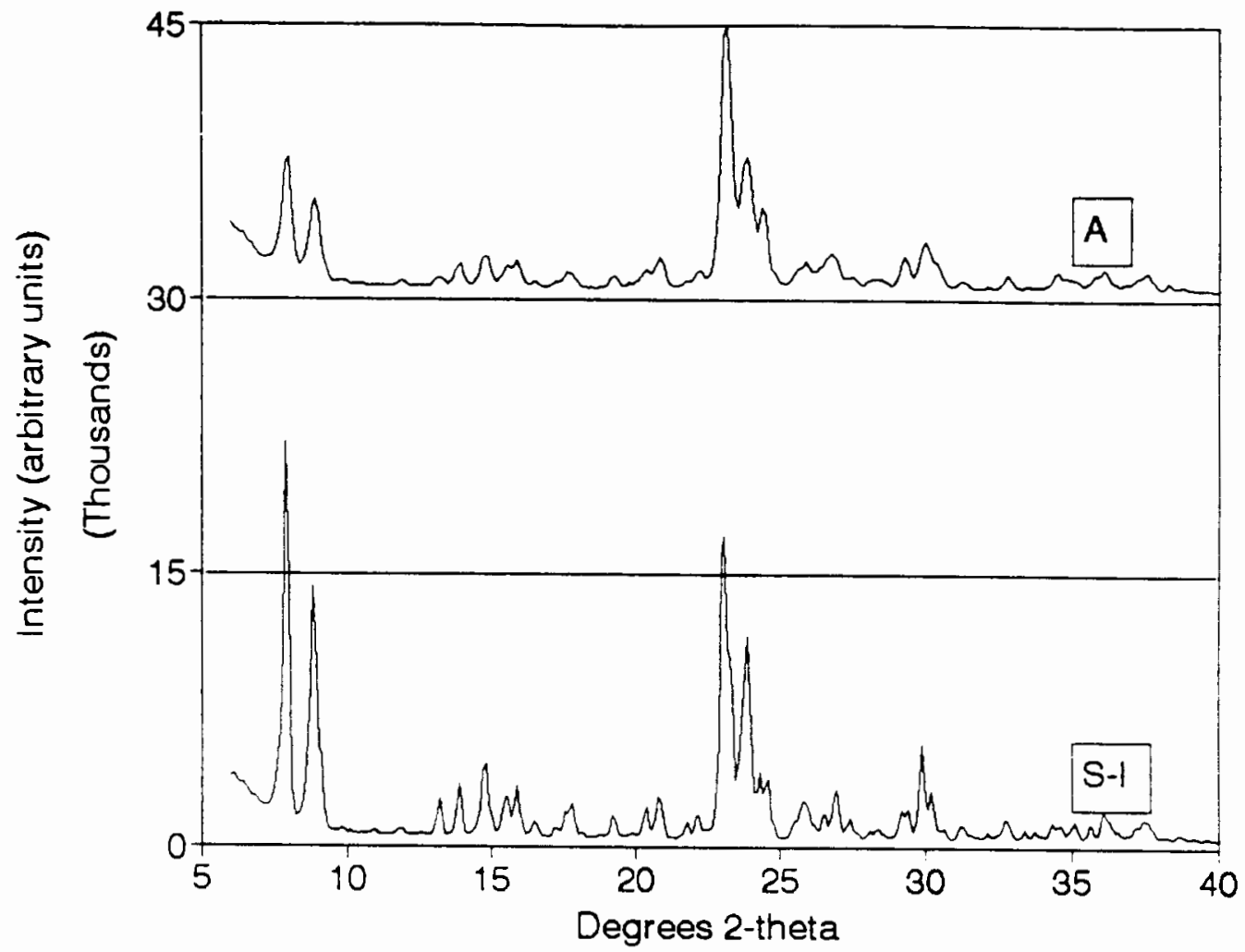

FIGURE 3.1: XRD patterns of $A$ and S-I

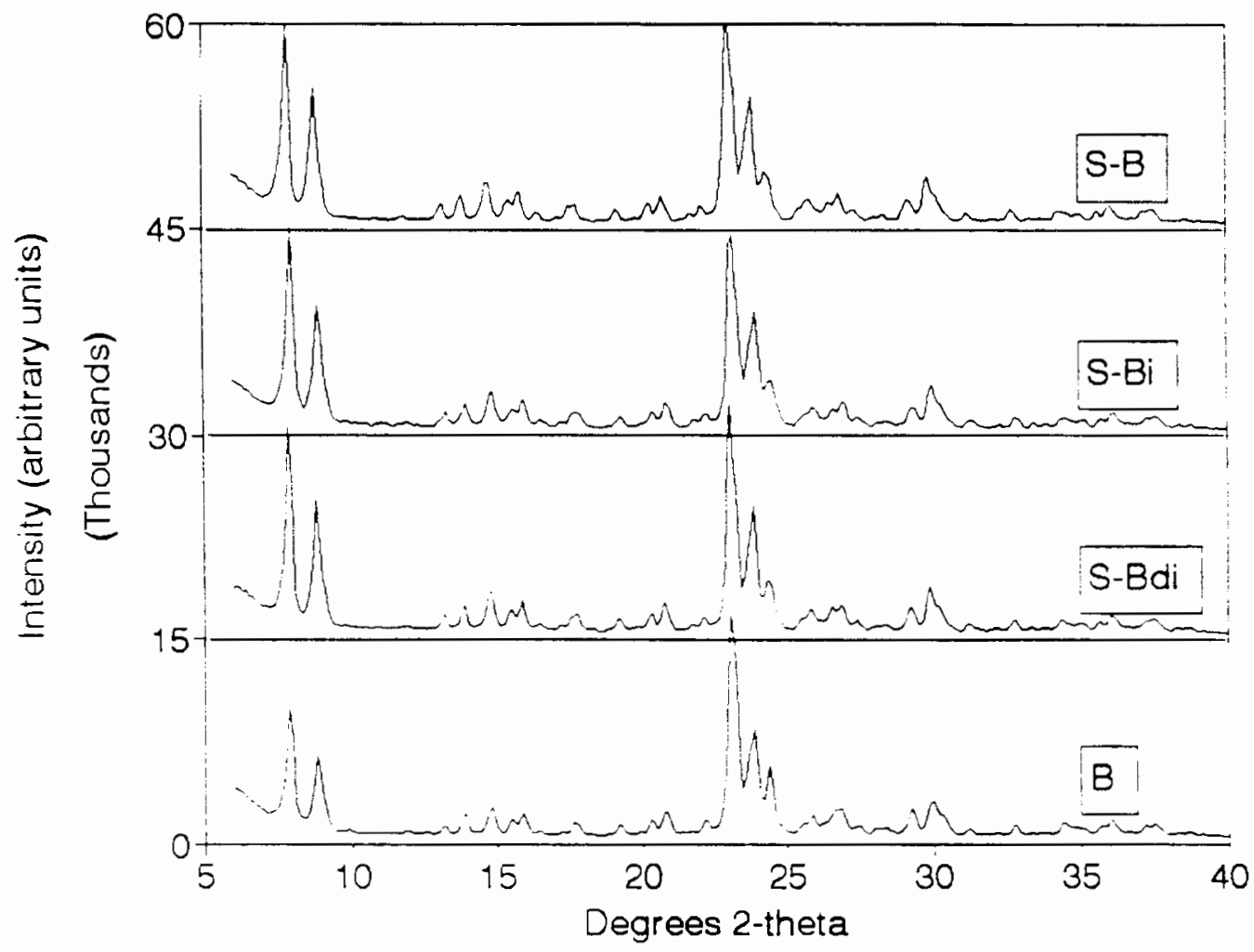

FIGURE 3.2: XRD patterns of $B, S-B d i, S-B i$ and S-B 


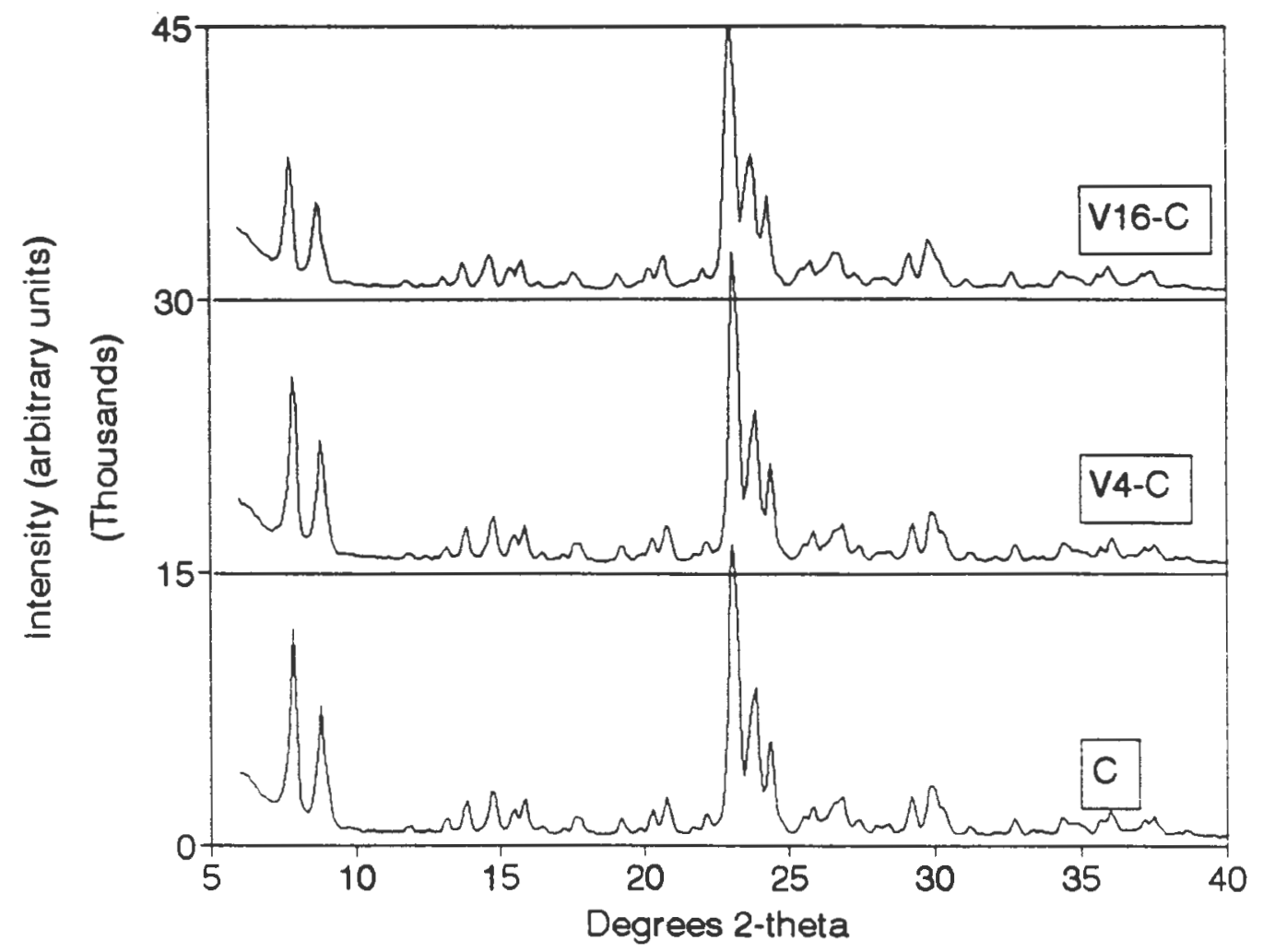

FIGURE 3.3: XRD patterns of $C, V_{4}-C$ and $V_{18}-C$

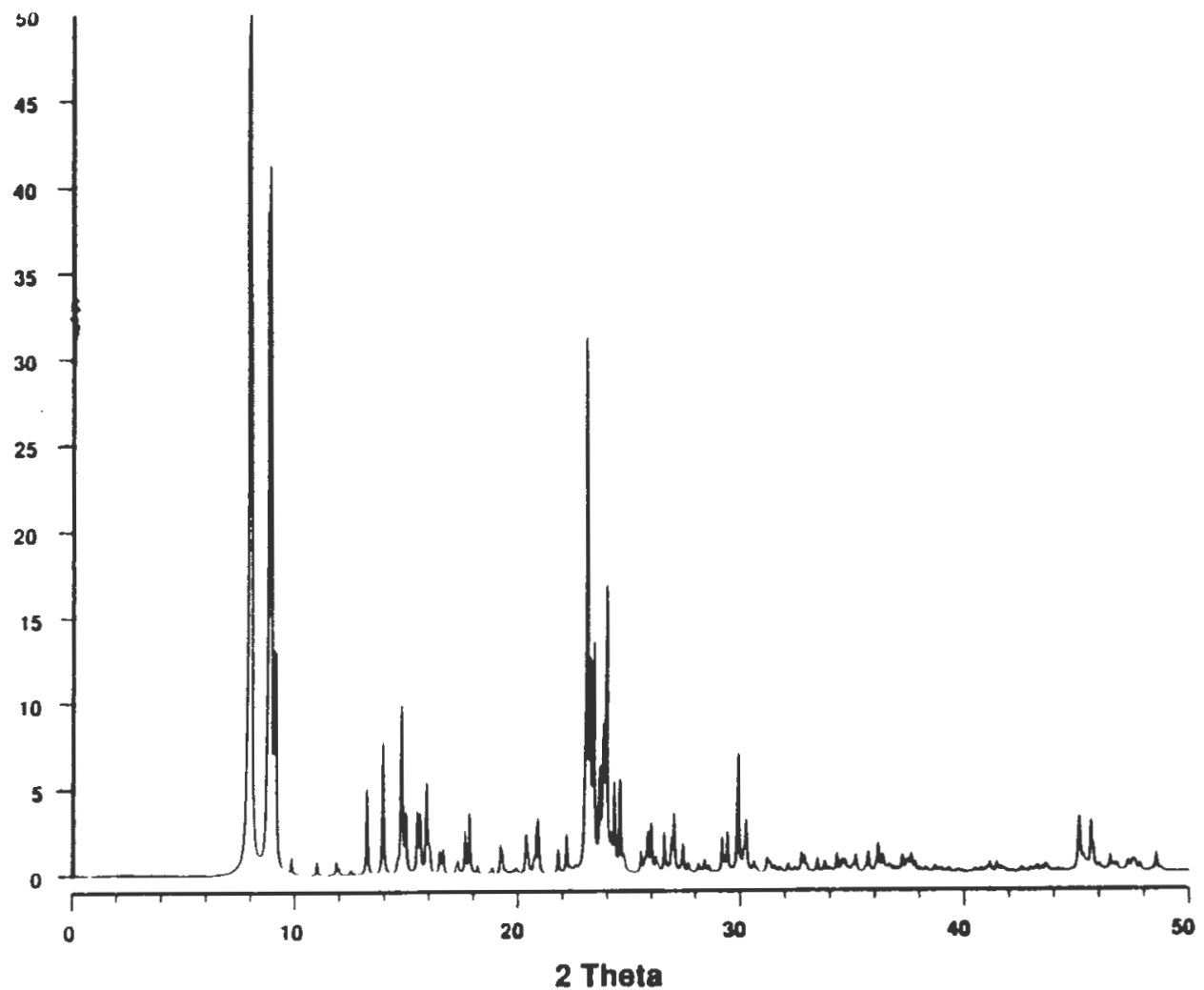

FIGURE 3.4: Simulated XRD pattern of ZSM-5 [Von Ballmoos and Higgins, 1990] 


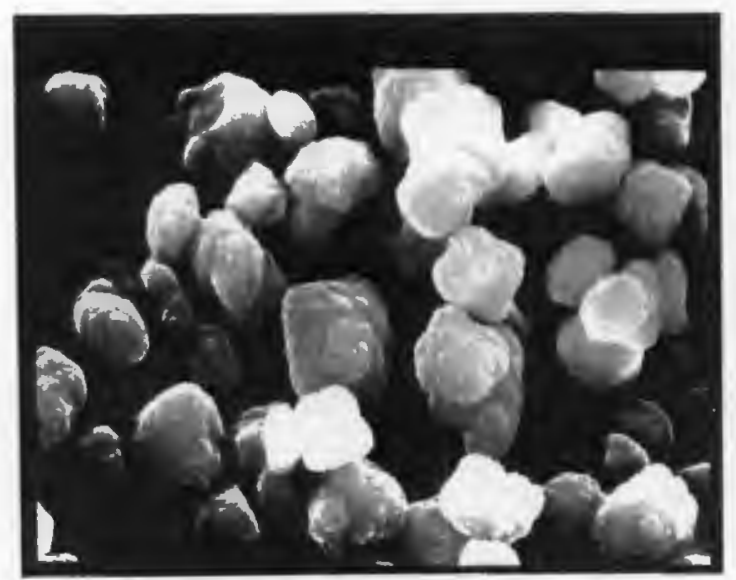

(a)

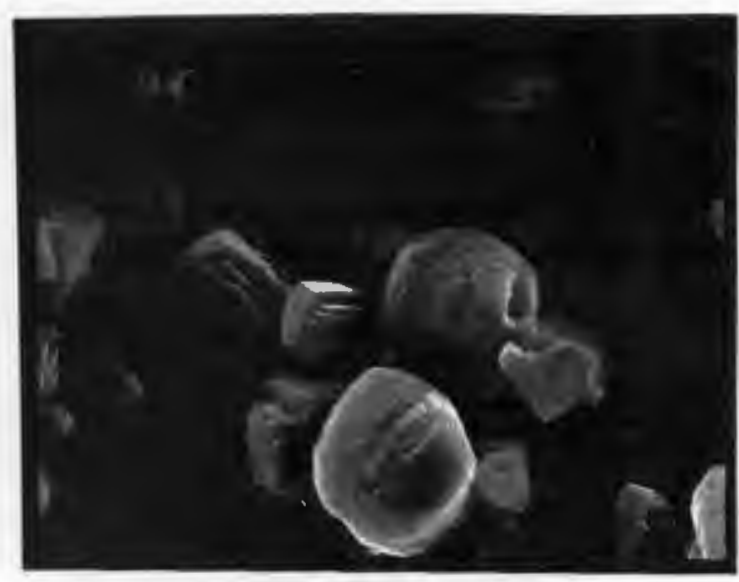

(b)

FIGURE 3.5: Electron micrographs of (a) A and (b) S-1

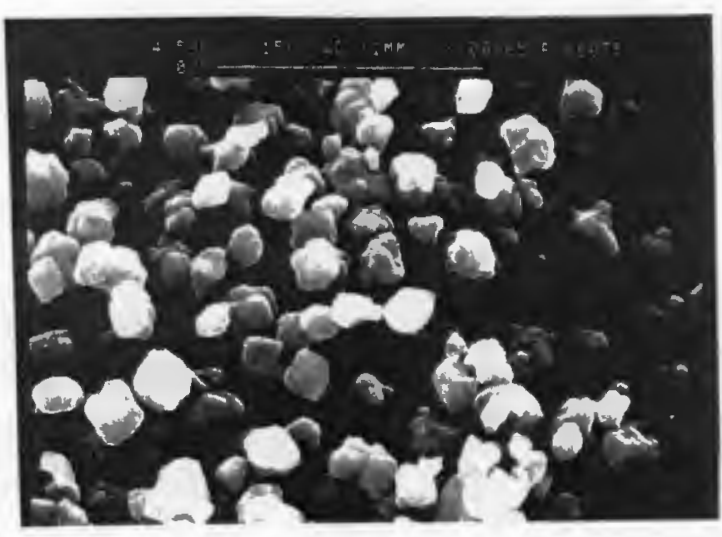

(a)

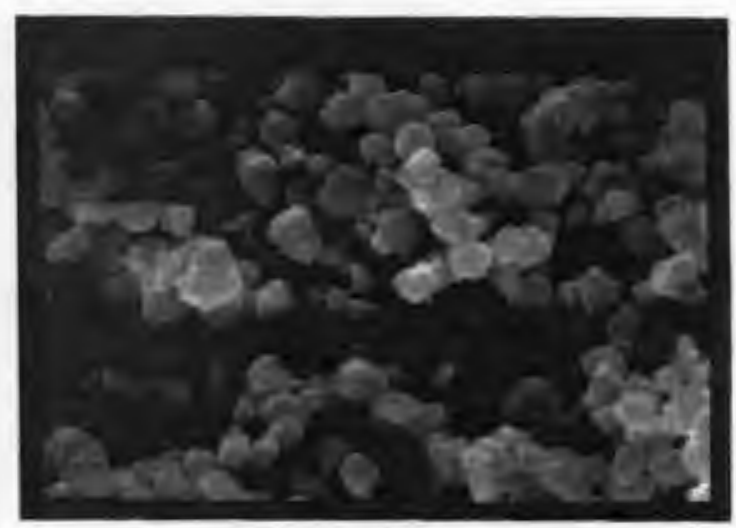

(b)

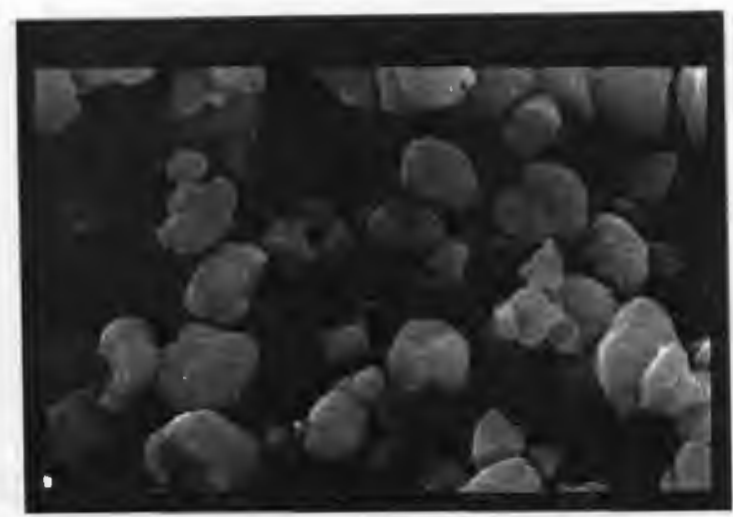

(c)

FIGURE 3.6: Electron micrographs of (a) $C$, (b) $V_{4}-C$ and (c) $V_{16}-C$ 


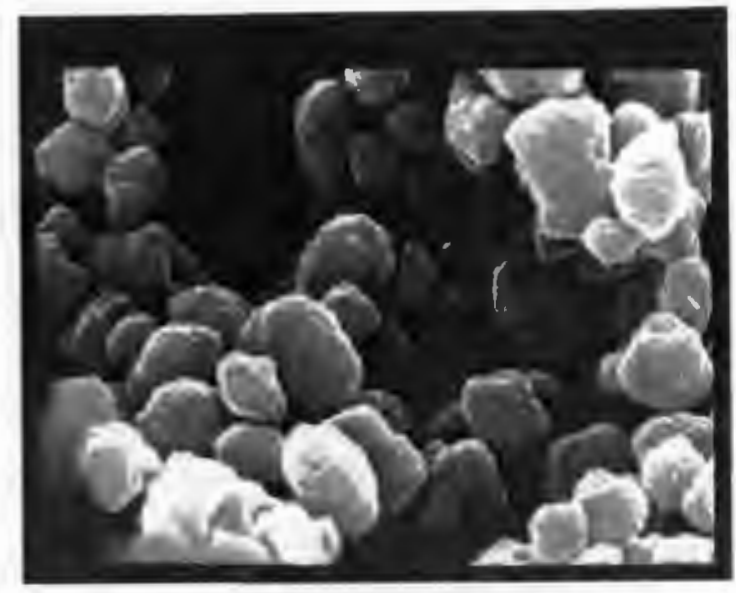

(a)

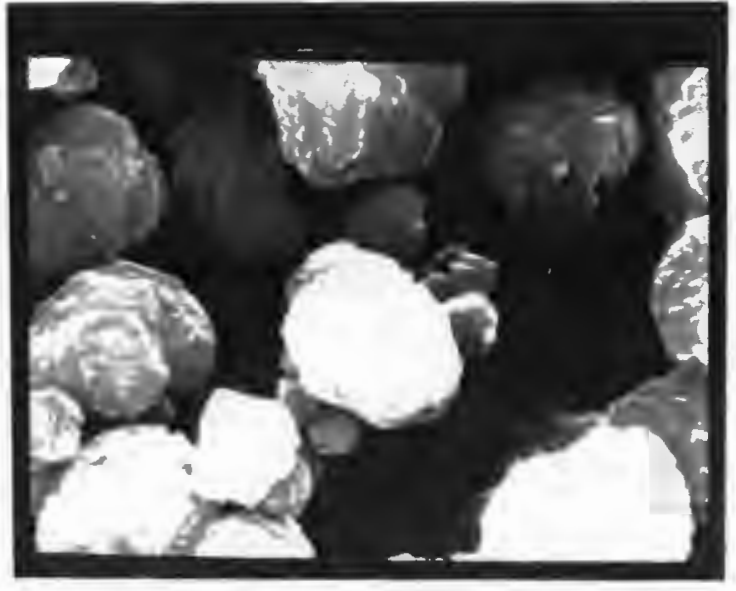

(b)

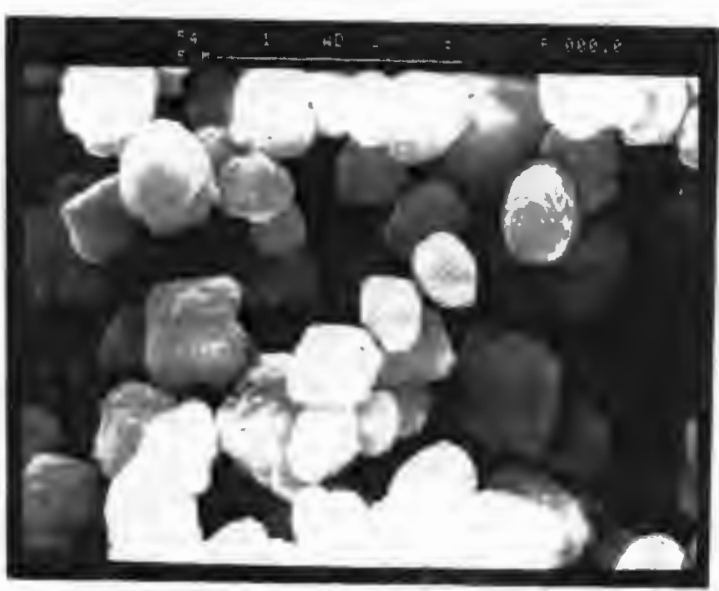

(c)

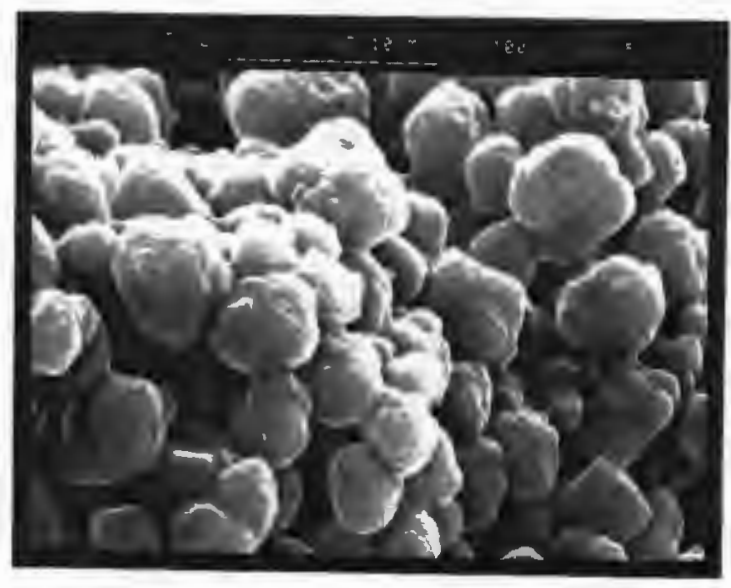

(d)

FIGURE 3.7: Electron micrographs of (a) B, (b) S-Bdi, (c) S-Bi and (d) S-B 


\subsubsection{CATALYST COMPOSITION}

\subsubsection{Silicon and aluminium content}

The Si/Al ratio of the various batches, as determined by atomic absorption spectroscopy (AAS), is shown in Table 3.1. The number of mmol Al per gram of dry sample as determined by AAS has also been included in Table 3.1. The $\mathrm{Si} / \mathrm{Al}$ ratio for the unmodified catalyst lies in the range $35-47$, sample $C$ having the highest ratio. No aluminium was detected in the silicalite-I sample. Coating the sample with silicalite shells produced a large increase in the Si/Al ratio in each sample, with sample S-B showing the highest increase. The Si/Al ratio for CVD modified samples decreased slightly compared to sample $C$, although these changes are within the experimental error. No sodium was detected in any of the samples after $\mathrm{NH}_{3}$ ion exchange. The aluminium reading contributes the most to the overall error (due to the low levels) and the corresponding error increases with increasing $\mathrm{Si} / \mathrm{Al}$ ratio. Therefore the Si/Al ratios of the samples modified by coating with silicalite shells have a greater error associated with them than the other samples. However, the aluminium content determined by AAS corresponds well with the aluminium in the synthesis mixture, as the expected value should be approximately $1 /(1+1.5)$ times that of the parent sample if $1 \mathrm{~g}$ of ZSM-5 is reimmersed in a synthesis mixture expected to yield $1.5 \mathrm{~g}$ of silicalite-I.

\subsubsection{Catalyst acidity}

The number of acid sites, as measured by mmol of $\mathrm{NH}_{3}$ per gram of catalyst, was obtained by quantitative $\mathrm{NH}_{3}$-TPD using the apparatus and procedures described in Section 2.2.2.2. Only the high temperature peak was integrated, "sus giving a measure of the chemisorbed material. The results are listed in Table 3.1. The number of acid sites of the unmodified samples range from 0.35 - $0.49 \mathrm{mmol} \mathrm{NH}_{3}$ per gram of catalyst. Silicalite-I shows virtually no acidity. Samples modified by coating with silicalite shells show a reduction in the specific number of acid sites (ie. the number of acid sites per gram of resulting material). However, the values for the coated samples are higher than expected from the aluminium content in the synthesis mixture, and they are higher than the values obtained from AAS. Samples modified by chemical vapour 
deposition do not show a significant change in the number of acid sites as measured by $\mathrm{NH}_{3}$-TPD. The error associated with $\mathrm{NH}_{3}-\mathrm{TPD}$ is estimated to be at least $15 \%$.

\subsubsection{Thermogravimetric analysis}

The moisture content and $n$-hexane adsorption capacity of selected samples were measured by thermogravimetric analysis. The results are listed in Table 3.1. The moisture content of the unmodified samples lies in the range $5.8-6.8$ $w t \%$. Silicalite-I shows a 0.1 wt \% moisture content. Samples modified by coating with silicalite shells show a moisture content which is intermediate between unmodified HZSM-5 and silicalite-I. Samples modified by chemical vapour deposition do not show a significant change in moisture content from their parent sample. $n$-Hexane adsorption capacities of selected samples do not show significant changes for the modified samples, either by coating with silicalite shells or by chemical vapour deposition. The estimated error for these data is $7 \%$.

TABLE 3.1: Catalyst characterization

\begin{tabular}{|c|c|c|c|c|c|c|}
\hline CATAL. & $\begin{array}{l}\mathrm{Si} / \mathrm{Al} \\
\text { ratio }\end{array}$ & $\begin{array}{c}\text { Al } \\
\text { content } \\
\text { (mmol/g) }\end{array}$ & $\begin{array}{c}\mathrm{NH}_{3}-\mathrm{TPD} \\
\mathrm{HTD} \text { peak } \\
(\mathrm{mmol} / \mathrm{g})\end{array}$ & $\begin{array}{c}\mathrm{H}_{2} \mathrm{O} \\
\text { content } \\
\text { (wt \%) }\end{array}$ & $\begin{array}{c}n \text {-Hexane } \\
\text { adsorption } \\
(w t \%)\end{array}$ & $\begin{array}{c}\text { Relative } \\
\text { Crystal. } \\
(\%)\end{array}$ \\
\hline A & 35.6 & 0.462 & 0.428 & 6.8 & - & 86.5 \\
\hline S-I & $\propto$ & 0.0 & 0.026 & 0.1 & - & 99.2 \\
\hline B & 38.8 & 0.463 & 0.491 & 6.6 & 8.7 & 95.2 \\
\hline S-Bdi & 81.0 & 0.191 & 0.275 & 3.2 & - & 94.4 \\
\hline $\mathrm{S}-\mathrm{Bi}$ & 81.0 & 0.191 & 0.298 & 3.3 & - & 85.4 \\
\hline S-B & 108.1 & 0.144 & 0.287 & 3.6 & 9.0 & 88.9 \\
\hline $\mathrm{C}$ & 46.4 & 0.393 & 0.348 & 5.8 & 8.9 & 95.3 \\
\hline$V_{4}-C$ & 42.5 & 0.396 & 0.380 & 6.3 & - & 100.0 \\
\hline$V_{16}-C$ & 44.7 & 0.364 & 0.371 & 5.6 & 8.9 & 93.5 \\
\hline ERROR & $10-15 \%$ & $10-15 \%$ & $15 \%$ & $7 \%$ & $7 \%$ & $5 \%$ \\
\hline
\end{tabular}

NOTE: A statistical error analysis was not possible. The error listed in the table above is a nonstatistical estimation made by the author, based on accuracy of the equipment and reproducibility of the measurements. 


\subsection{TEMPERATURE PROGRAMMED DESORPTION FROM HZSM-5}

The TPD spectra in this section were obtained using the apparatus and procedures described in Section 2.3. Values of $T_{\max }$ are rounded to the nearest $5{ }^{\circ} \mathrm{C}$. Typically the ions shown in the spectra are $m / e=17\left(\mathrm{NH}_{3}\right), m / e=79$ (Py) and $m / e=78$ (MQ-4).

\subsubsection{PRELIMINARY RESULTS}

Dispersion of the signal prior to detection

To check the effect of the signal dispersion in the transfer line from the reactor to the GC/MS, a pulse of air was injected though a septum installed for this purpose (i) after valve V14 (Figure 2.3), or (ii) prior to valve V13 (Figure 2.3). These two points are the closest points to the sample where such a septum could be installed. This could then be compared to a pulse of air injected through the injector port of the GC.

When a pulse of air is injected after valve V14 the intensity $\left(1.5 \times 10^{6}\right.$ units) and width $(3 \mathrm{sec})$ of the peak are the same as for an injection through the injector port. However, when a pulse of air is injected prior to valve V13, the intensity of the peak drops $\left(2.0 \times 10^{5}\right.$ units) and the width increases $(10 \mathrm{sec})$. This is as a result of the signal being dispersed due to the two valves (V13 and $\checkmark 14$ ) and the TPD cell. When a TPD spectrum is obtained, the signal will only pass through valve $V 14$ and approximately $1 / 3$ of the TPD cell. The dispersion will hence be less. Furthermore, it should be kept in mind that a peak in a TPD spectrum is typically 30 - 40 minutes long (sampling each ion every 6 - 10 sec with a MS dwell time of 1 - $5 \mathrm{sec}$ ). Therefore such a small amount of dispersion will have a negligible effect on the shape of the actual TPD curve.

Adsorption of the adsorbates onto the transfer line.

To estimate whether adsorbate is adsorbed onto the walls of the stainless steel transfer lines, small doses of pyridine vapour were injected through a septum as described in the paragraph above. It was noted that even though the transfer 
line from the reactor to the GC/MS was heated to $150{ }^{\circ} \mathrm{C}$, a small amount of the adsorbate would adsorb onto the stainless steel walls. The estimated amount of pyridine adsorbed onto the stainless steel pipe is less than $10^{-5}$ mmol. This is 2-3 orders of magnitude smaller than the estimated amount of pyridine desorbed from the catalyst sample using typical operating conditions. In the case of MQ-TPD experiments, even though the external surface of the catalyst is much smaller than the total surface, the catalyst mass used is 20 times greater. Hence the amount of adsorbate, used in MQ-TPD studies of the external surface, which is adsorbed onto the transfer line during desorption is small (typically less than $5 \%$ ) compared to the total amount which is desorbed from the sample.

\section{Mass spectrometer settings}

To prevent condensation of $\mathrm{H}_{2} \mathrm{O}$ and adsorbates in the transfer lines and $\mathrm{GC}$ column, the transfer lines and GC oven were kept above the boiling points of each component (Boiling Point of $\mathrm{NH}_{3}=-33^{\circ} \mathrm{C}$, BP of $\mathrm{Py}=115^{\circ} \mathrm{C}$, BP of $\left.\mathrm{MQ}-4=262^{\circ} \mathrm{C}\right)$.

The total flow entering the GC is split. A large fraction is vented and only a small fraction enters the MS. The length of the column and the column head pressure of the GC governs the flowrate to the MS. By installing a $15 \mathrm{~m}$ long column the required range of flowrates $(0.5-1 \mathrm{ml} / \mathrm{min})$ to the $\mathrm{MS}$ could be obtained for each adsorbate.

The catalyst mass and carrier gas flowrate affect the concentration of the adsorbate in the carrier gas stream. The carrier gas flowrate and column head pressure affect the split ratio of the GC/MS, and hence the flowrate entering the MS. The MS dwell time governs the time during which the MS "counts" the ions entering the MS, and hence this affects the intensity of the signal. These settings were optimized for each adsorbate investigated, such that the best possible spectrum was obtained. It must be understood that the settings for Py-TPD and MQ-TPD experiments are different, and direct comparisons between PY-TPD and MQ-TPD experiments cannot be made. 


\section{Baseline spectra}

To investigate whether either Py or MQ-4 is adsorbed onto the quartz reactor or quartz particles, baseline spectra were obtained and compared to Py-TPD and MQ-TPD spectra obtained under identical conditions as the baseline spectra. These comparisons can be found in Appendix VII. The baseline spectra show that there is no significant adsorption on the quartz reactor or quartz particles when no catalyst is present.

\subsubsection{A COMPARISON OF THE DESORPTION SPECTRUM OF THE ADSORBATES INVESTIGATED}

Three adsorbates have been compared in these studies, namely $\mathrm{NH}_{3}$, pyridine (Py) and 4-methyl quinoline (MQ-4). Figure 3.8 shows the TPD spectra for each of these adsorbates from HZSM-5 (catalyst A). The two most abundant ions are shown in each case.

Only one peak is seen for both the $\mathrm{NH}_{3}$-TPD and Py-TPD spectra under these conditions. In both these cases the peak is skewed towards higher desorption temperatures, showing a leading edge on the TPD spectrum. An additional small peak can be seen at $585{ }^{\circ} \mathrm{C}$ in the $\mathrm{NH}_{3}$-TPD spectrum. This is not due to the desorption of $\mathrm{NH}_{3}$, but due to the loss of $\mathrm{H}_{2} \mathrm{O}$ from the catalyst (ions 16 and 17 are common to both $\mathrm{NH}_{3}$ and $\mathrm{H}_{2} \mathrm{O}$ ). The $\mathrm{H}_{2} \mathrm{O}$ loss may be ascribed to dehydroxylation. The TPD spectrum of the loss of $\mathrm{H}_{2} \mathrm{O}$, after calcination, from HZSM- 5 can be found in Appendix VII (catalyst A, $0.010 \mathrm{~g}$ catalyst, $150 \mathrm{ml} / \mathrm{min}$ carrier gas flowrate). In the case where MQ-4 has been used as adsorbate two peaks can be seen. This is most clearly visible for $m / e=128$. More importantly, no leading edge is evident.

The intensity of the signal is much greater for $\mathrm{Py}$ than for $\mathrm{NH}_{3}$ under the same conditions $10.050 \mathrm{~g}$ catalyst, $150 \mathrm{ml} / \mathrm{min}$ carrier gas flowrate). This can be attributed to a greater sensitivity of the MS to Py ions. The intensity of the signal for MQ-4 is lower than that of Py, even though a greater mass of catalyst $(1 \mathrm{~g}$ vs $0.050 \mathrm{~g}$ ) and a lower flowrate $(60 \mathrm{ml} / \mathrm{min}$ vs $150 \mathrm{ml} / \mathrm{min})$ are usually used for MQ-TPD than for Py-TPD. In the case of both $\mathrm{NH}_{3}$ and Py both characteristic ions are present in the same proportions throughout the experiment. However, in the case of MO-4 the two most abundant ions are not 
(a)

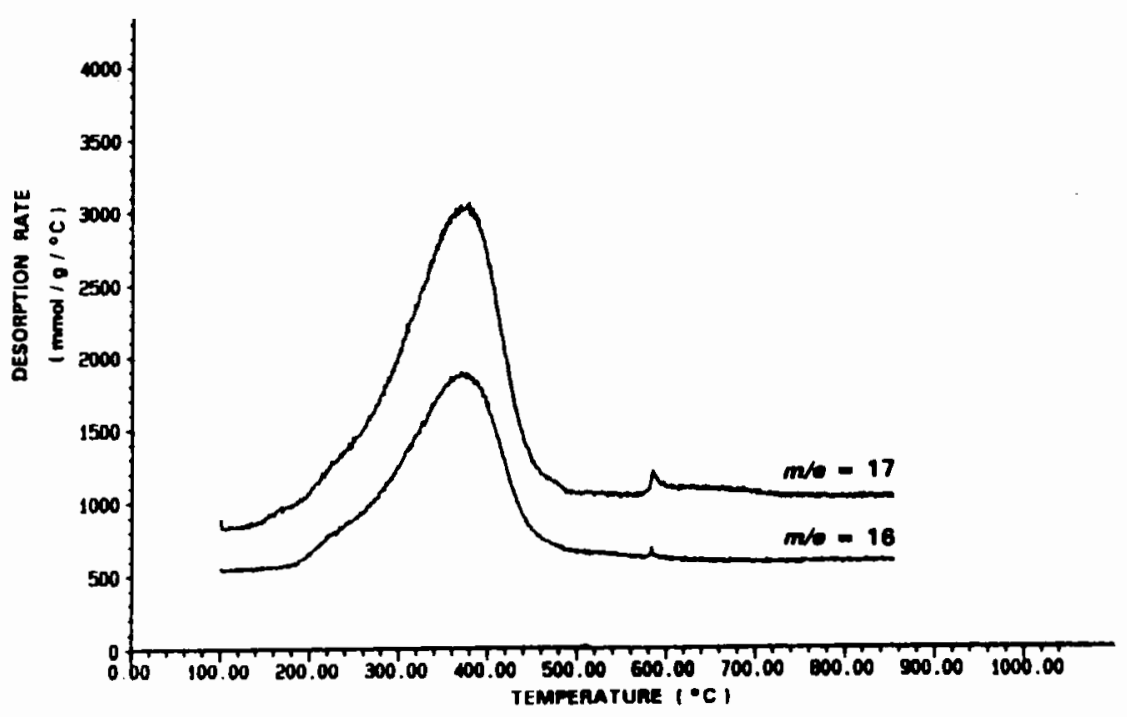

(b)

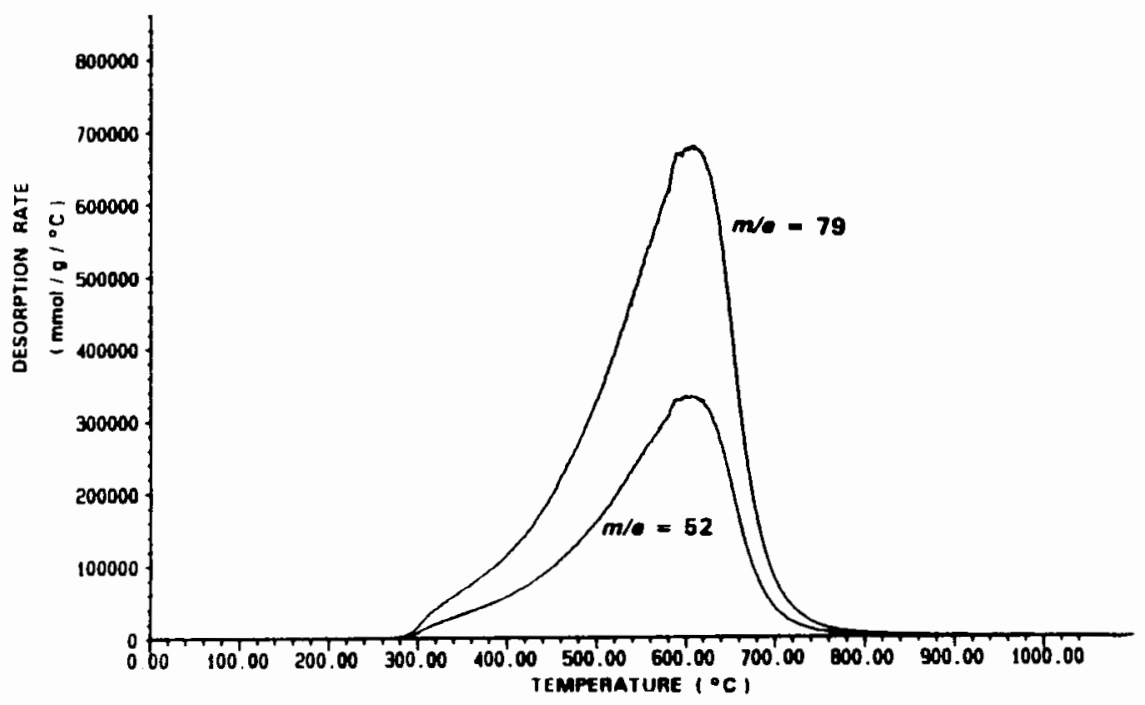

(c)

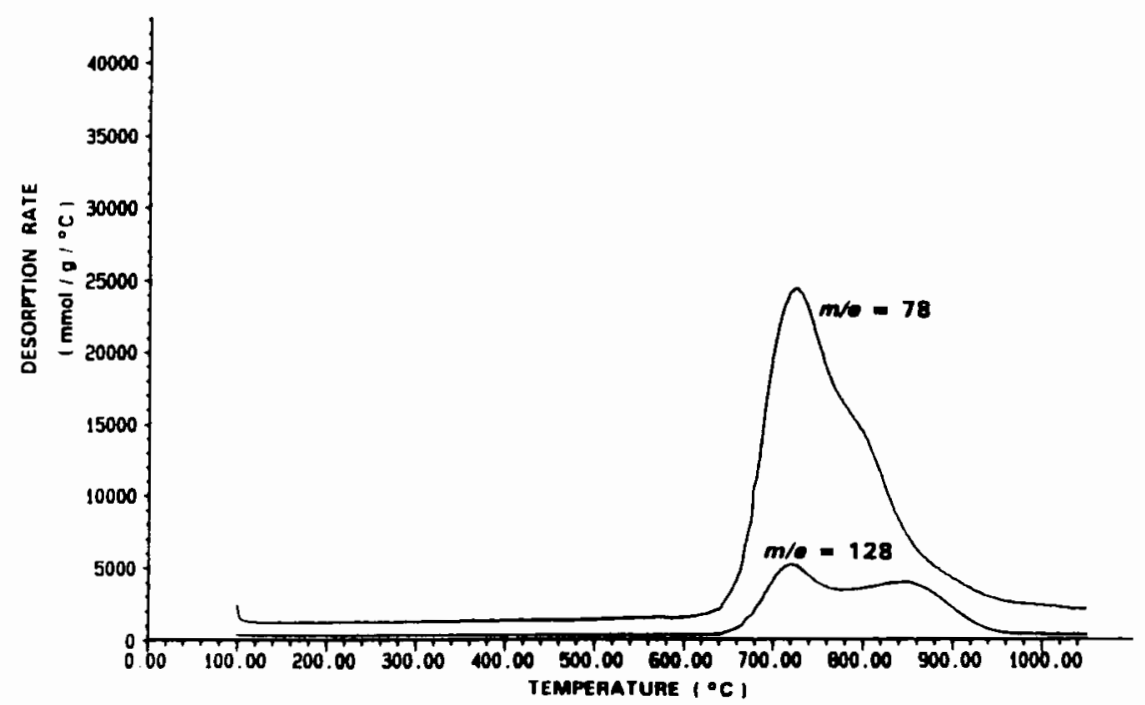

FIGURE 3.8: TPD spectra of (a) $\mathrm{NH}_{3}$, (b) Py and (c) MQ-4 from HZSM-5 (catalyst A) 
present in the same proportions (Figure 3.8c). This will be discussed in more detail in Section 3.2.7.

Under the conditions used here, $T_{\max }$ is found to increase in the following order: $\mathrm{NH}_{3}<$ Py $<$ MO-4 $\left(375,620\right.$ and $725^{\circ} \mathrm{C}$ respectively). TPD spectra of the above adsorbates from silica-alumina showed the same order for $T_{\max }$. Appendix VII shows a Py-TPD spectrum from silica-alumina. It is interesting to note that this peak is skewed towards lower desorption temperatures, thus showing a tailing edge.

\subsubsection{REPRODUCIBILITY STUDIES}

The reproducibility for pyridine desorption was tested for catalyst $\mathrm{A} 10.050 \mathrm{~g}$ catalyst, $150 \mathrm{ml} / \mathrm{min}$ carrier gas flowrate, $23 \mathrm{~h}$ evacuation at $200{ }^{\circ} \mathrm{C}$ ), as can be seen from Figure 3.9. Figure 3.10 shows the reproducibility for 4-methyl quinoline desorption from catalyst $A(1 \mathrm{~g}$ catalyst, $60 \mathrm{ml} / \mathrm{min}$ carrier gas flowrate, $1 / 4 \mathrm{~h}$ evacuation at $100^{\circ} \mathrm{C}$ ).

The peak shape (ie. the skewness) is reproducible in both cases, but less so for MQ-4. Furthermore, the peak maximum temperature is reproducible to within 5 ${ }^{\circ} \mathrm{C}$. The intensity of the signal and hence the peak area is, to a large extent, dependent on the sensitivity of the mass spectrometer, and varies with time (ie. consecutive experiments are reproducible, but experiments performed far apart may not be). This is evident from the peak areas given in Figures 3.9 and 3.10. The reproducibility may also be affected by variations in catalyst mass, flowrate and split ratio. Therefore qualitative data can be obtained, but due to the difficulty of obtaining reproducible, integratable TPD peaks with similar areas, quantitative results (in terms of mmol adsorbate desorbed per gram of catalyst) have not been obtained. An attempt has been made to calibrate the MS for Py, by the injection of a range of standard concentrations. Due to the differences between "injections" and "spectra", as well as the non-linearity of the range in which the data was obtained, it was not possible to calibrate the MS satisfactorily and, consequently, quantitative data are not reported for Py and MQ-4 in this study. 


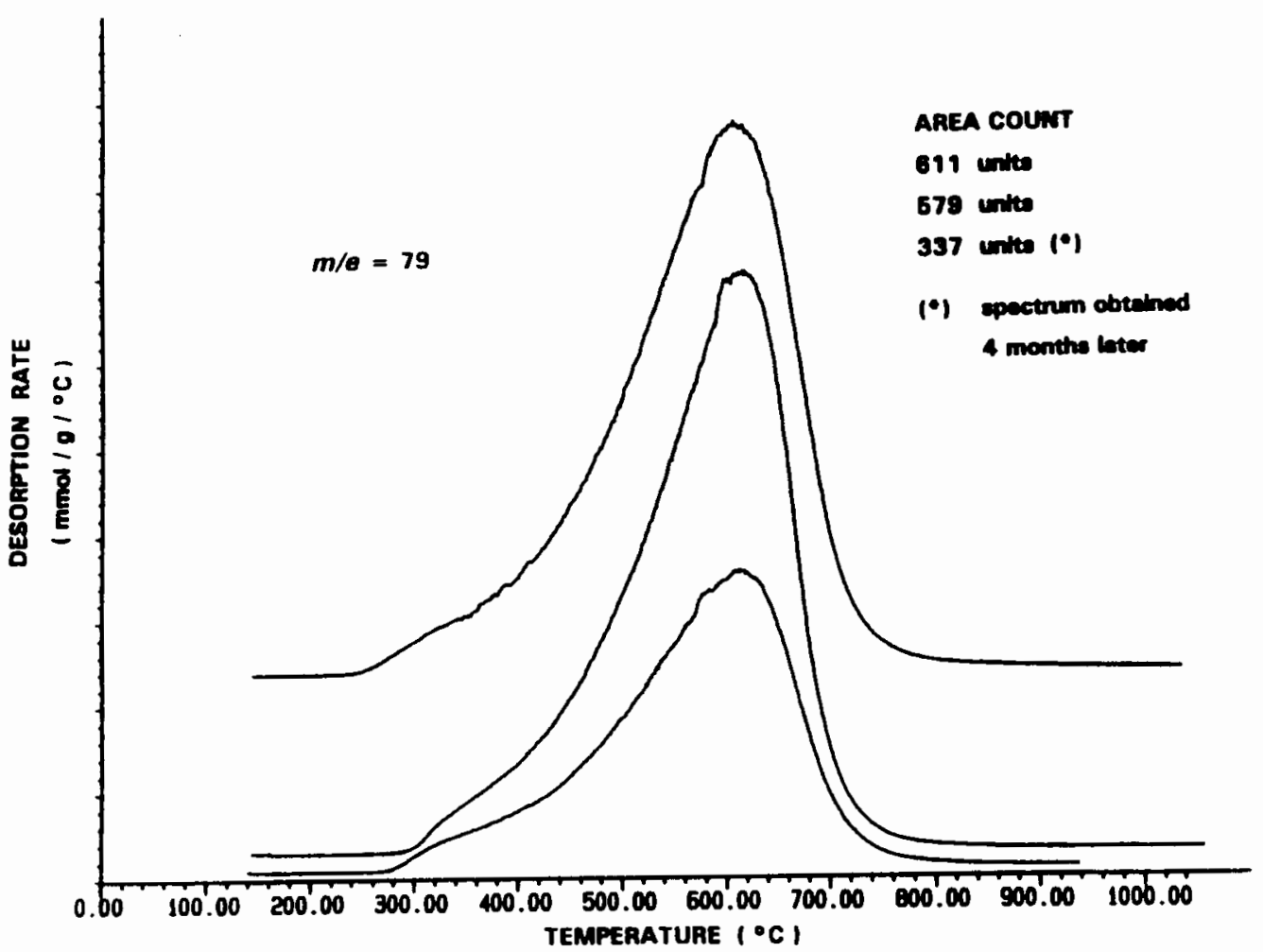

FIGURE 3.9: Reproducibility of PY-TPD spectra from HZSM-5 (catalyst A)

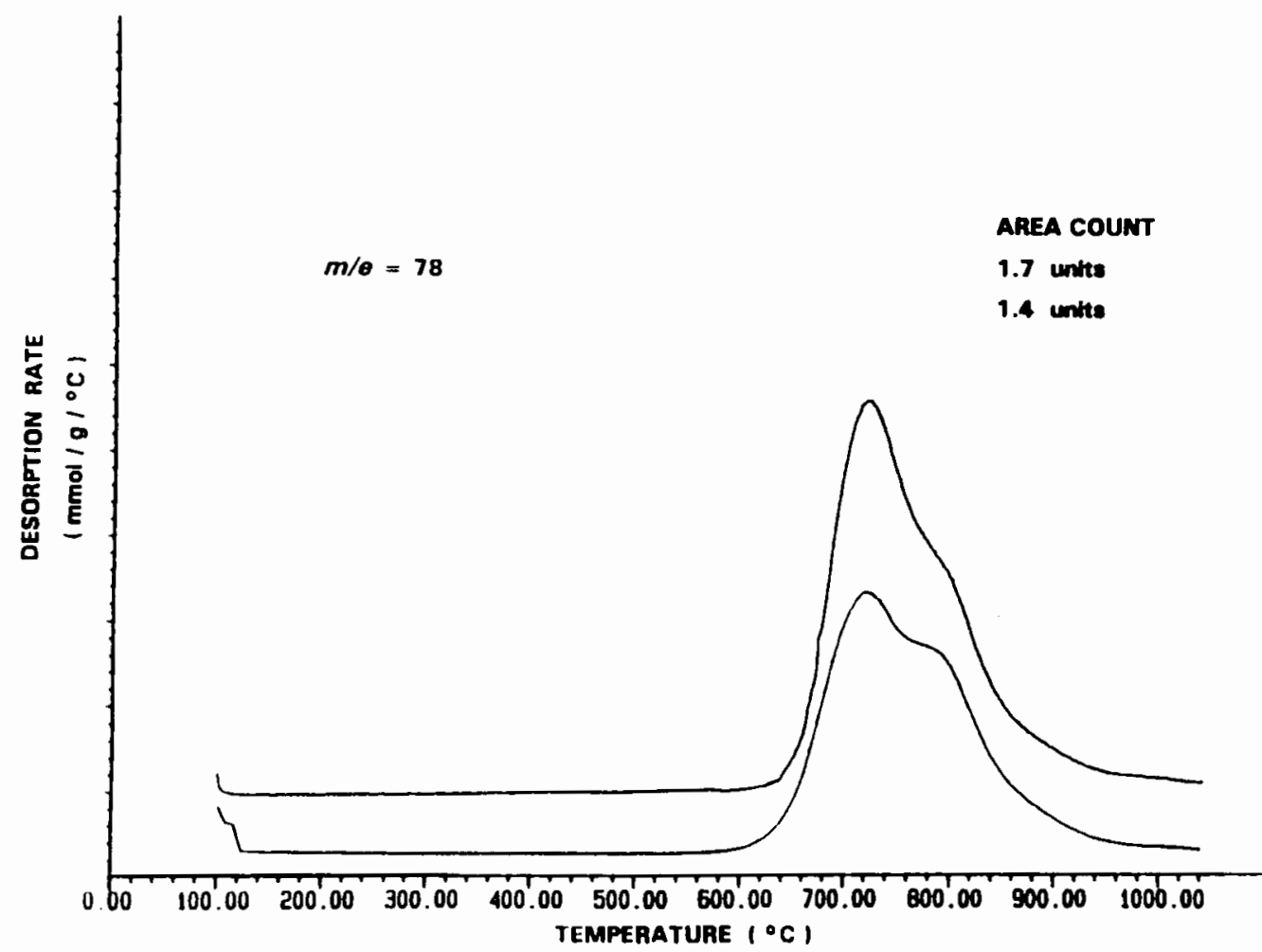

FIGURE 3.10: Reproducibility of MQ-TPD spectra from HZSM-5 (catalyst A) 


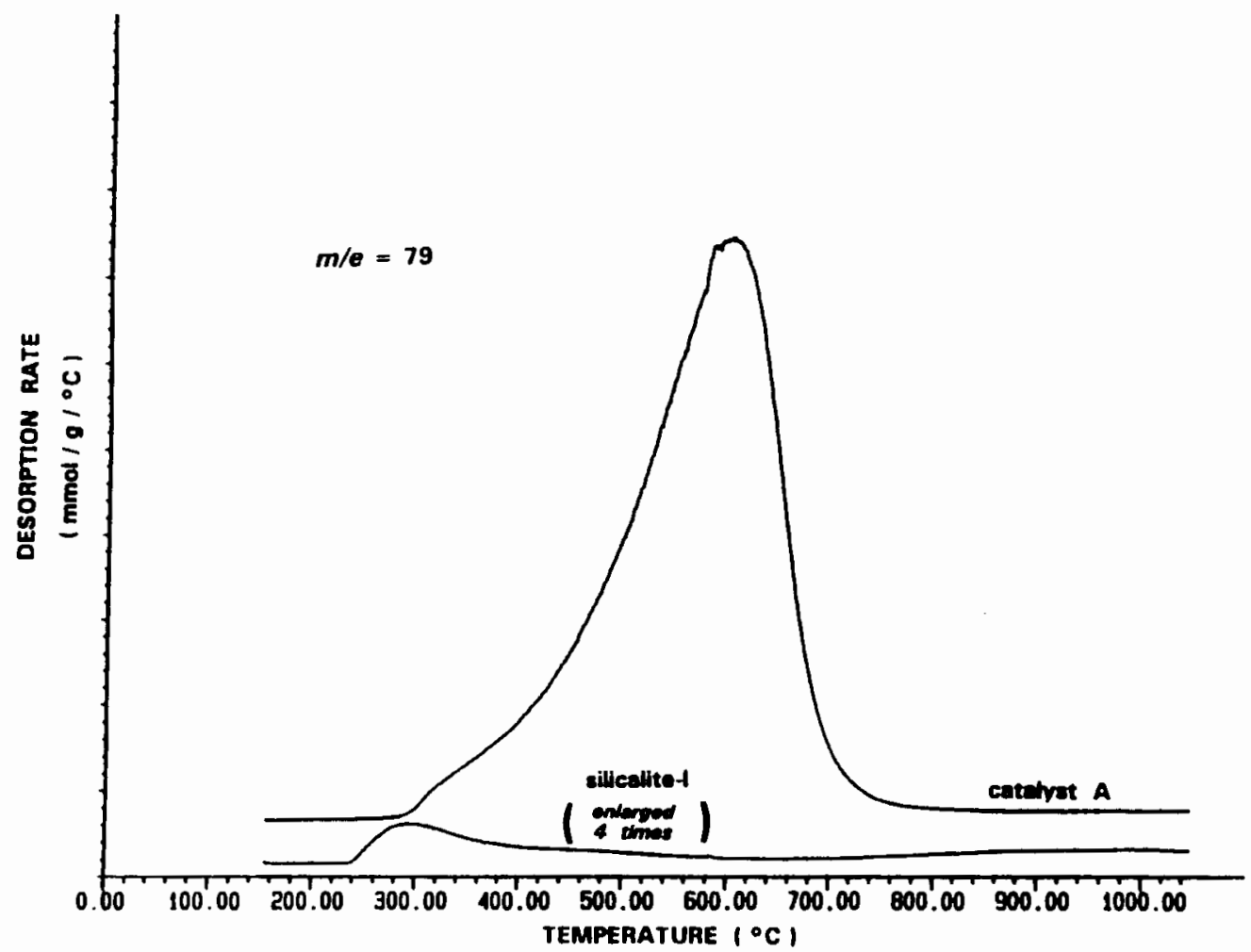

FIGURE 3.11: Py-TPD spectra from HZSM-5 and silicalite-I

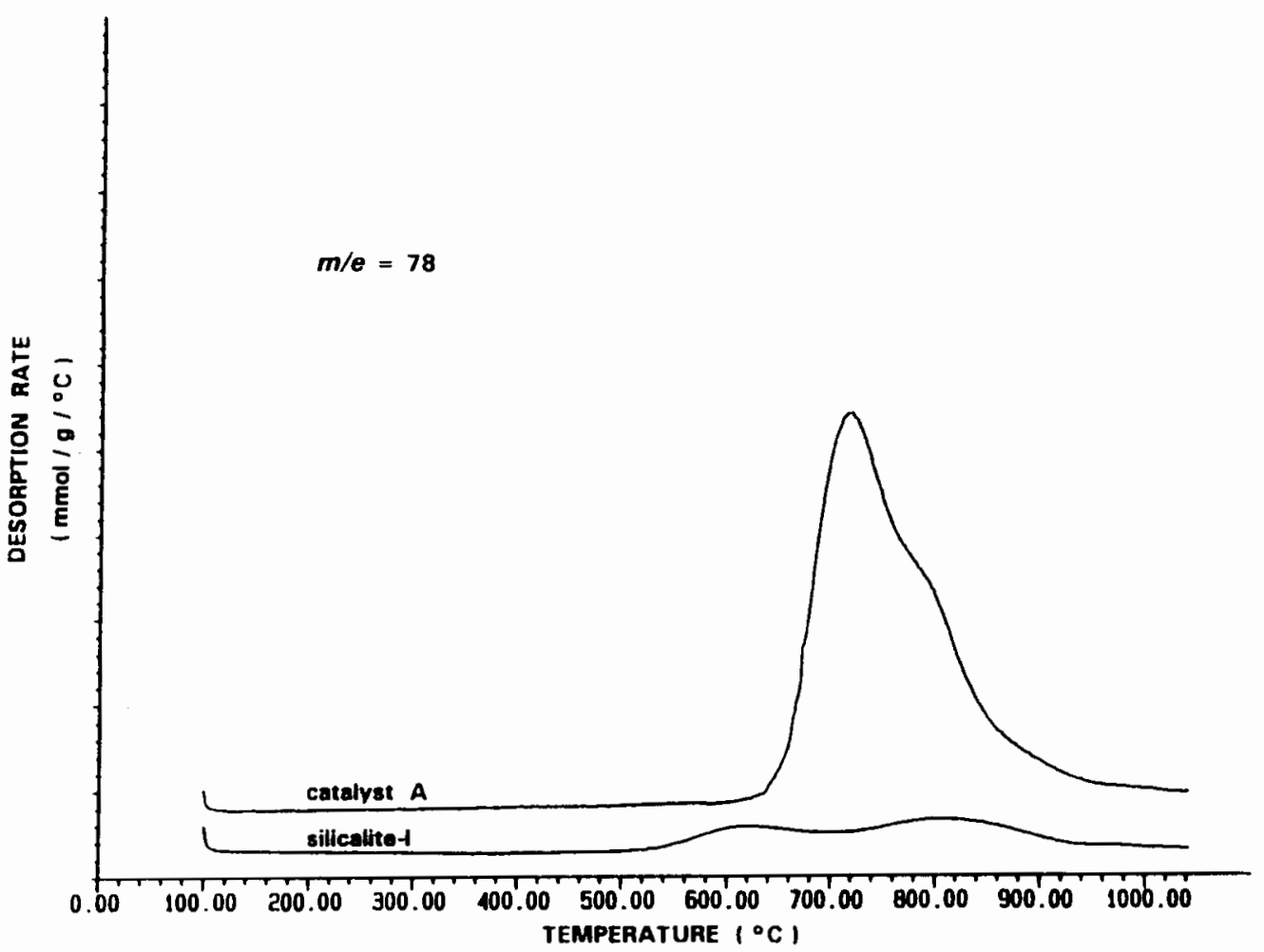

FIGURE 3.12: MQ-TPD spectra from HZSM-5 and silicalite-I 


\subsubsection{A COMPARISON OF HZSM-5 AND SILICALITE-I}

HZSM-5 (catalyst A) and silicalite-I (S-I) were used to compare an acidic catalyst (HZSM-5) with an isostructural inert catalyst (silicalite-1). This would indicate whether any adsorption takes place on silicalite-I, either on the internal or the external surface. Moreover, this would also indicate the contribution of silicalite-I, if any, to the total amount of desorbed adsorbate of catalysts modified by the silicalite shell method.

Figure 3.11 shows a comparison of Py-TPD spectra $(0.050 \mathrm{~g}$ catalyst, 150 $\mathrm{ml} / \mathrm{min}$ carrier gas flowrate, $23 \mathrm{~h}$ evacuation) from HZSM-5 (catalyst Al and silicalite-I (S-I). It can be seen clearly that there is only a small peak on silicalite-I, which is significantly smaller than the peak obtained from HZSM-5. Furthermore, the Py spectrum from silicalite-I shows that the peak appears skewed towards lower desorption temperatures. Similarly, Figure 3.12 shows a comparison of MQ-TPD spectra $11 \mathrm{~g}$ catalyst, $60 \mathrm{ml} / \mathrm{min}$ carrier gas flowrate, $1 / 4 \mathrm{~h}$ evacuation) from HZSM-5 (catalyst $A$ ) and silicalite-I (S-I). Again, in the case of silicalite-I, there is only a slight elevation of the baseline when this is compared to the desorption spectrum obtained from HZSM-5.

\subsubsection{THE EFFECTS OF CATALYST MASS AND FLOWRATE}

TPD experiments have been conducted using different sample masses, using $\mathrm{NH}_{3}$, pyridine and 4-methyl quinoline as adsorbates. The flowrate has been changed for $\mathrm{NH}_{3}$. Table 3.2 and Figures 3.13, 3.14 and 3.15 show these effects. The samples in Figures 3.13, 3.14 and 3.15 are compared on the same mass basis (ie. although in the actual experiments different catalyst masses and flowrates were used, the spectra have been standardized to the same catalyst mass and flowrate by multiplying the intensity of the signal by a suitable factor).

Under the conditions used it can be seen that, only for $\mathrm{NH}_{3}$ and $\mathrm{Py}$, a change in peak maximum temperature is obtained by changing the catalyst mass. For MQ-4 the peak maximum temperature is independent of catalyst mass. It should also be noted that when the mass used is large and, as in the case of $\mathrm{NH}_{3}$, the sample is not evacuated but only flushed with $\mathrm{He}$ (an ineffective method of removing excess adsorbate), a LTD peak can be observed as well as 
a HTD peak (Figure 3.13). The peak maximum temperature of the LTD peak changes slightly. Using a lower TPD carrier gas flowrate resulted in an increase in the peak maximum temperature.

TABLE 3.2: The effects of catalyst mass and flowrate on the peak temperature of TPD spectra

\begin{tabular}{|c|c|c|c|c|c|c|c|c|c|}
\hline EXP. & CATAL. & ADSORB. & $\begin{array}{l}\text { FLOWRATE } \\
\text { (ml/min) }\end{array}$ & $\begin{array}{l}\text { MASS } \\
\text { (g) }\end{array}$ & $\begin{array}{c}\text { ADS. TEMP. } \\
\left({ }^{\circ} \mathrm{C}\right)\end{array}$ & $\begin{array}{c}\text { EVAC. TIME } \\
\text { (h:min) }\end{array}$ & $\begin{array}{c}\text { FLUSH. TIME } \\
\text { (h:min) }\end{array}$ & $N^{\circ}$ PEAKS & $\begin{array}{l}T_{\max } \\
\left({ }^{\circ} \mathrm{C}\right)\end{array}$ \\
\hline $\mathrm{A} 1$ & $A$ & $\mathrm{NH}_{3}$ & 60 & 0.250 & 100 & - & $24: 00$ & 2 & 445 \\
\hline$A 2$ & A & $\mathrm{NH}_{3}$ & 150 & 0.250 & 100 & - & $24: 00$ & 2 & 420 \\
\hline A3 & A & $\mathrm{NH}_{3}$ & 150 & 0.100 & 100 & - & $24: 00$ & sh & 390 \\
\hline A4 & A & $\mathrm{NH}_{3}$ & 150 & 0.050 & 100 & - & $24: 00$ & 1 & 375 \\
\hline P1 & A & Py & 150 & 0.050 & 150 & $23: 00$ & $1: 00$ & 1 & 620 \\
\hline P2 & A & Py & 150 & 0.010 & 150 & $23: 00$ & $1: 00$ & 1 & 570 \\
\hline M1 & A & MQ-4 & 60 & 1.00 & 100 & $0: 15$ & $0: 15$ & 1 & 725 \\
\hline M2 & A & MO-4 & 60 & 0.50 & 100 & $0: 15$ & $0: 45$ & 1 & 725 \\
\hline
\end{tabular}

NOTE: sh - shoulder on the leading edge of the peak

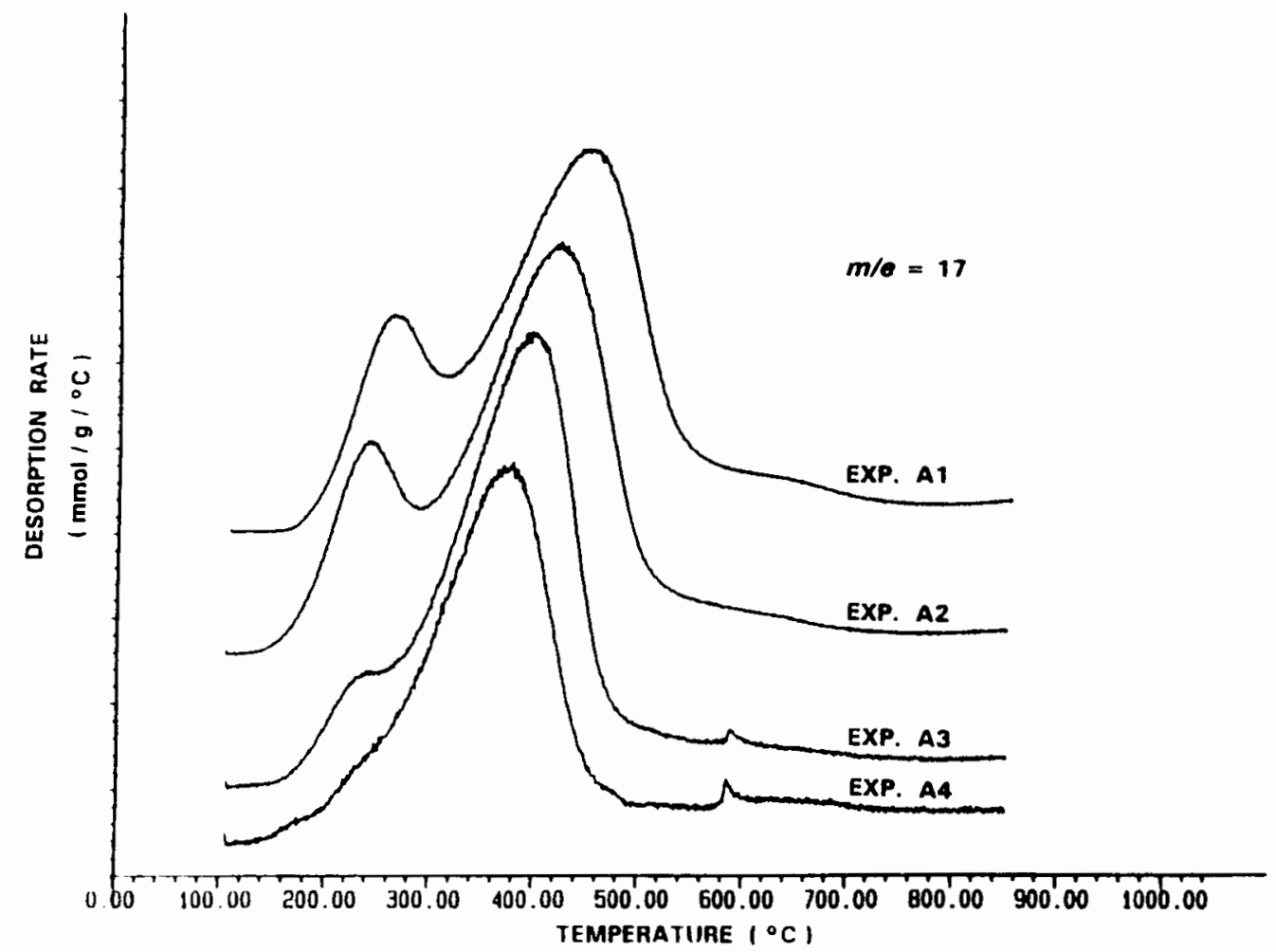

FIGURE 3.13: The effects of catalyst mass and flowrate on the $\mathrm{NH}_{3}-\mathrm{TPD}$ spectrum of HZSM-5 (catalyst A) 


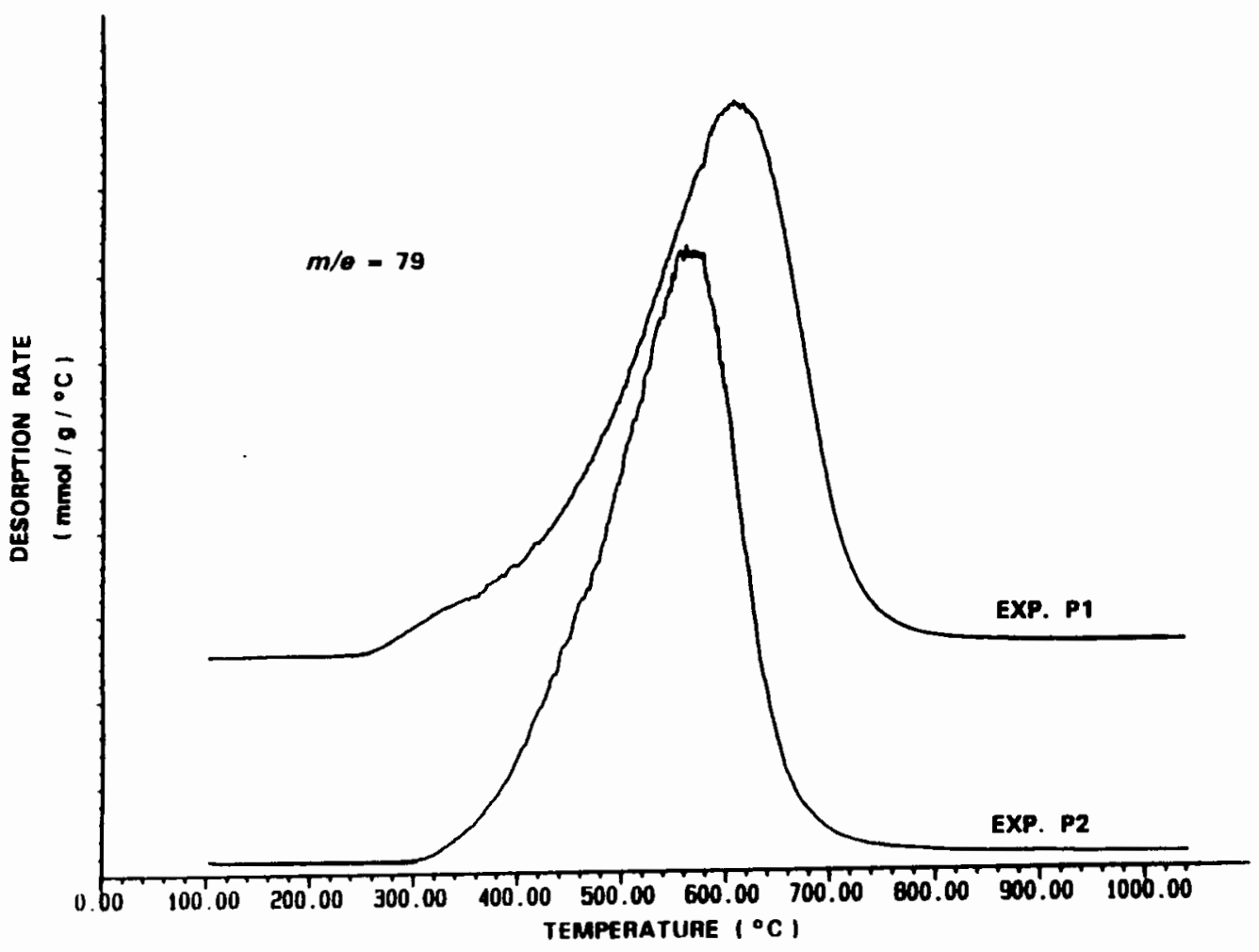

FIGURE 3.14: The effect of catalyst mass on the PY-TPD spectrum of HZSM-5 (catalyst A)

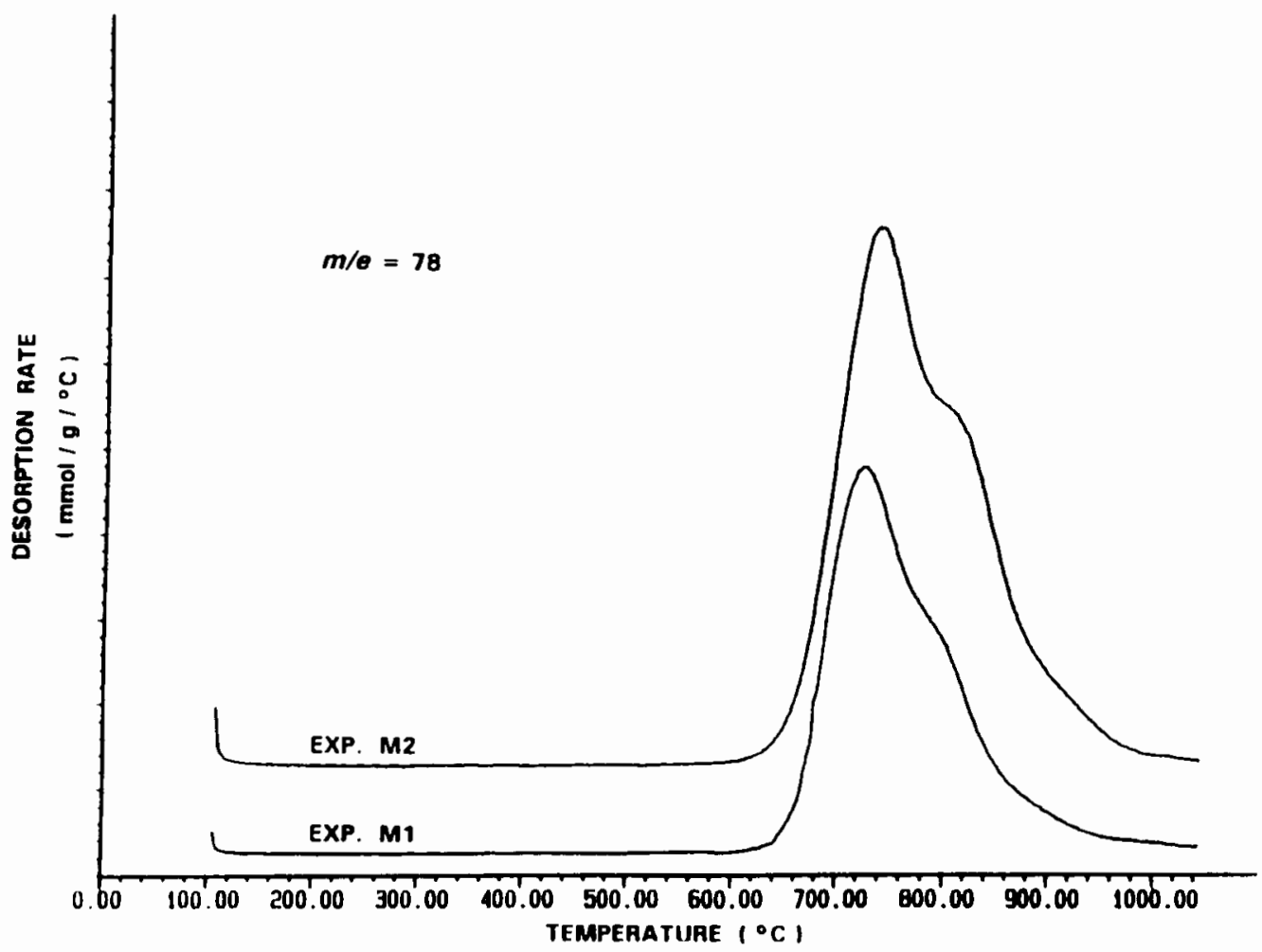

FIGURE 3.15: The effect of catalyst mass on the MO-TPD spectrum of HZSM-5 (catalyst A) 


\subsubsection{THE EFFECTS OF EVACUATION TIME AND ADSORPTION TEMPERATURE}

The evacuation times and adsorption temperatures were varied to determine the conditions which would result in a spectrum of chemisorbed material only. At low pyridine adsorption temperatures $\left(100^{\circ} \mathrm{C}\right)$ and short evacuation times $(1 \mathrm{~h}$ or less), two TPD peaks are observed. Figure 3.16 shows that the LTD peak is sharp when compared to the HTD peak. The start of the LTD peak coincides with the adsorbate adsorption/evacuation temperature. By raising the adsorption/evacuation temperature to $150{ }^{\circ} \mathrm{C}$ and increasing the desorption time to $23 \mathrm{~h}$ the LTD peak completely disappears. Increasing the adsorption/evacuation temperature to $200^{\circ} \mathrm{C}$ results in no significant change in the spectrum. At these high adsorption temperatures $\left(200^{\circ} \mathrm{C}\right)$ increasing the evacuation time results in a small increase in the temperature at which the desorption process begins, although the total amount of material desorbed remains virtually unchanged. The maximum peak temperature is raised slightly by about $5^{\circ} \mathrm{C}$ by using longer evacuation times (Table 3.3), but as this remains within the experimental error this change is not significant.

When MO-4 is used as adsorbate the peak shape remains unchanged for long versus short evacuation times. Figure 3.17 shows that even though the sample is evacuated for only $15 \mathrm{~min}$ after adsorption, the peak shape is the same as for a $16 \mathrm{~h}$ long evacuation period.

TABLE 3.3: The effects of evacuation time and adsorption temperature on the peak temperature of TPD spectra

\begin{tabular}{|c|c|c|c|c|c|c|c|c|c|}
\hline EXP. & CATAL. & ADSORB. & $\begin{array}{l}\text { FLOWRATE } \\
(\mathrm{ml} / \mathrm{min})\end{array}$ & $\begin{array}{l}\text { MASS } \\
\text { (g) }\end{array}$ & $\begin{array}{l}\text { ADS. TEMP. } \\
\left({ }^{\circ} \mathrm{C}\right)\end{array}$ & $\begin{array}{c}\text { EVAC. TIME } \\
\text { (h:min) }\end{array}$ & $\begin{array}{l}\text { FLUSH. TIME } \\
\text { (h:min) }\end{array}$ & $N^{0}$ PEAKS & $\begin{array}{l}T_{\max } \\
\left({ }^{\circ} \mathrm{C}\right)\end{array}$ \\
\hline P3 & A & Py & 150 & 0.050 & 100 & $0: 30$ & $1: 00$ & 2 & 610 \\
\hline P1 & A & Py & 150 & 0.050 & 150 & 23:00 & $1: 00$ & 1 & 620 \\
\hline P4 & A & Py & 150 & 0.050 & 200 & $1: 00$ & $1: 00$ & 1 & 610 \\
\hline P5 & A & Py & 150 & 0.050 & 200 & $23: 00$ & $1: 00$ & 1 & 615 \\
\hline M1 & A & MQ-4 & 60 & 1.00 & 100 & $0: 15$ & $0: 15$ & 1 & 725 \\
\hline M3 & $A$ & MQ-4 & 60 & 1.00 & 100 & $16: 00$ & $1: 00$ & 1 & 725 \\
\hline
\end{tabular}




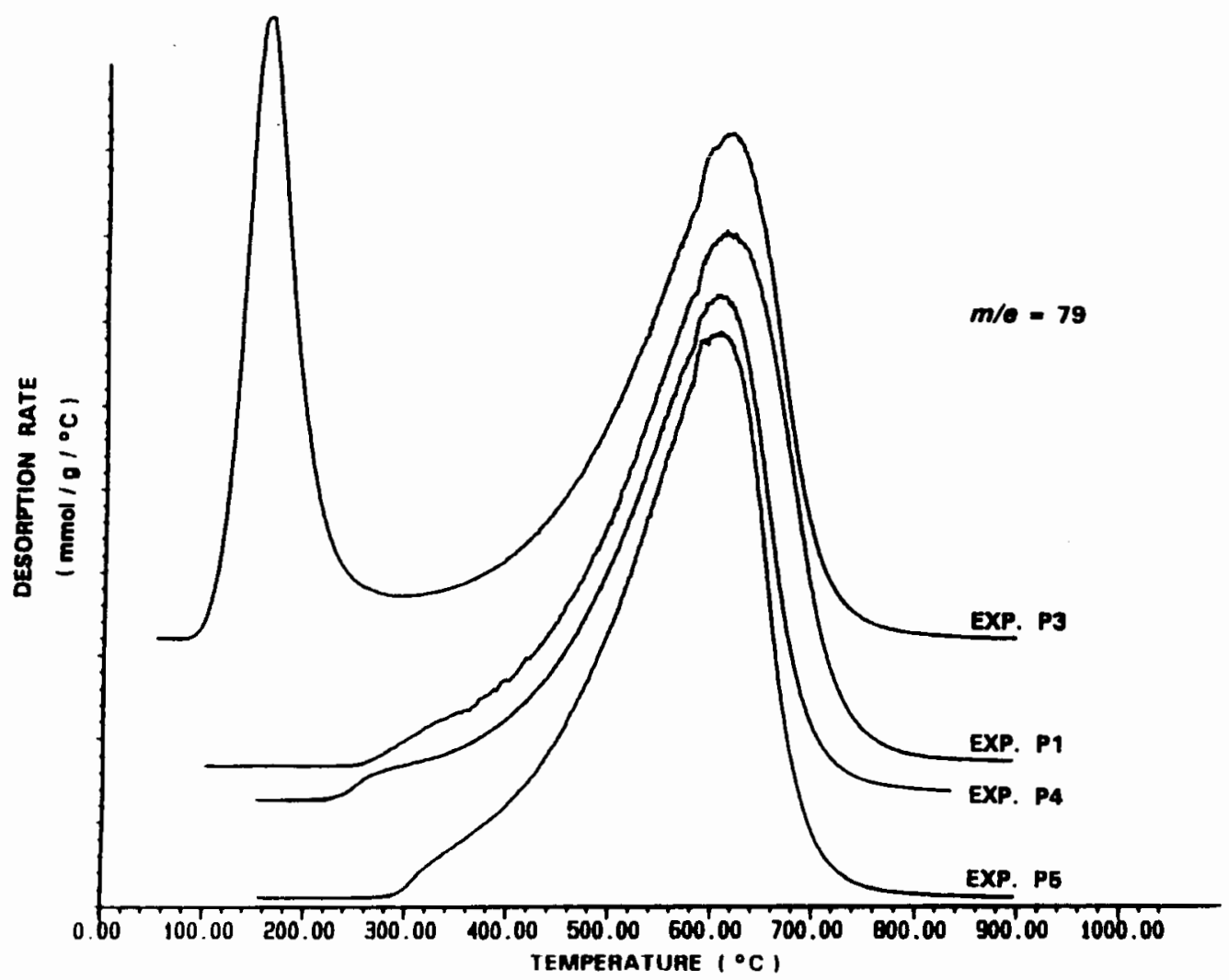

FIGURE 3.16: The effects of adsorption temperature and evacuation time on the Py-TPD spectrum of HZSM-5 (catalyst A)

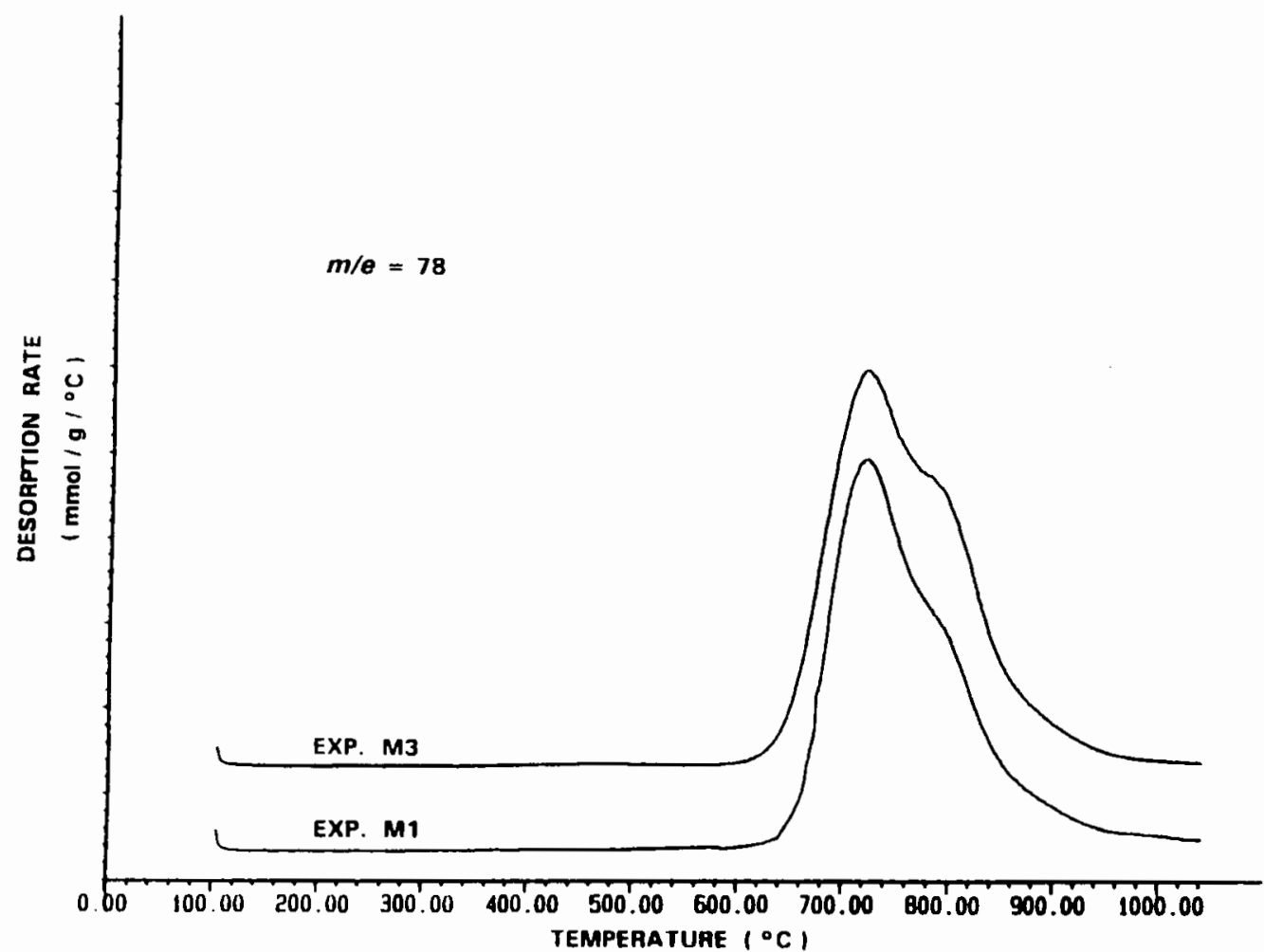

FIGURE 3.17: The effect of evacuation time on the MO-TPD spectrum of HZSM-5 (catalyst A) 


\subsubsection{THE STABILITY OF THE ADSORBATE}

As mentioned in Section 2.3.5.1, the stability of the adsorbate can be determined by monitoring the characteristic ions of the desorbing species. Figure 3.18 shows the five most abundant ions of Py. The relative intensity of these ions remains the same throughout the experiment. In addition, the relative intensities of these ions is similar to those observed for Py injected directly into the detector. Thus it is clear that $\mathrm{Py}$ is stable upon desorption from HZSM-5.

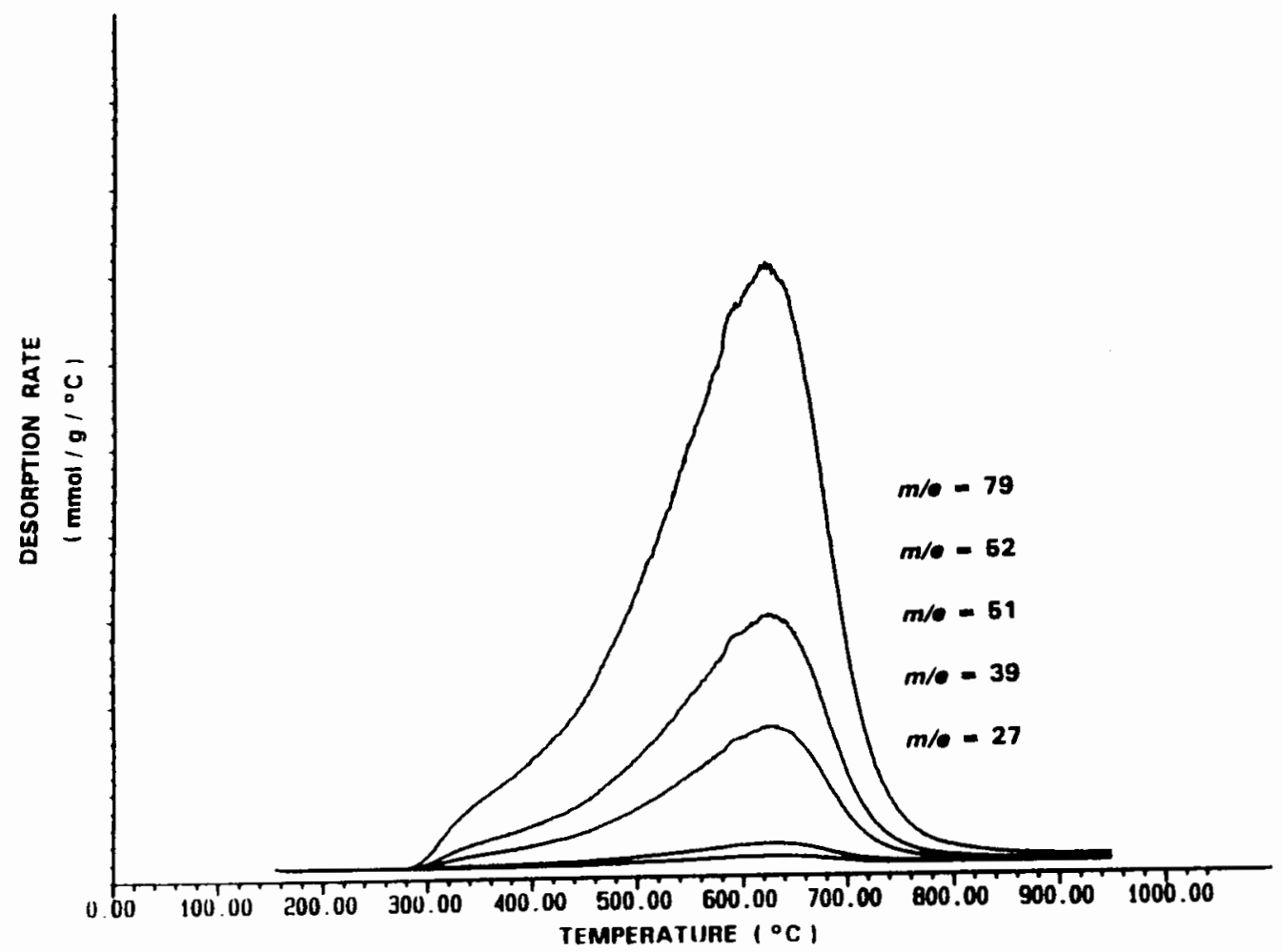

FIGURE 3.18: The stability of Py upon desorption from HZSM-5 (catalyst A)

Figure 3.19 shows the relative intensities of several ions from a typical MQ-TPD spectrum. The two most abundant ions seen here are $m / e=78$ and 128 , and not those obtained by injecting MQ-4 directly into the injection port of the detector $(m / e=143$ and 115$)$. This indicates that MO-4 is not stable but decomposes upon desorption from ZSM-5. It is clear from Figure 3.19 that the relative intensities of the ions do not remain the same throughout the 
experiment. This implies that the desorption/cracking mechanism of MO-4 changes as the temperature is increased during TPD. At higher desorption temperatures, some of the parent material $(\mathrm{m} / \mathrm{e}=143$ ) can be seen to desorb intact. These phenomena may give rise to the double peak feature, giving the peak a "distorted" appearance, and a wide desorption range for the removal of adsorbate. This must therefore not be interpreted as being due to a change in acidity or to a difference in acid site strength, but rather to the desorption/cracking mechanism. Also, changes to the peak shapes and intensities must not be interpreted as changes in acidity. Only when no material is seen to desorb from the catalyst can it be said that the external acidity has been eliminated.

These features may be partly responsible for the poor reproducibility of MQ-TPD spectra, especially the poor reproducibility of the MQ-TPD spectra of different batches of unmodified HZSM-5. This also has a great bearing on the MQ-TPD spectra of the modified catalysts (see Section 3.3).

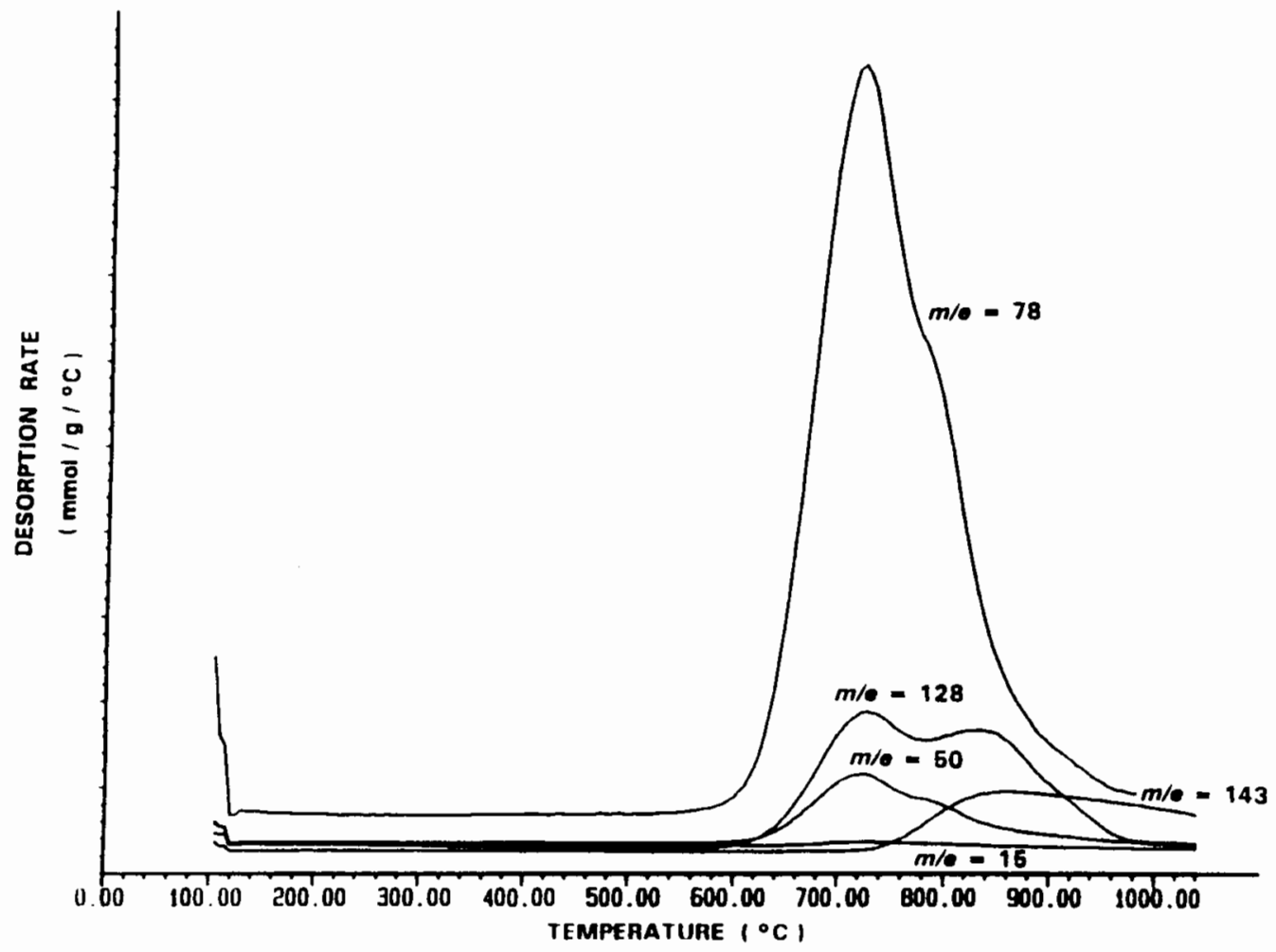

FIGURE 3.19: The stability of MQ-4 upon desorption from HZSM-5 (catalyst A) 


\subsection{MODIFICATIONS}

\subsubsection{THE EFFECT OF COATING ZSM-5 WITH SILICALITE SHELLS}

This section compares the results of the samples which have been modified by coating the parent crystals with silicalite shells. Figure 3.20 shows the Py-TPD spectra from HZSM-5 and HZSM-5 modified by coating the parent crystals with silicalite shells. It can be seen that, for the same total amount of sample used, there is a drop in intensity of the signal for the modified samples compared to that of unmodified HZSM-5. The response larea counts per unit mass of sample) is shown in Table 3.4. These values, even though they should not be regarded as quantitative data (see Section 3.2.3), show that the peak areas of the Py-TPD spectra of the modified samples have halved.

Figure 3.20 and Table 3.4 show that $T_{\max }$ is lower for the modified samples compared to the unmodified HZSM-5. The shapes of the PY-TPD spectra for samples $\mathrm{S}-\mathrm{Bi}$ and $\mathrm{S}-\mathrm{B}$ show an increase in the Py desorption rate at lower temperatures when compared to that of unmodified HZSM-5 (Figure 3.20). Increasing the evacuation time from $23 \mathrm{~h}$ to $34 \mathrm{~h}$ does not remove or alter this feature, illustrating that the sites responsible for this feature indicate chemisorbed Py (Figure 3.21). The TPD spectrum of sample S-Bdi has the same shape as that of unmodified HZSM-5, but still $T_{\max }$ is lower. All the Py-TPD spectra are skewed towards higher desorption temperatures.

Figure 3.22 compares the MQ-TPD spectra for catalysts modified by the silicalite shell method to that of unmodified HZSM-5. The shape of the MQ-TPD spectra of samples S-Bdi and $\mathrm{S}-\mathrm{Bi}$ show one peak for $m / e=78$, although two peaks can still be distinguished for $m / e=128$ (not shown here, but similar to Figure 3.19). This indicates that the cracking pattern has changed on these samples. Sample S-B has a MQ-TPD spectrum with a very low intensity, indicating very few accessible acid sites. Again, the response in Table 3.4 gives an indication of the relative area counts of the MQ-TPD spectra. Sample S-B has a response which is approximately $10 \%$ of the value for sample $B$. The response of the MQ-TPD spectrum of sample $B$ is approximately $0.3 \%$ of the value for the Py-TPD spectrum. 
TABLE 3.4: The effect of coating ZSM-5 with silicalite shells

\begin{tabular}{llcccccc}
\hline EXP. & CATAL. & ADSORB. & $\begin{array}{c}\text { FLOWRATE } \\
\text { (ml/min) }\end{array}$ & $\begin{array}{c}\text { MASS } \\
\text { (o) }\end{array}$ & $\begin{array}{c}\text { EVAC. TIME } \\
\text { (h:min) }\end{array}$ & $\begin{array}{c}T_{\text {max }} \\
\left.\text { ( }{ }^{\circ} \mathrm{C}\right)\end{array}$ & $\begin{array}{c}\text { RESPONSE } \\
\text { (A.U.) }\end{array}$ \\
\hline P6 & B & Py & 150 & 0.050 & $23: 00$ & 615 & 598 \\
P7 & S-Bdi & Py & 150 & 0.050 & $23: 00$ & 590 & 302 \\
P8 & S-Bi & Py & 150 & 0.050 & $23: 00$ & 585 & 262 \\
P9 & S-B & Py & 150 & 0.050 & $23: 00$ & 585 & 312 \\
P10 & S-B & Py & 150 & 0.050 & $34: 00$ & 590 & 280 \\
M4 & B & MQ-4 & 60 & 1.00 & $0: 15$ & 730 & 2.1 \\
M5 & S-Bdi & MQ-4 & 60 & 1.00 & $0: 15$ & 785 & 3.3 \\
M6 & S-Bi & MQ-4 & 60 & 1.00 & $0: 15$ & 795 & 2.9 \\
M7 & S-B & MQ-4 & 60 & 1.00 & $0: 15$ & 785 & 0.2 \\
& & & & & & & \\
\hline
\end{tabular}

NOTE: The mass of catalyst used for samples coated with a silicalite shell is the mass of the total sample (ie. ZSM-5 + silicalite-1). The response is the integrated response (area counts) per unit mass of sample and unit flowrate.

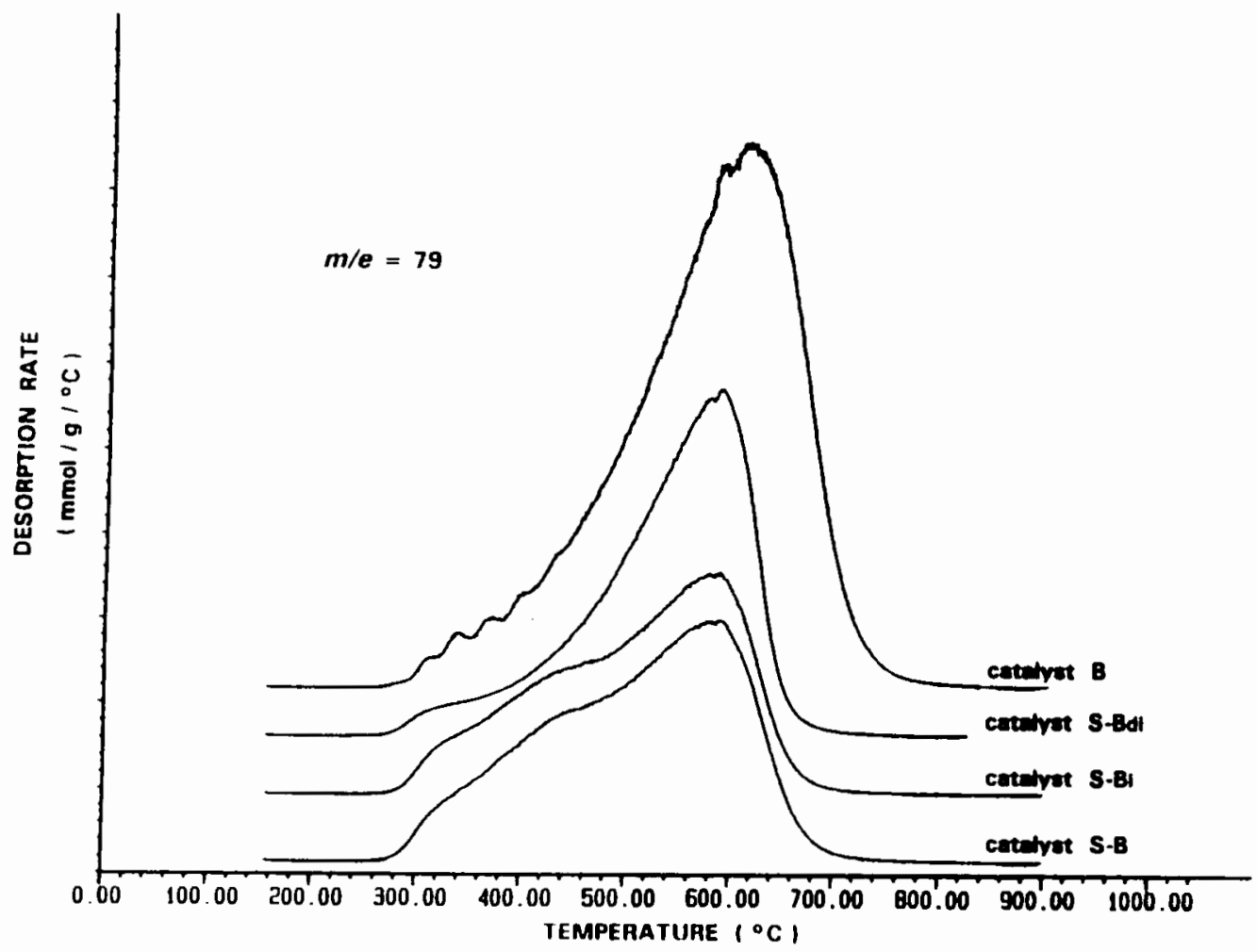

FIGURE 3.20: PY-TPD spectra of HZSM-5 and ZSM-5 coated with silicalite shells 


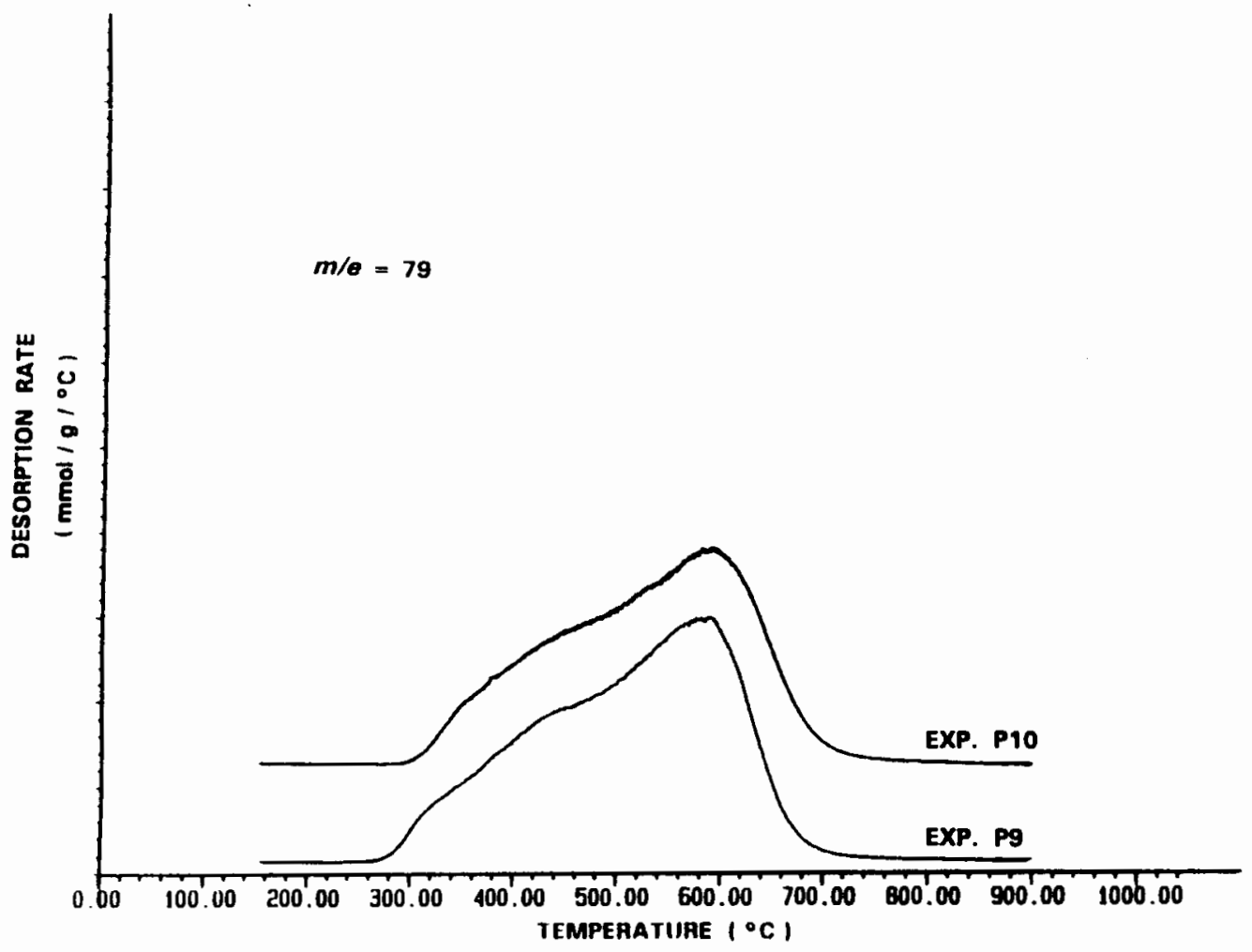

FIGURE 3.21: The effect of evacuation time on the Py-TPD spectrum of S-B

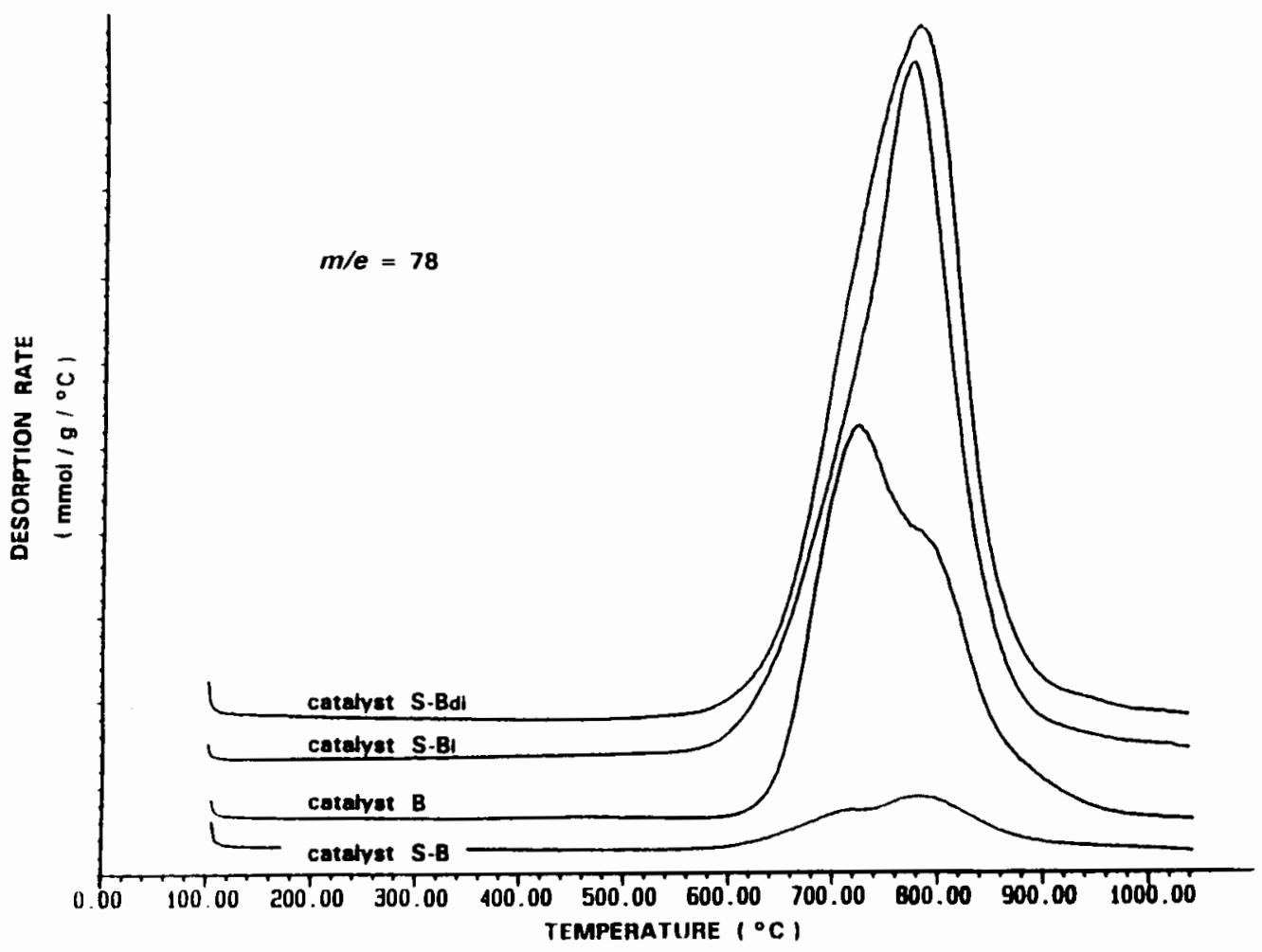

FIGURE 3.22: MQ-TPD spectra of HZSM-5 and ZSM-5 coated with silicalite shells 


\subsubsection{THE EFFECT OF CHEMICAL VAPOUR DEPOSITION (CVD)}

The samples which have been modified by CVD are compared in this section. Figure 3.23 shows the PY-TPD spectra from HZSM-5 and HZSM-5 modified by CVD. The PY-TPD spectra of the CVD modified samples are virtually identical to that of HZSM-5. From Figure 3.23 and Table 3.5 it can be seen that the intensity, the shape of the peak and $T_{\max }$ remain the same. Thus the internal acidity remains largely unaffected.

The response for samples modified by CVD is given in Table 3.5. The response of the PY-TPD spectra for the CVD modified samples is similar to that of its parent crystal (sample $C$ ). The response for sample $C$ is approximately half that of sample $B$ (Table 3.4). This may be due to change in sensitivity of the MS with time (see Section 3.2.3). These data should therefore not be regarded as quantitative measurements but rather as an indication of relative changes.

Figure 3.24 shows the MQ-TPD spectra of HZSM-5 and HZSM-5 modified by CVD. Sample $V_{16}-C$ shows a reduced MQ-4 desorption. This indicates that for longer tetraethoxysilane deposition times and greater deposition temperatures less MQ-4 is adsorbed/desorbed. However, the MQ-TPD spectrum of sample $\mathrm{V}_{4}-\mathrm{C}$ shows a greater response than sample $C$. This may be due to the desorption/cracking mechanism as discussed in Sections 3.2.7 and 4.2.1.

TABLE 3.5: The effect of Chemical Vapour Deposition on ZSM-5

\begin{tabular}{|c|c|c|c|c|c|c|c|}
\hline EXP. & CATAL. & ADSORB. & $\begin{array}{l}\text { FLOWRATE } \\
\text { (ml/min) }\end{array}$ & $\begin{array}{l}\text { MASS } \\
\text { (g) }\end{array}$ & $\begin{array}{c}\text { EVAC. TIME } \\
\text { (h:min) }\end{array}$ & $\begin{array}{l}T_{\max } \\
\left({ }^{\circ} \mathrm{C}\right)\end{array}$ & $\begin{array}{c}\text { RESPONSE } \\
\text { (A.U.) }\end{array}$ \\
\hline P11 & C & Py & 150 & 0.050 & $22: 00$ & 620 & 327 \\
\hline P12 & $V_{4}-C$ & Py & 150 & 0.050 & $23: 00$ & 620 & 281 \\
\hline P13 & $V_{16}-C$ & Py & 150 & 0.050 & $22: 00$ & 620 & 301 \\
\hline M8 & C & $M Q-4$ & 60 & 1.00 & $0: 15$ & 730 & 1.4 \\
\hline M9 & $V_{4}-C$ & MO-4 & 60 & 1.00 & $0: 15$ & 810 & 2.6 \\
\hline M10 & $V_{16}-C$ & MO-4 & 60 & 1.00 & $0: 15$ & 760 & $<0.1$ \\
\hline
\end{tabular}

NOTE: The mass of catalyst used for samples modified by chemical vapour deposition is the mass of the total sample (ie. $\mathrm{ZSM}-5+\mathrm{SiO}_{2}$ ). The response is the integrated response (area counts) per unit mass of sample and unit flowrate. 


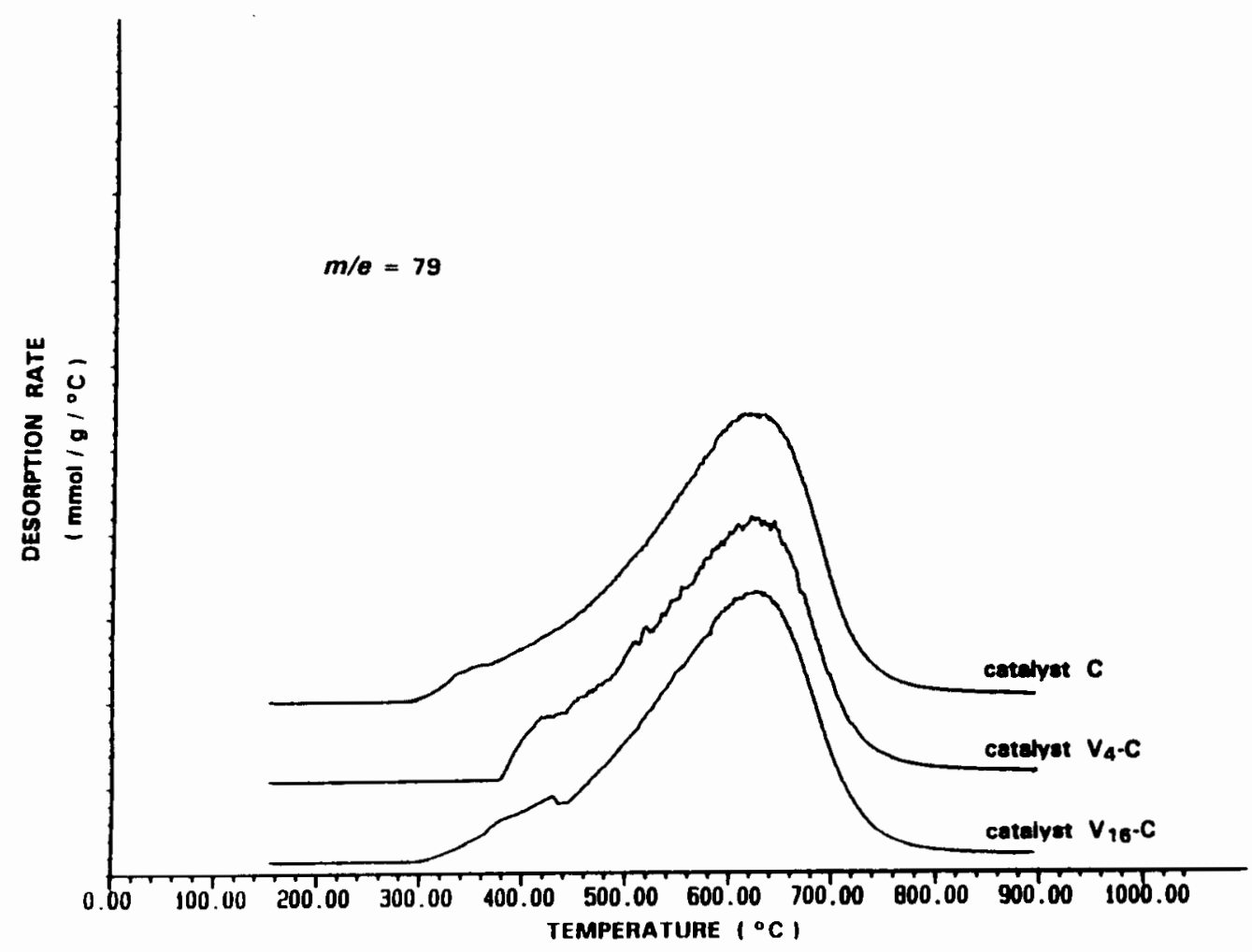

FIGURE 3.23: PY-TPD spectra of HZSM-5 and ZSM-5 modified by CVD

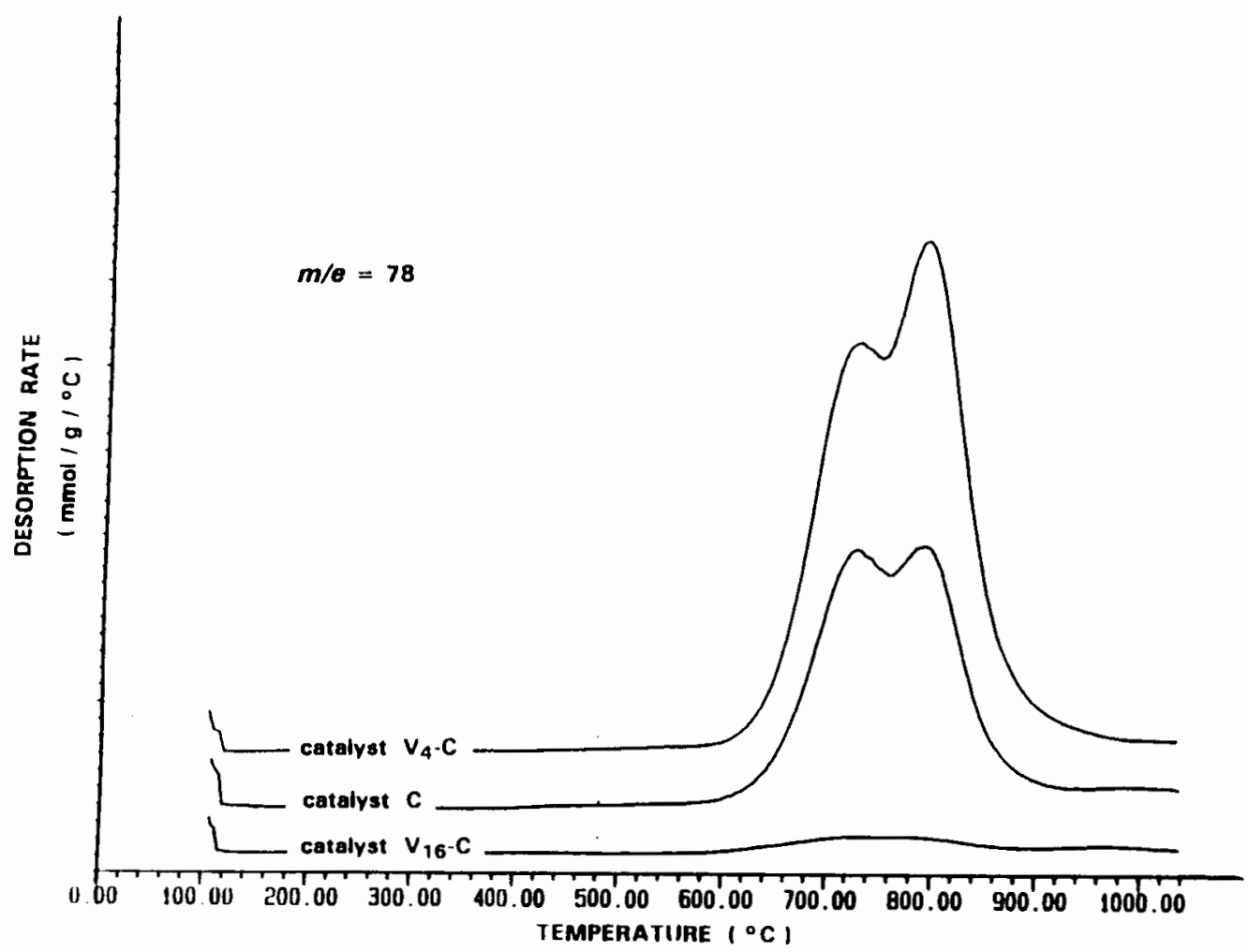

FIGURE 3.24: MO-TPD spectra of HZSM-5 and ZSM-5 modified by CVD 
CHAPTER 4

\section{DISCUSSION}





\subsection{DESORPTION FROM THE TOTAL SURFACE OF HZSM-5}

\subsubsection{THE DESORPTION SPECTRUM}

\subsubsection{The desorption spectrum of pyridine}

The preliminary results show that the signal obtained in Py-TPD spectra is the true signal from HZSM-5, insofar that it is not affected by desorption from the reactor walls or adsorption onto the transfer lines. Dispersion of the signal in the transfer lines from the sample to the detector can also be assumed to be negligible (Section 3.2.1). Also, pyridine does not react upon desorption (Figure 3.18 in Section 3.2.7).

Only one high temperature desorption (HTD) peak is observed for pyridine desorption from HZSM-5 (Figure 3.8b). The peak shapes of the Py-TPD spectra are all skewed towards higher desorption temperatures, thus showing a leading edge. This leading edge is due to the combined effects of diffusional restrictions and readsorption in the channels of HZSM-5. This phenomenon is analogous to the models by Jones and Griffin [1983], Gorte [1982], Demmin and Gorte [1984] and the findings of Herz et al. [1982]. In contrast, the PyTPD spectrum of silica-alumina shows a spectrum which is skewed towards lower desorption temperatures (Appendix VII), because silica-alumina is amorphous and therefore does not exhibit strong diffusional restrictions and readsorption effects. Similarly, silicalite-I also shows a Py-TPD spectrum which appears skewed towards lower desorption temperatures (Figure 3.11). Silicalite-I has a crystalline structure but has essentially no acidity, and therefore readsorption is limited. This therefore confirms that due to diffusional restrictions and readsorption effects in the channels of HZSM-5, the spectrum changes such that the peak maximum temperature is shifted towards higher desorption temperatures. Moreover, the shape of the Py-TPD spectrum indicates that Py readily enters the channel structure of ZSM-5 and that it is a suitable probe for the total acidity of ZSM- 5 .

The peak maximum temperature of the HTD peak of Py $\left(620^{\circ} \mathrm{C}\right)$ was found to be greater than that of $\mathrm{NH}_{3}\left(375{ }^{\circ} \mathrm{C}\right)$ under the same experimental conditions (Figure 3.8). This is in agreement with TPD studies of Parrillo et al. [1990]. This is also consistent with adsorption enthalpies from the literature. The 
adsorption enthalpy of Py is $200 \mathrm{~kJ} / \mathrm{mol}$ [Parrillo and Gorte, 1993], whereas the adsorption enthalpy of $\mathrm{NH}_{3}$ is $150 \mathrm{~kJ} / \mathrm{mol}$ [Parrillo and Gorte, 1993; Sharma et al., 1993]. Electrons can be delocalized by the resonance effect of the ring structure in pyridine, thereby stabilizing the adsorbed structure. Even though $\mathrm{NH}_{3}$ is the stronger base, the zeolite-pyridine complex is thought to be more stable than the zeolite-ammonia complex. Furthermore, the diffusional resistances in the channels of ZSM-5 are greater for Py than for $\mathrm{NH}_{3}$, thereby increasing the peak maximum temperature [Sharma et al., 1993].

\subsubsection{The desorption spectrum of ammonia}

The desorption spectrum of $\mathrm{NH}_{3}$ from HZSM-5 shows features similar to those of Py (Figure 3.8). The HTD peak of the $\mathrm{NH}_{3}$-TPD spectrum is also skewed towards higher desorption temperatures, indicating diffusional resistances and, in particular, the readsorption of $\mathrm{NH}_{3}$ in the channels of HZSM-5. Also, it is clear that $\mathrm{NH}_{3}$ enters the channel system of ZSM-5 and that it is a suitable probe for the total acidity of ZSM-5. As mentioned in the paragraph above, the peak maximum temperature of the HTD peak is lower than that of Py, due to a weaker bond between the zeolite and $\mathrm{NH}_{3}$, and smaller diffusional resistances in the channels. The abundance of the signal for $\mathrm{NH}_{3}$ is far less than for Py (Figure 3.8), but this may be explained by the difference in sensitivity of the MS to different ions (Section 2.3.5.1).

\subsubsection{THE EFFECTS OF CATALYST MASS AND FLOWRATE}

Kapustin et al. [1988] reported a lowering of $T_{\max }$ for a decrease in catalyst mass for the desorption of $\mathrm{NH}_{3}$ from $\mathrm{HZSM}-5$. Indeed, it has also been shown here that by reducing the catalyst mass for $\mathrm{NH}_{3}$-TPD from $\mathrm{HZSM}-5$ a lowering of $T_{\max }$ of the HTD peak is observed for constant flowrates (Table 3.2 and Figure 3.13). This phenomenon can be explained by considering the influence of the concentration gradient present in the crystal during the desorption process on $T_{\text {max }}$, as described by the models of Demmin and Gorte [1984] and Rieck and Bell [1984]. By reducing the catalyst mass the total amount of adsorbate which is able to desorb is also reduced. Thus reducing the catalyst mass results in a lower concentration of the adsorbate in the carrier gas stream. 
This in turn results in a greater intraparticular concentration gradient (the gradient from the center to the external surface). This results in a faster desorption rate of the adsorbate from the catalyst, which is indicated on the TPD spectrum by the lowering of $T_{\max }$. Also, a smaller catalyst mass shortens the bed length, thereby reducing the chance that a desorbing molecule will readsorb as it passes through the bed. Similar effects can be observed on the Py-TPD spectrum from HZSM-5 (Table 3.2 and Figure 3.14).

According to the models mentioned above [Demmin and Gorte, 1984; Rieck and Bell, 1984], a change in flowrate of the carrier gas should have similar effects, since a decrease in the flowrate should increase the concentration of the adsorbate in the carrier gas stream. Indeed, a decrease in the carrier gas flowrate shows an increase in $T_{\max }$ of the HTD peak of the $\mathrm{NH}_{3}$-TPD spectrum (Table 3.2 and Figure 3.13). Experimental observations of this phenomenon have aiso been reported for $\mathrm{NH}_{3}$ desorption from HZSM-5 by Kapustin et al. [1988] and for $\mathrm{CO}$ desorption from $\mathrm{Pt} / \mathrm{Al}_{2} \mathrm{O}_{3}$ by $\mathrm{Herz}$ et al. [1982]. As the position of $T_{\max }$ is affected by changes in catalyst mass and flowrate, pore diffusion and/or readsorption phenomena must be influencing the $\mathrm{NH}_{3}$ and $\mathrm{Py}$ TPD spectra of HZSM-5.

The intensity of the LTD peak in the $\mathrm{NH}_{3}$-TPD spectrum is reduced to a greater extent than the intensity of the HTD peak by the reduction of the catalyst mass or increase in flowrate, even though $T_{\text {max }}$ of the LTD peak is only lowered slightly (Figure 3.13). This gradual disappearance of the LTD peak indicates that the $\mathrm{NH}_{3}$ desorbed (as indicated by the LTD peak) is readily removed during the evacuation/flushing period prior to TPD and that it is not strongly bonded onto the zeolite, but is in fact either physisorbed or weakly chemisorbed. If it was strongly chemisorbed then a decrease in catalyst mass or an increase in flowrate should not affect the magnitude of the LTD peak as observed.

\subsubsection{THE EFFECTS OF ADSORPTION/EVACUATION TEMPERATURE AND EVACUATION TIME}

For the adsorption and removal of excess $\mathrm{Py}$ at low temperatures $\left(100{ }^{\circ} \mathrm{C}\right.$, which is below the boiling point of Py) and short evacuation times ( $1 \mathrm{~h}$ or less), the Py-TPD spectrum shows a distinct LTD peak (Table 3.3 and Figure 3.16). The start of this peak coincides with the adsorption/evacuation temperature, 
and the peak is extremely sharp. When the adsorption/evacuation temperature is raised to $150{ }^{\circ} \mathrm{C}$ (which is above the boiling point of Py) and the evacuation time is increased to $23 \mathrm{~h}$, the LTD peak completely disappears. Topsoe et al. [1981] report a similar adsorption temperature $\left(150^{\circ} \mathrm{C}\right)$ and an evacuation time of 30 min for infrared studies on HZSM-5, and conclude that all physisorbed Py has been removed from the zeolite. A further increase in adsorption/evacuation temperature does not alter the desorption spectrum significantly, although the start of the desorption spectrum is at slightly higher temperatures for longer evacuation times (Figure 3.16). The fact that the desorption spectrum does not change much after prolonged evacuation indicates that this material is strongly chemisorbed. Thus the HTD peak observed in the Py-TPD spectra from HZSM-5 results from the desorption of strongly chemisorbed material.

In contrast, in the case of $\mathrm{NH}_{3}$, the adsorption takes place at about $130{ }^{\circ} \mathrm{C}$ above the boiling point of $\mathrm{NH}_{3}$. Even though the sample is flushed as opposed to evacuated, it could be argued that the relatively high adsorption temperature and subsequent flushing at this temperature should readily remove physisorbed $\mathrm{NH}_{3}$ and thus prevent the formation of a LTD peak. Iwamoto et al. [1986] suggested that the LTD peak of $\mathrm{NH}_{3}$ results from physisorbed or very weakly chemisorbed molecules, but not from $\mathrm{NH}_{3}$ bonded to weak acid sites. Pope [1990] further suggested that, unlike other larger amines, more than one $\mathrm{NH}_{3}$ molecule can be adsorbed strongly per acid site. $\mathrm{NH}_{3}$, being a much smaller molecule, could form a secondary adsorption layer. It has been shown that for $\mathrm{NH}_{3}$ desorption from $\mathrm{HZSM}-5$ there exist three desorption peaks when adsorption takes place at room temperature [Topsoe et al., 1981; Hidalgo et al., 1984]. The desorption peak at the lowest temperatures ( $a$-peak) could thus be ascribed to physisorbed $\mathrm{NH}_{3}$, the $\beta$-peak (the LTD peak described here) to weakly chemisorbed $\mathrm{NH}_{3}$, and the $\gamma$-peak (the HTD peak described here) to strongly chemisorbed $\mathrm{NH}_{3}$.

Due to steric hindrance effects in the channel system of ZSM-5, it is unlikely that two Py molecules will be able to adsorb onto one acid site. Thus a secondary adsorption layer for Py on HZSM-5 is less likely to occur. This may thus explain why the LTD peak of $\mathrm{NH}_{3}$ (due to a secondary adsorption layer) has a higher $T_{\max }$ than the LTD peak of Py (due to physisorbed Py), whereas the opposite is true for $T_{\max }$ of the HTD peaks (due to chemisorbed material). Results published by Parrillo et al. [1990] also show that in their studies the LTD peak and HTD peak of $\mathrm{NH}_{3}$ fall between those of Py. 


\subsection{DESORPTION FROM THE EXTERNAL SURFACE OF HZSM-5}

\subsubsection{THE DESORPTION SPECTRUM OF 4-METHYL QUINOLINE}

The desorption spectrum of MQ-4 from HZSM-5 is very different from that of either $\mathrm{Py}$ or $\mathrm{NH}_{3}$. Firstly, due to the stabilizing effect of the double ring structure of $\mathrm{MQ}-4$, the complex formed with the acid site on the zeolite is very stable, which may explain the high desorption temperatures of MQ-4. Indeed, Anderson et al. [1979] reported that the desorption of MQ-4 from ZSM-5 was extremely slow under reaction conditions at $450{ }^{\circ} \mathrm{C}$.

From the discussion in Section 3.2.7 and Figure 3.19 it can be seen that MQ-4 decomposes/cracks on desorption from HZSM-5, as the parent ion of MQ-4 $(m / e=143)$ is present in very low quantities or not at all. Also, the relative intensities of the ions seen in the spectrum change during the course of the experiment, indicating a change in the desorption/cracking mechanism. Since it is expected that the methyl group will crack readily at higher temperatures, an attempt was made to monitor the methyl group $(m / e=15)$ during TPD. However, due to the small quantities involved and due to the low sensitivity of the MS to $m / e=15$, no desorption of the methyl group could be detected. The methyl group did not seem to react with $\mathrm{H}_{2} \mathrm{O}$ from the zeolite framework as no methanol was detected. Similarly, due to the low sensitivity to these ions, it was not possible to check whether methane $(m / e=16)$ or $\mathrm{NH}_{3}(m / e=16$ and 17) formed part of the reaction products. These ions would also be masked by the loss of $\mathrm{H}_{2} \mathrm{O}$ (which is present is substantial amounts when $1 \mathrm{~g}$ of material is used) from the framework due to dehydroxylation.

The species remaining on the catalyst after the methyl group has cracked would be a quinoline radical. The parent ion of quinoline $(m / e=129)$ could not be detected, whereas $m / e=128$ could be observed. This further suggests that the methyl group cracks, leaving a quinoline radical bonded to the acid site lie. quinoline is left with a negative charge). This charge can be distributed through the double ring structure of quinoline and the protonic acid site, thereby stabilizing the quinoline-zeolite complex. As $m / e=128$ reaches the detector, it seems that at least a fraction of the quinoline radicals must be desorbed without undergoing further decomposition. The most abundant ion in the spectrum of 
MQ-TPD (Figure 3.8(c) and Figure 3.19) is $m / e=78$, which can probably be ascribed to benzene or perhaps a pyridine radical.

The reaction products are small enough to enter the channel structure, thus possibly further complicating the MQ-TPD spectrum. But, since the desorption/cracking mechanism occurs only at high temperatures, and because only a small amount of material is desorbed (see arguments in Section 4.2.2), it is extremely unlikely that any material would enter the channeis during the adsorption step. Thus any material entering the channels can only do so during the TPD process. Therefore any material detected originates from the external surface of the catalyst.

Furthermore, due to the changes in the desorption/cracking mechanism as the temperature is increased, changes in the peak shape must not be interpreted as changes in acidity. Only when no material is seen to desorb from the catalyst can it be said that the external acidity has been eliminated.

\subsubsection{EVIDENCE FOR THE ADSORPTION OF 4-METHYL QUINOLINE ONTO THE EXTERNAL SURFACE ONLY}

4-Methyl quinoline was chosen because it was not expected to enter the channels of ZSM-5. The critical diameter of MO-4 is $7.3 \AA$ [Rollmann, 1991], whereas the largest pore diameter of ZSM- 5 is $5.4 \times 5.3 \AA$ [Haag and Chen, 1987].

It has been argued in Section 2.3.5.1 that the abundance for different ions is very different. Indeed, in the case of $\mathrm{NH}_{3}(m / e=17)$ and $\mathrm{Py}(m / e=79)$ the intensity of the signal for similar experimental conditions was much larger for Py. The most abundant ion of the MQ-TPD spectrum is $m / e=78$. Although $m / e=78$ is not the parent ion of MQ-4, and in fact arises from desorption/cracking phenomena as discussed in Section 4.2.1, it is the most stable ion representing removal of MQ-4 from the external surface. This ion is similar in molecular weight and chemical structure to that of $\operatorname{Py}(m / e=79)$, and it may therefore be assumed that even if there is a difference in sensitivity for these ions, this difference is small. When the signals of a Py-TPD spectrum and 
a MQ-TPD spectrum are compared, it can be seen that the maximum intensities are approximately $7 \times 10^{5}$ and $2.5 \times 10^{4}$ units respectively. If the differences in catalyst mass $(0.05 \mathrm{~g}$ and $1.0 \mathrm{~g}$ respectively), flowrate $(150 \mathrm{ml} / \mathrm{min}$ and 60 $\mathrm{ml} / \mathrm{min}$ respectively) and $\mathrm{MS}$ dwell time $(0.985 \mathrm{sec}$ and $5.000 \mathrm{sec}$ respectively) are taken into account, it becomes evident that the amount of MQ-4 adsorbed/desorbed per gram of catalyst is approximately 2-3 orders of magnitude smaller than the amount of Py adsorbed onto HZSM-5. Indeed, comparing the response of Py-TPD and MQ-TPD spectra (Figures 3.9 and 3.10), the response of MQ-TPD spectra is $0.25 \%$ compared to that of the Py-TPD spectra. These estimates are slightly lower than the ratio of external to internal surface of HZSM-5 (1:100) reported by Sayari et al. [1991], although these values are very dependent on crystal size.

Experimental evidence also suggests that MQ-4 is adsorbed only onto the external surface. By changing the catalyst mass no change was observed in $T_{\max }$ (Figure 3.15). Therefore a decrease in catalyst mass does not result in an increase in the desorption rate. This indicates that there is no concentration gradient in the catalyst particle, and thus that no readsorption occurs. This therefore suggests that MQ- 4 is adsorbed solely onto the external surface of HZSM-5.

The MQ-TPD spectrum is not altered by prolonged evacuation times $116 \mathrm{~h}$ at $100^{\circ} \mathrm{C}$ ). This suggests that MQ-4 is strongly chemisorbed, which is consistent with its high desorption temperature. Furthermore, in none of the experiments was there an indication of a LTD peak, and since the adsorption and evacuation steps were carried out at low temperatures, this suggests that no physisorbed material is present. This could be true if any physisorbed material present were to be removed extremely quickly on evacuation. This is consistent with the deduction that MQ-4 is not present within the channel structure, and physisorbed MQ-4 is therefore readily removed from the external surface upon evacuation.

Even though the reaction of MQ-4 on desorption makes it difficult to determine whether the peak is skewed either towards lower or higher desorption temperatures, it would seem (from $m / e=78$ ) that the peak is skewed towards lower temperatures (Figure 3.19 for example). This again implies that there are no diffusional limitations or readsorption effects, and hence that the desorbed species are likely to be derived from the external surface. 


\subsection{MODIFICATIONS}

\subsubsection{COATING WITH SILICALITE SHELLS}

\subsubsection{Structure of the resulting material}

The first question that needs to be answered is whether the phase formed in the modification is silicalite-I or some other (amorphous) phase. None of the electron micrographs (Figure 3.7) show distinguishable deposits of amorphous material at the magnifications used here. It is possible that separate silicalite-I crystals were formed. None of the XRD patterns reveal a noticeable increase in the baseline at any point in their pattern (Figure 3.2), suggesting the absence of $\mathrm{X}$-ray detectable amorphous phases.

The intensity of the two peaks at $7.9^{\circ}$ and $8.8^{\circ} 2 \theta$ decreases with the amount of $\mathrm{H}_{2} \mathrm{O}$ adsorbed by the sample [Hardenberg et al., 1992; Szostak, 1989]. Thermogravimetric analysis has shown that silicalite-I has only $0.1 w t \%$ adsorbed $\mathrm{H}_{2} \mathrm{O}$, whereas ZSM-5 has approximately 6-7 wt\% adsorbed $\mathrm{H}_{2} \mathrm{O}$ (Table 3.1). This explains the low intensity of these reflections for sample B. It is interesting to note that these reflections have increased in magnitude for the modified samples, due to the presence of the silicalite-I phase and the corresponding decrease in adsorbed $\mathrm{H}_{2} \mathrm{O}$ (Figure 3.2). This is contrary to findings of Lee et al. [1993], who report a decrease in the intensities of the peaks at $7.9^{\circ}$ and $23.1^{\circ} 2 \theta$ for silicalite modified ZSM-5. However, the findings reported by Lee et al. [1993] are contrary to what might be expected, whereas those of this study are consistent with what may be expected to result from the catalyst preparation methods.

The XRD patterns of the three modified samples thus indicate that silicalite-I (or possibly highly siliceous ZSM-5) phases have been formed. The observation that the silicalite modified samples are apparently "less crystalline" (Table 3.1) may be a result of an overlap of ZSM-5 and silicalite-I patterns, which is likely to broaden the reflections, resulting in an apparent loss in intensity. Therefore, given that these relative crystallinities differ only minimally from the parent material, it is likely that all samples studied (ie. those listed in Table 3.1) are of good crystallinity. 


\subsubsection{Internal acidity of the resulting material}

The number of acid sites per gram of catalyst has been reduced by the formation of the silicalite-I phase. The aluminium content determined by AAS corresponds well with the aluminium in the synthesis mixture, as the expected value should be approximately $1 /(1+1.5)$ times that of the parent sample if 1 gram of ZSM-5 is reimmersed in a synthesis mixture expected to yield 1.5 grams of silicalite-I (Table 3.1 ).

The PY-TPD spectra of samples modified by coating with silicalite shells all show a reduction in the intensity of the signal and a lowering of $\mathrm{T}_{\max }$ (Table 3.4 and Figure 3.20). Lee et al. [1993] have reported similar results for $\mathrm{NH}_{3}$-TPD spectra from ZSM-5 coated with silicalite shells. This is due to the reduction in the specific number of acid sites (ie. acid sites per gram of total sample), which results from the presence of the silicalite-I phase. It has been shown by several researchers that an increase in the Si/Al ratio lowers both the intensity of the signal and $T_{\max }$ [Hidalgo et al., 1984; Kapustin et al., 1988]. However, it has also been shown in Section 3.2.5 that a reduction in catalyst mass results in similar observations. In both cases the number of acid sites are reduced. The silicalite shell effectively reduces the mass of ZSM-5 in the sample and hence the specific number of acid sites. The overall reduced acid site density results in reduced gas phase concentrations and reduced readsorption effects, the result of which is the observed reduction of the intensity of the signal and the lowering of $\mathrm{T}_{\text {max }}$.

The peak shape of each modified sample is skewed towards higher desorption temperatures, indicating that readsorption occurs. Sample S-Bdi has a very similar shape to sample $B$, whereas samples $S-B i$ and $S-B$ show an increase in the desorption rate at lower temperatures (Figure 3.20). According to Jones and Griffin [1983], such an increase in the desorption rate at lower temperatures occurs when the initial surface coverage is higher (Figure 1.23). However, it is unlikely that this is the case, as the sample has been exposed to the adsorbate for extended periods and total site saturation is expected. (It was shown earlier that even at low temperatures $\left(100^{\circ} \mathrm{C}\right)$ the sample was fully saturated (Section 3.2.6) and at these higher adsorption temperatures saturation should be even faster, as diffusional restrictions will be smaller.) To investigate whether this increase in the desorption rate at lower temperatures arises from physisorbed Py "trapped" in the channels as a result of pore blockage, due to 
the deposition of silicalite rich deposits during the coating procedure, the sample S-B was evacuated for $34 \mathrm{~h}$. This did not alter the Py-TPD spectrum of sample S-B (Figure 3.21). Therefore, the material desorbed at lower temperatures is also chemisorbed material.

The two samples which show an increased desorption rate at lower temperatures, samples $S-B_{i}$ and $S-B$, are both detemplated during the intermediate treatment. This opens the channels of the zeolite, thus making it possible for the silicalite-I synthesis gel to enter the channels. Thus it may be possible for silicon ions in the synthesis mixture to exchange for aluminium ions in the framework. The aluminium ions released could thus be either incorporated into the shell or included in the form of amorphous material. This is less likely to happen for sample S-Bdi as it is not detemplated during the intermediate treatment. Hence the channels of S-Bdi are filled with template, such that the silicalite-I synthesis gel is unable to enter the channels. The relative crystallinities are apparently slightly lower for samples $S-B_{i}$ and $S-B$ (Table 3.1).

This is supported by quantitative $\mathrm{NH}_{3}$-TPD results (Table 3.1 ), which show that more than one $\mathrm{NH}_{3}$ molecule is adsorbed per acid site, although this is the case for samples $\mathrm{S}-\mathrm{B}_{i}, \mathrm{~S}-\mathrm{B}$ as well as for sample $\mathrm{S}-\mathrm{B}_{\mathrm{di}}$. It is possible that the silicalite-1 phase adsorbs a small amount of $\mathrm{NH}_{3}$, as sample $\mathrm{S}-1$ also showed some desorption of $\mathrm{NH}_{3}$ (Table 3.1). This may be due to trace aluminium in the synthesis mixture which is undetected by AAS. It is also possible that amorphous acidic material, which can adsorb more than one $\mathrm{NH}_{3}$ molecule per acid site, causes this increase. Indeed, Handreck and Smith [1990] suggested that this modification method may form acidic amorphous material. Such material may be the source of increased desorption rates at lower temperatures as shown by Figure 3.21 .

On the other hand, $n$-hexane adsorption capacities for samples B and S-B did not seem to indicate pore blockage or a reduction in the pore volume. Rollmann [1980] also did not see a reduction in $n$-hexane adsorption capacities for catalysts coated with silicalite shells, which remained approximately $11 \mathrm{wt} \%$ at $25{ }^{\circ} \mathrm{C}$. $n$-Hexane adsorption capacities for HZSM-5 reported by Szostak $11992 \mid$ are $11.0 \mathrm{wt} \%$ at $50{ }^{\circ} \mathrm{C}$. Values reported here are slightly lower, namely $9 \mathrm{wt} \%$ at $50^{\circ} \mathrm{C}$ (Table 3.1). 
In each of the modified catalysts the internal acidity is still essentially intact. The modification seems to have formed mostly ZSM-5 and silicalite-I phases. It is possible that small amounts of acidic amorphous material have also been formed, although SEM, XRD and $n$-hexane adsorption capacity data seemingly contradict the TPD results.

\subsubsection{External acidity of the resulting material}

MQ-TPD spectra of the modified samples (Figure 3.22 ) show that sample S-B has a peak intensity which is much lower than that of the unmodified catalyst (sample B). This indicates that the coating has been successful for this sample, without seriously having affected the internal acidity of the catalyst. Samples S-Bdi and S-Bi still show external acidity and have therefore not been modified successfully (Figure 3.22). In the case of this study, $\mathrm{NH}_{4}-\mathrm{ZSM}-5$ was used as seed material for the synthesis of S-B, whereas Na-ZSM-5 was used in the synthesis of S-Bdi and S-Bi. Lee et al. [1993] used Na-ZSM-5 as seeds.

Samples $\mathrm{S}-\mathrm{B}_{\mathrm{di}}$ and $\mathrm{S}-\mathrm{Bi}_{\mathrm{i}}$ have in fact a greater peak height for $m / e=78$ than sample $B$. It should be noted, however, that the peak shape has changed and that $T_{\text {max }}$ is higher for these samples than for sample $B$. It is difficult to speculate why this is so, as this may be due to changes in the desorption/cracking mechanism on the external surface. The change in peak shape should not be interpreted as a change in catalyst acidity (see arguments in Section 3.2.7 and Section 4.2.1).

\subsubsection{CHEMICAL VAPOUR DEPOSITION}

\subsubsection{Structure of the resulting material}

The structure of catalysts modified using the chemical vapour deposition method show very little change when compared to the unmodified catalyst. The electron micrographs of the crystals show no differences (Figure 3.6). The $X R D$ patterns of samples $V_{4}-C$ and $V_{16}-C$ show small decreases in the peaks at $2 \theta$ values of $7.9^{\circ}$ and $8.8^{\circ}$ for increasing silane deposition (Figure 3.3), but the relative crystallinities are similar to sample $C$ (Table 3.1 ). Thus it can be 
concluded that the resulting samples have essentially the same structure as the parent material. Niwa et al. [1986] have suggested that only a thin layer of $\mathrm{SiO}_{2}$ covers the crystals. The Si/Al ratio of the modified samples remains essentially the same (Table 3.1). This implies that very little silicon has been deposited onto the catalyst, and that only a thin layer of $\mathrm{SiO}_{2}$ has formed around sample $V_{16}-C$, as supported by the Al content data (Table 3.1).

\subsubsection{Internal acidity of the resulting material}

$\mathrm{NH}_{3}$-TPD studies carried out by Niwa et al. [1986] revealed that neither strength nor amount of the acidity was changed by the deposition of tetramethoxysilane on HZSM-5. Similar results were obtained by Niwa et al. [1984a] for $\mathrm{NH}_{3}$ desorption from HM. This study has shown that Py-TPD spectra of HZSM-5 modified by chemical vapour deposition using tetraethoxysilane (samples $V_{4}-C$ and $V_{16}-C$ ) also show no essential differences from the parent HZSM-5 (sample C). The intensity of the signal, the peak shape and $T_{\text {max }}$ remain essentially unchanged by chemical vapour deposition (Table 3.5 and Figure 3.23).

$n$-Hexane adsorption capacities for samples $C$ arid $V_{16}-C$ are identical (Table 3.1). Niwa et al. [1984a and 1989] have reported a slight decrease in the $n$ hexane adsorption capacities of CVD modified HM, and a much larger decrease in the $\sigma$-xylene and $p$-xylene adsorption capacities of CVD modified HZSM-5 [Hibino et al., 1991] and HM [Niwa et ái., 1984a; Niwa et al., 1989]. However, the $\mathrm{H}_{2} \mathrm{O}$ adsorption capacity remained the same [Niwa et al., 1984a; Niwa et al., 1989]. They concluded that the pore volume remains the same, and that the reduced adsorption capacities for the larger molecules was due to the narrowing of the pore openings by the deposition of tetramethoxysilane.

As the $\mathrm{NH}_{3}$-TPD and Py-TPD data do not indicate a change in the number or strength of acid sites foi the modified samples, and $n$-hexane adsorption capacities are unchanged, it can be concluded that the internal acidity is not affected by the deposition of tetraethoxysilane and that the pore volume remains the same. 


\subsubsection{External acidity of the resulting material}

The MQ-TPD spectrum of sample $V_{16}-C$ shows almost no adsorption/desorption of MQ-4, whereas sample $V_{4}-C$ does show a desorption peak (Figure 3.24). The increased temperature of deposition and the increase in deposition time has therefore been responsible for a more effective elimination of the external acidity.

The peak height of sample $V_{4}-C$ is greater than that of sample $C$, but it must be reiterated that the change in peak shape does not necessarily imply a change in catalyst acidity. Hibino et al. [1990] investigated the cracking of 1,3,5triisopropylbenzene over HZSM-5 and CVD modified HZSM-5. This reaction can only take place on the external surface of the catalyst. They reported that the conversion decreased with increasing amounts of silane deposition. This implies that the elimination of the external acidity occurs gradually. Since a desorption peak for sample $\mathrm{V}_{4}-\mathrm{C}$ is still visible (Figure 3.24), the elimination of the external acidity has not been completed for this sample.

Although the deposition time and temperature required for elimination of the external acidity in these studies are greater than those used by Niwa and coworkers, this can probably be attributed to two factors: (i) tetraethoxysilane is less reactive than tetramethoxysilane [Niwa et al., 1989], and (ii) in this study the catalyst mass used is larger than that typically used by Niwa and coworkers. 
CHAPTER 5

\section{CONCLUDING REMARKS}





\section{CONCLUDING REMARKS}

These studies have confirmed that temperature programmed desorption is a suitable method for determining whether the elimination of the external acidity of ZSM-5 has been achieved. It has been shown that both $\mathrm{NH}_{3}$ and $\mathrm{Py}$ readily enter the channel system of ZSM-5 and that they are suitable probes for the total acidity of ZSM-5. 4-Methyl quinoline has been shown to be suitable as a selective probe for the external acidity of ZSM-5. The elimination of the external surface acidity has been successful both for samples modified by coating with silicalite shells and for samples modified by chemical vapour deposition.

The results have also shown that, in the case of $\mathrm{NH}_{3}$, a secondary adsorption layer is formed, where more than one $\mathrm{NH}_{3}$ molecule is adsorbed per acid site. This then gives rise to two desorption peaks for chemisorbed $\mathrm{NH}_{3}$. The $\mathrm{NH}_{3}$ desorbed as indicated by the LTD peak may be removed during the evacuation/flushing period prior to temperature programmed desorption, and it is not strongly chemisorbed to the zeolite. Because a secondary adsorption layer for Py on HZSM-5 was not observed, two Py molecules are not able to adsorb onto one acid site due to steric hindrance effects in the channel system of ZSM5. Thus a LTD peak of $\mathrm{NH}_{3}$ (due to a secondary adsorption layer of $\mathrm{NH}_{3}$ ) with a higher value of $T_{\max }$ than the LTD peak of $P y$ (due to physisorbed $P y$ ) is observed, whereas the opposite is observed for $T_{\max }$ of the HTD peak (strongly chemisorbed material). This is because the pyridine-zeolite complex is more stable than the ammonia-zeolite complex.

Furthermore, the peak shapes of the $\mathrm{NH}_{3}$-TPD and Py-TPD spectra are skewed towards higher desorption temperatures, and the position of the peak maximum temperature of the $\mathrm{NH}_{3}$-TPD and Py-TPD spectra are affected by changes in catalyst mass and carrier gas flowrate. This indicates that diffusion and readsorption phenomena are present in the channels during temperature programmed desorption of these adsorbates from HZSM-5. These phenomena account for a spectrum that is skewed towards higher desorption temperatures.

The amount of 4-methyl quinoline which is adsorbed/desorbed from ZSM-5 is approximately 2-3 orders of magnitude smaller than that of pyridine. Furthermore, the MO-TPD spectrum is not influenced by changes in catalyst 
mass (indicating no readsorption phenomena in the channels) or evacuation times (indicating physisorbed MQ-4 is readily removed). Therefore it can be concluded that 4-methyl quinoline is adsorbed solely onto the external surface of ZSM-5. Thus it is suitable as a selective probe for the external acidity of ZSM-5. Moreover, due to its high desorption temperatures, MQ-4 could be a suitable poison for the external surface of ZSM-5 for reactions below $500^{\circ} \mathrm{C}$.

It has been found that MQ-4 reacts upon desorption from ZSM-5. Therefore, no quantitative measurements of $\mathrm{MQ}-4$ can be made using a mass spectrometer. Furthermore, this phenomenon is responsible for the inability to draw conclusions about changes to the catalyst acidity from the peak shapes of $\mathrm{MQ}$ TPD spectra. It is possible that products of reaction could enter the channels. However, since the desorption/cracking mechanism occurs only at high temperatures, and given that only a small amount is desorbed, it is extremely unlikely that any material would enter the channels during the adsorption step (ie. any material entering the channels can only do so during the TPD process). Therefore any material detected originates from the external surface of the catalyst, and elimination of the external acidity has been achieved when no material is detected.

A silicalite-I (or possibly a highly siliceous ZSM-5) phase has been formed in samples modified using the silicalite shell method, and separate silicalite-I crystals may have been formed. The silicalite-l phase has resulted in a decrease in the specific number of acid sites (the number of acid sites per gram of resulting material), as shown by the $\mathrm{Al}$ content and quantitative $\mathrm{NH}_{3}$-TPD measurements. The samples have retained good crystallinities and $n$-hexane adsorption capacities. In each of the silicalite modified catalysts the internal acidity is still essentially intact. Thus the channel structure remains accessible to the adsorbates. The external acidity has been eliminated for the sample where the $\mathrm{NH}_{4}$-form of the parent crystal has been used as seed material (sample S-B). The use of undetemplated seed crystals is preferred, in that the deposition of amorphous species in the channels can be prevented during the modification process.

Samples modified using the chemical vapour deposition method have retained good crystallinities and $n$-hexane adsorption capacities. No decrease in the specific number of acid sites is observed. In each of the CVD modified samples the internal acidity remains unchanged and accessible to the adsorbates. The 
external acidity has been eliminated for the sample on which the largest amount of tetraethoxysilane has been deposited (ie. using the longest deposition time and highest deposition temperature - sample $\mathrm{V}_{16}-\mathrm{C}$ ).

A description of the materials resulting from the two methods employed to eliminate the external acidity from ZSM-5 may be proposed as follows:

\section{Silicalite shell modification}

The nature of the material resulting from silicalite shell modification seems to be a combination of ZSM-5 and silicalite-I phases. The silicalite-I phase does not always coat the ZSM-5 crystal completely, but when it does las for sample S-B), a thick shell of silicalite-I is required to ensure coverage of the crystals. It appears that during the modification procedure with detemplated seed crystals, a small amount of amorphous material is formed, as indicated by an increase in the desorption rate at lower temperatures of Py-TPD spectra and by quantitative $\mathrm{NH}_{3}$-TPD results. It may be speculated that the synthesis mixture used in the modification procedure may extract aluminium out of the framework and replace it with silicon, provided the channels of the seed crystal have been detemplated (ie. the channels are not filled with template). The freed aluminium could thus be included in the formation of the shell, or in the formation of amorphous material. However, the channels are still accessible to the adsorbates.

\section{Chemical vapour deposition modification.}

The nature of the material resulting from modification using chemical vapour deposition is very similar to that of the unmodified HZSM-5. The internal acidity and pore volume are unchanged. The external surface is thought to be covered only by a thin layer of inert silica (of the order of a few monolayers).

Modification by chemical vapour deposition therefore seems to be more suitable than the silicalite shell method for elimination of the external acidity of ZSM-5. However, the effects on the activity, selectivity and life-times of these modified catalysts have not been studied here. Each modification method may have different effects on these parameters. The suitability of the above modification methods, and indeed of other modification methods not studied here, for yielding catalysts of improved performance for specific reactions must therefore still be investigated. 
APPENDICES 

APPENDIX I: LIST OF CHEMICALS AND REAGENTS

\begin{tabular}{|c|c|c|}
\hline REAGENT & SUPPLIER & PURITY \\
\hline \multicolumn{3}{|l|}{ CHEMICALS } \\
\hline $\mathrm{AllOH})_{3}$ & $\mathrm{BDH}$ & $99.5 \%$ \\
\hline $\mathrm{NaOH}$ & Saarchem & $97 \%$ \\
\hline Ludox HS4O & Du Pont & $40 \% \mathrm{SiO}_{2}$ \\
\hline tetrapropylammonium bromide & Fluka Chemie A.G. & $98 \%$ \\
\hline tetraethoxysilane (TES) & Fluka Chemie A.G. & \multirow{2}{*}{$\begin{array}{l}98 \% \\
99 \%\end{array}$} \\
\hline $\mathrm{NH}_{4} \mathrm{NO}_{3}$ & Saarchem & \\
\hline HF & Riedel-de-Haen & $40 \% \mathrm{HF}$ \\
\hline Boric acid & GPR & \multirow{2}{*}{$\begin{array}{l}99.5 \% \\
31 \% \mathrm{HCl}\end{array}$} \\
\hline & $\mathrm{BDH}$ & \\
\hline Al solution & Saarchem & 1000 PPM \\
\hline Si solution & Saarchem & 1000 PPM \\
\hline Na solution & Saarchem & \multirow{2}{*}{$\begin{array}{l}1000 \text { PPM } \\
99 \%\end{array}$} \\
\hline$n$-hexane & Merck & \\
\hline \multicolumn{3}{|l|}{ ADSORBATES } \\
\hline pyridine & Merck & $99.7 \%$ \\
\hline 4-methyl quinoline & Aldrich & $99 \%$ \\
\hline $\mathrm{NH}_{3} / \mathrm{He}$ & Air Products & $5 \mathrm{~mol}^{2} \mathrm{NH}_{3}$ \\
\hline \multicolumn{3}{|l|}{ CARRIER GASES } \\
\hline air & Fedgas & $99.99 \%$ \\
\hline $\mathrm{He}$ & Fedgas & $99.996 \%$ \\
\hline $\mathrm{N}_{2}$ & Fedgas & $99.995 \%$ \\
\hline \multicolumn{3}{|l|}{ OTHER } \\
\hline $\mathrm{N}_{2}$ (liquid) & Afrox & \\
\hline molecular sieve (3A) & Merck & $>2.5 \mathrm{~mm} \quad 5 \%$ \\
\hline
\end{tabular}




\section{APPENDIX II: LIST OF EQUIPMENT}

DESCRIPTION

VACUUM PUMPS

rotary pump

air-cooled oil diffusion pump

oil for rotary pump

oil for diffusion pump

accessories

\section{VACUUM GAUGES}

Pirani vacuum gauge

Penning vacuum gauge

vacuum display unit

accessories
MANUFACTURER

Edwards

Edwards

Edwards

Dow Corning

Edwards

Edwards

Edwards

Edwards

Edwards
MODËL

ED100

E050/60

No 16

Silicone 705

\section{TPD FURNACE and TEMPERATURE CONTROLLERS}

TPD furnace

temp. programmer

temp. controller

temp. display indicator

temp. selector unit

thermocouples

heating tape

\section{FLOWMETERS}

mass flow controller

4-channel display unit

QUARTZ and GLASSWARE

quartz tubing and frits

glass stopcocks

glass male/female joints

glass ball joints

o-rings and accessories
Kiln Contracts

RKC instruments

RKC Instruments

RKC Instruments

RKC Instruments

ElectroHeat

ElectroHeat

Brooks

Brooks

5850 TR

5878

Heraeus

J.Young Glassware

J.Young Glassware

J.Young Glassware

J.Young Glassware

Hewlett Packard

5890 Series II

Hewlett Packard

5971A

Scientific Glass Eng.

062447

\section{MISCELLANEOUS}

valves, fittings, filters

regulators

Jo'burg V\&F

Air Products 


\section{APPENDIX IV: SAMPLE CALCULATION OF AAS RESULTS}

The sample calculation of the aluminium content in catalyst $A$, as determined by AAS, is shown below. The silicon and sodium contents can be calculated similarly. The figures in brackets are those for silicon. As no sodium was detected no values are given for sodium.

$\begin{array}{lrl}\text { Al reading: } & 7.0 \mathrm{PPM} & \text { (dilution = 1) } \\ \text { Si reading: } & 52.0 \mathrm{PPM} & \text { (dilution = 5) } \\ \text { Na reading: } & 0.0 \mathrm{PPM} & \\ \text { wet mass: } & 301.7 \mathrm{mg} & \\ \text { moist. cont.: } & 6.8 \mathrm{wt} \% & \end{array}$

(i) $\quad$ mass $\% \mathrm{Al}_{2} \mathrm{O}_{3}$

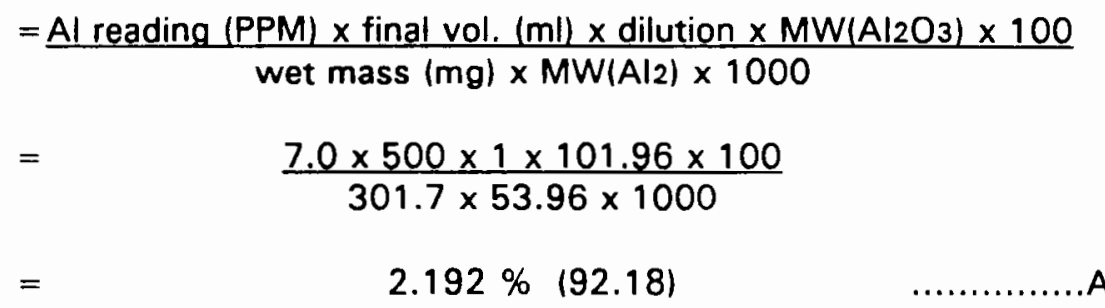

(ii) $\quad$ mass $\mathrm{Al}_{2} \mathrm{O}_{3}$ in sample $=$

$$
=
$$$$
=
$$

(iii) $\mathrm{mmol} \mathrm{Al} \mathrm{/} \mathrm{g} \mathrm{sample} \mathrm{=}$ mass \% $\mathrm{Al}_{2} \mathrm{O} 3 \times$ wet mass $(\mathrm{mg}) / 100$

$$
\begin{aligned}
& 2.192 \times 301.7 / 100 \\
& 6.613 \mathrm{mg}(278.1)
\end{aligned}
$$

(iv) theor. dry mass $=$ mass $\mathrm{Al}_{2} \mathrm{O}_{3}+$ mass $\mathrm{SiO}_{2}+$ mass $\mathrm{Na}_{2} \mathrm{O}$ in sample

$$
\begin{array}{cc}
= & 6.613+278.1+0.0 \\
= & 284.7 \mathrm{mg}
\end{array}
$$

theor. \% moisture $=$ [wet mass $(\mathrm{mg})$-theor. dry mass $(\mathrm{mg})] \times 100$ wet mass $(\mathrm{mg})$

$=\frac{[301.7-284.7] \times 100}{301.7}$
$=5.63 \%$





\section{APPENDIX III: CATALYST NOMENCLATURE}

The catalysts are named according to the following code:

$$
M_{\mathrm{t}}-P_{\mathrm{di}}
$$

where $\quad-M$ is the modification step.

S - modification using silicalite shells

V - modification using chemical vapour deposition

- $t$ is a number indicating the time, in hours, during which chemical vapour deposition took place (Not applicable to the silicalite shell method).

- $P$ is the primary synthesis batch $(A-C)$

A - used mainly for catalyst characterization and testing

$B$ - used for modification using silicalite shells

C - used for modification using chemical vapour deposition

- $\mathbf{d}$ indicates that during the intermediate treatment, detemplation did not occur.

- $\mathbf{i}$ indicates that during the intermediate treatment, ion exchange did not occur.

NOTE: $\quad S-I$ is a silicalite-I batch

\section{examples}

1. A

This is unmodified ZSM-5, batch $A$.

2. S-Bdi This is the primary ZSM-5 of batch $B$, not detemplated and not ionexchanged during the intermediate treatment, which is modified using the silicalite shell method.

3. $V_{4}-C$ This is the primary batch $C$, detemplated and ion exchanged (not indicated), modified using the chemical vapour deposition method for $4 \mathrm{~h}$. 

(v) actual dry mass

$=$ wet mass $(\mathrm{mg})-[$ wet mass $(\mathrm{mg}) \times$ moist. cont. / 100 ]

$=$

$301.7-[301.7 \times 6.8 / 100]$

$=$

$281.2 \mathrm{mg}$

..F

(vi) $\quad$ mass $\% \mathrm{Al}_{2} \mathrm{O}_{3}$

per $\mathrm{g}$ dry sample

$=$

$=$

$=$

$=$

(vii) $\mathrm{mmol} \mathrm{Al}_{2} \mathrm{O}_{3}$

per g dry sample

$$
=
$$$$
=
$$

(viii) $\mathrm{mol} \% \mathrm{Al}_{2} \mathrm{O}_{3}$

(ix) Si/Al

$=$

$=$ mass $\mathrm{Al}_{2} \mathrm{O}_{3}$ in sample $(\mathrm{mg}) \times 100$ actual dry mass (mg)

$6.613 \times 100$

281.2

$2.35 \%(98.9)$

$\mathrm{G}$

mass $\% \mathrm{Al}_{2} \mathrm{O}_{3} \times 1000$

$\mathrm{MW}\left(\mathrm{Al} \mathrm{O}_{3}\right) \times 100$

$2.35 \times 1000$

$101.96 \times 100$

$0.231 \mathrm{mmol}(16.46)$

..H

$\mathrm{mmol} \mathrm{Al} 2 \mathrm{O}_{3} \times 100$

mmol TOTAL

$\underline{0.231 \times 100}$

16.691

$1.38 \% \quad(98.62)$

$\mathrm{mmol} \mathrm{SiO}_{2}$

$\mathrm{mmol} \mathrm{Al}_{2} \mathrm{O}_{3} \times 2$

$\frac{16.46}{231 \times}$

35.6 


\section{APPENDIX V: LEAK TESTING}

The vacuum line was leak tested prior to operation. Results of the pressure obtained in various parts of the vacuum line are given in the table below. The pressure in certain parts of the vacuum line was checked periodically, especially after maintenance tasks had been performed, and compared to the values given in the table below.

\begin{tabular}{|c|c|c|}
\hline open & closed & $\begin{array}{c}\text { PRESSURE } \\
\text { (mbar) }\end{array}$ \\
\hline $\begin{array}{l}V 1-V 12 \\
V 1-V 10 \\
V 9-V 12 \\
V 9-V 11 \\
V 9-V 10\end{array}$ & $\begin{array}{l}V 11, V 12 \\
V 1-V 8 \\
V 12 \\
V 11, V 12\end{array}$ & $\begin{array}{l}1.0 \times 10^{-5} \\
7.6 \times 10^{-6} \\
9.0 \times 10^{-6} \\
7.8 \times 10^{-6} \\
6.0 \times 10^{-6}\end{array}$ \\
\hline
\end{tabular}

NOTE: The pressure indicated is the pressure in the vacuum line with the valves (as given in Figure 2.3) opened or closed as indicated. Valves $V 13$ and $V 14$ are closed in each case.

These results indicate that the pressure in the clean line is less than $1 \times 10^{-5}$ mbar after pumping down for two days. Under normal operating conditions the vacuum line is pumped down to less than $1 \times 10^{-4}$ mbar prior to the adsorption stage. The pressure in the vacuum line during pyridine adsorption is approximately $10^{-1}$ mbar. An estimate of the leak rate showed that, during the adsorption step, the pressure increase due to "leaks" in the vacuum line was negligible compared to the partial pressure of the adsorbate. 


\section{APPENDIX VI: FURNACE CONFIGURATION AND TEMPERATURE RAMP}

The furnace shown below has been designed for this project. The heating element is alferon super, which is wound around twelve ceramic tubes. This is housed in a well insulated chamber. The TPD cell can be inserted through openings at the top and bottom of the furnace. Deflector shields above and below the furnace prevent heat losses from the top and bottom of the furnace, thus preventing the Cajon fittings from being heated excessively.

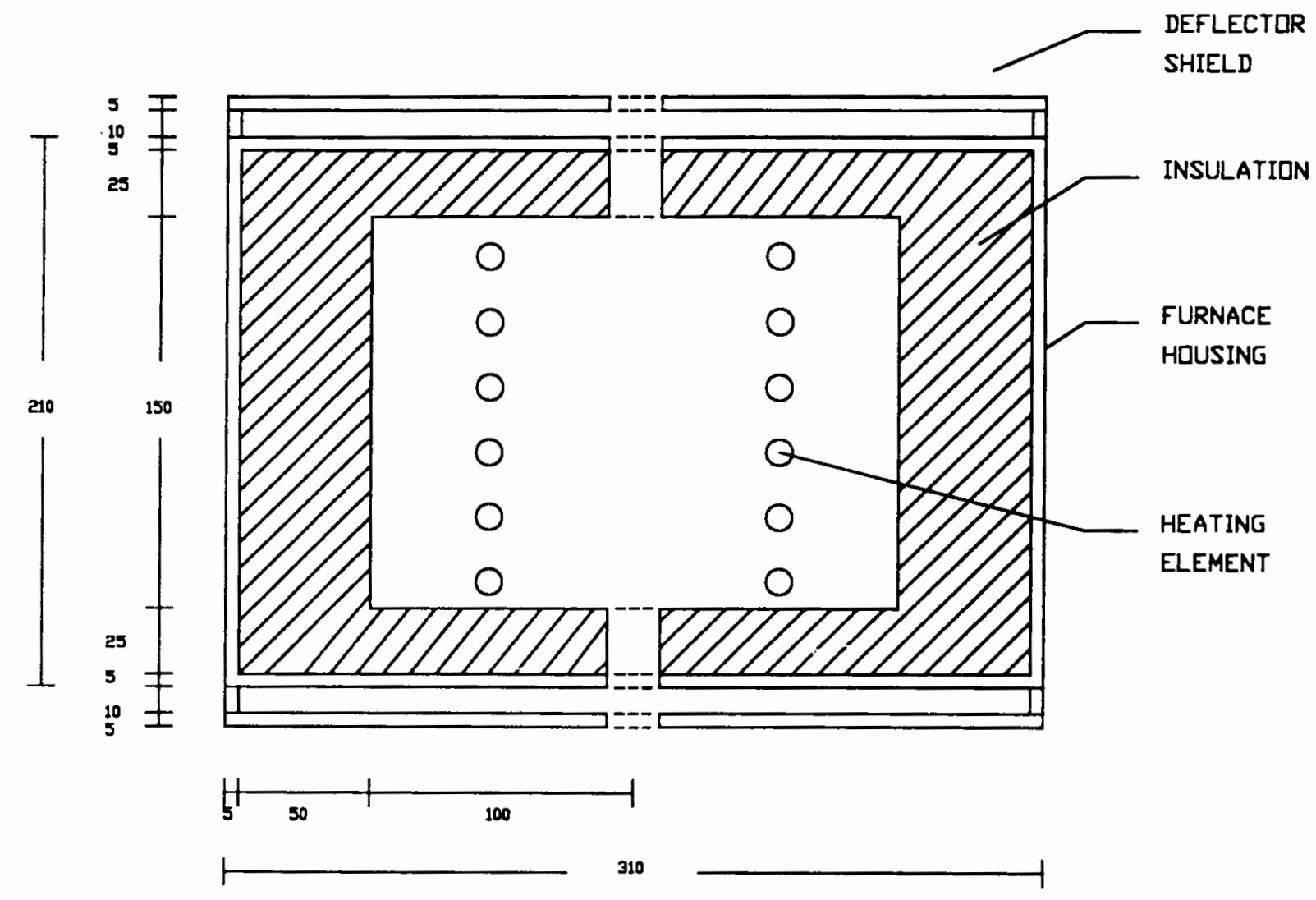

The TPD furnace 
The figure below shows the linearity of the temperature ramp for different heating rates from $50-1050{ }^{\circ} \mathrm{C}$. The slope of the temperature ramp is calculated by linear regression. In each case the correction coefficient (based on 101 data points) is better than 0.99999 .

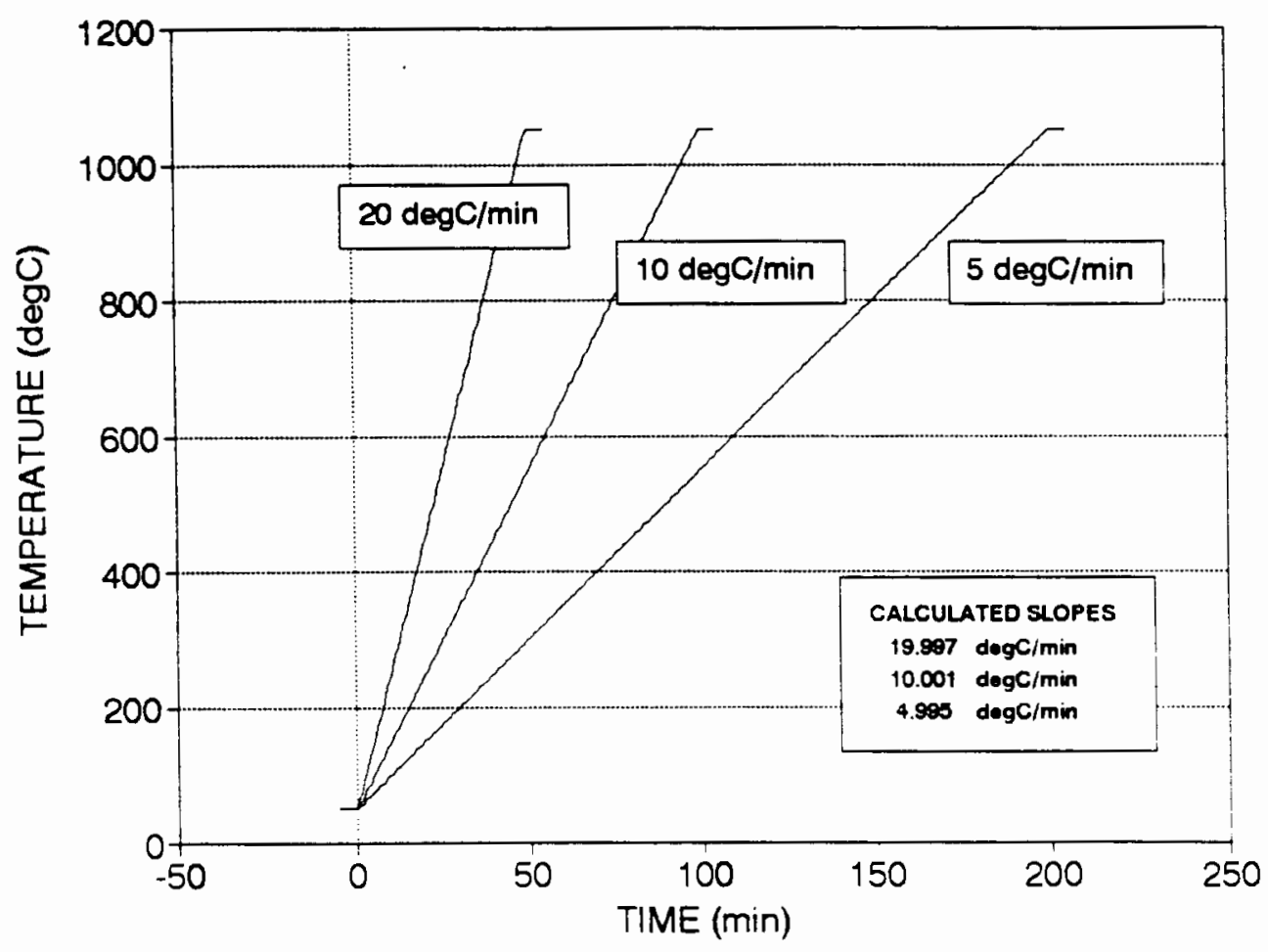

Profiles of the temperature ramps in the TPD furnace. 


\section{APPENDIX VII: MISCELLANEOUS TPD SPECTRA}
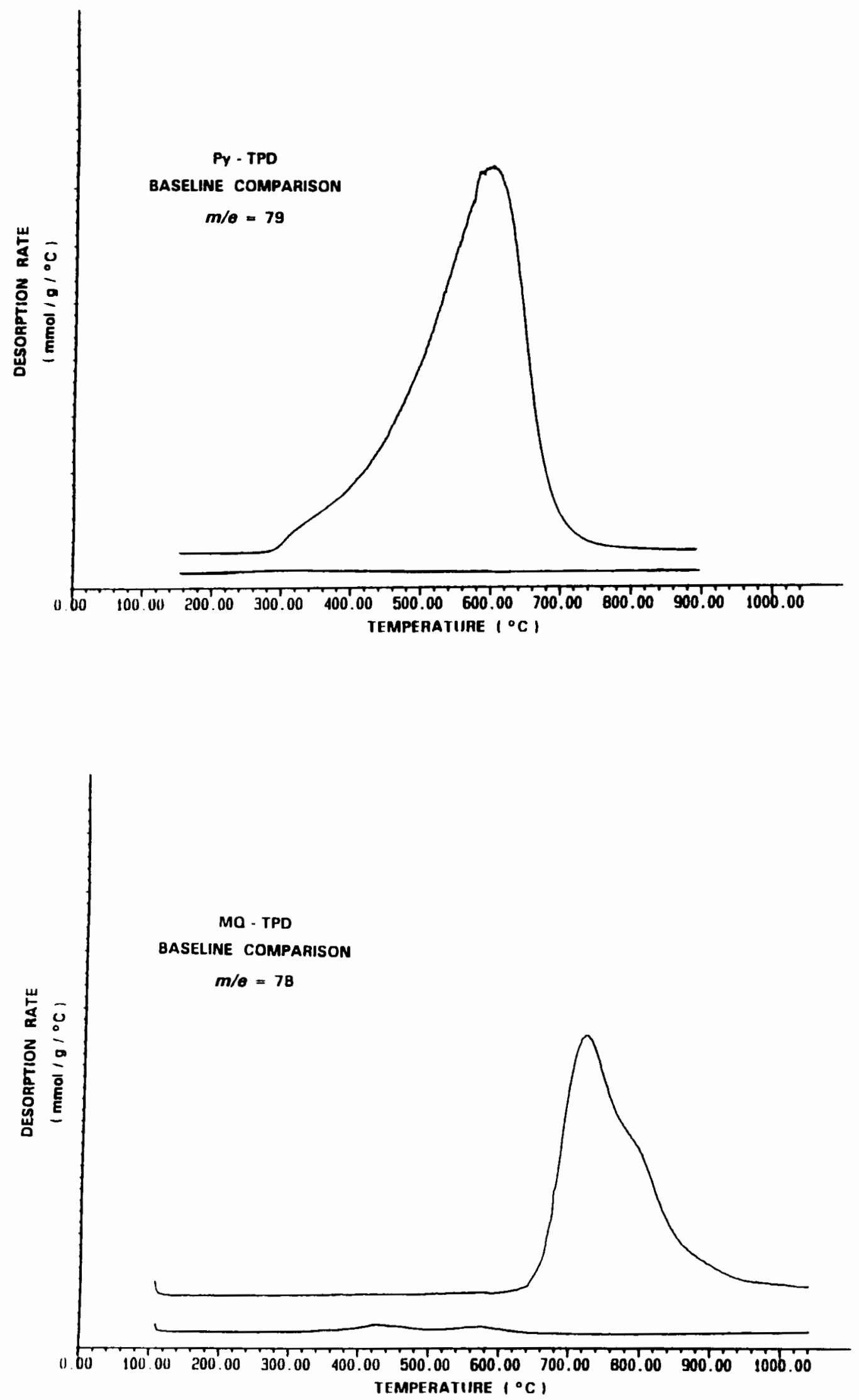

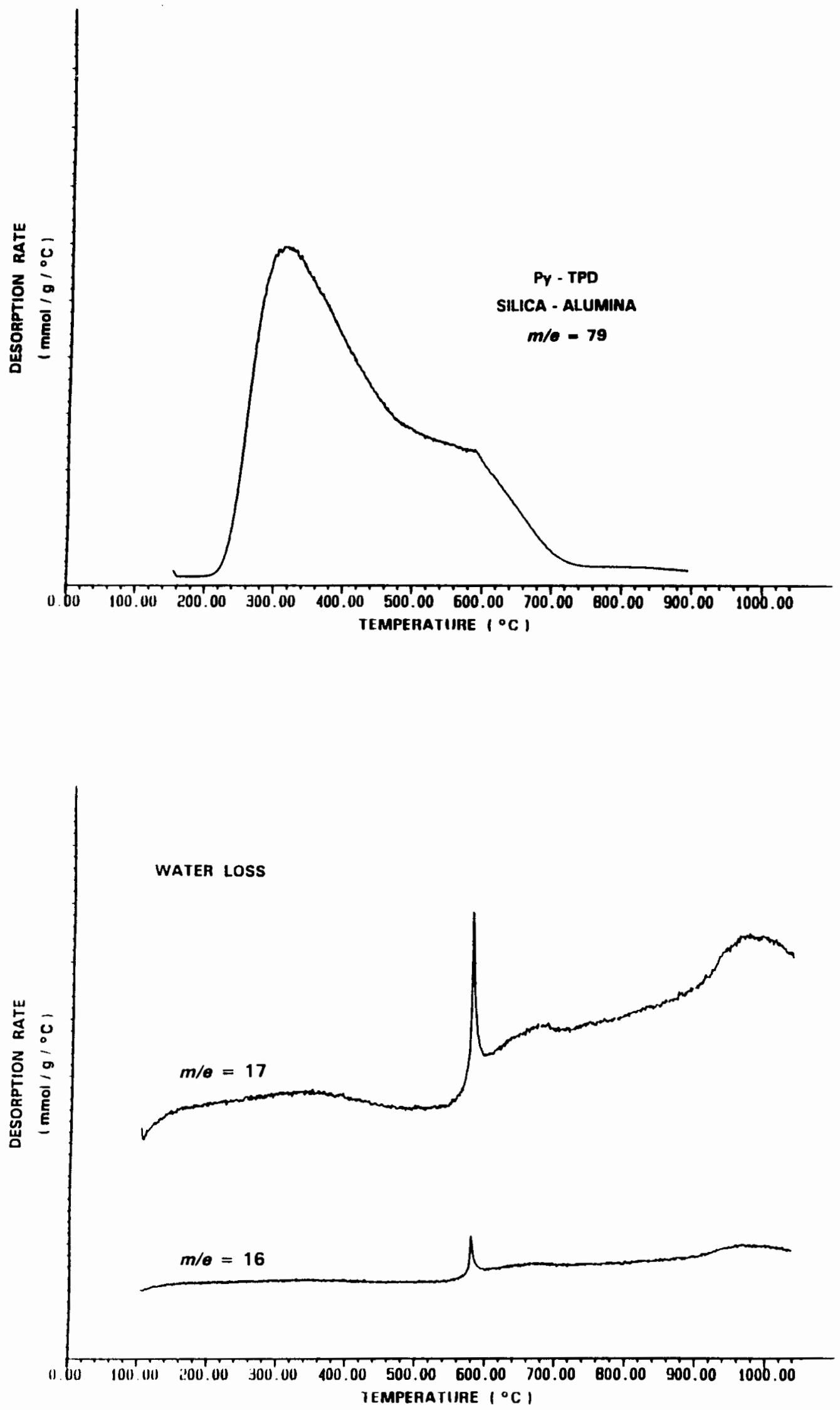


\section{REFERENCES}





\section{REFERENCES}

The references are listed in alphabetical order of the first author. Where more than one publication by the same first author has been listed, the references are listed in chronological order.

Akporiaye, D., Chapple, A.P., Clark, D.M., Dwyer, J., Elliott, I.S. and Rawlence, D.J., Stud. Surf. Sci. Catalysis, 28, 351-357 (1986)

Amenomiya, Y. and Cvetanovic, R.J., Journal of Physical Chemistry, 67, 144147 (1963a)

Amenomiya, Y. and Cvetanovic, R.J., Journal of Physical Chemistry, 67, 20462049 (1963b)

Amenomiya, Y. and Cvetanovic, R.J., Journal of Physical Chemistry, 67, 27052708 (1963c)

Amenomiya, Y., Chenier, J.H.B. and Cvetanovic, R.J., Journal of Physical Chemistry, 68, 52-57 (1964)

Amenomiya, Y. and Cvetanovic, R.J., Journal of Catalysis, 18, 329-337 (1970)

Andersen, B., in "Propene Oligomerization over Steam Dealuminated and Boron and Phosphorus Modified ZSM-5", PhD Thesis, University of Cape Town (1991)

Anderson, J.R., Foger, K., Mole, T., Rajadhyaksha, R.A. and Sanders, J.V., Journal of Catalysis, 58, 114-130 (1979)

Anderson, J.R., Chang, Y.-F. and Hughes, A.E., Catalysis Letters, 2, 279-286 (1989a)

Anderson, J.R., Chang, Y.-F. and Western, R.J., Journal of Catalysis, 118, 466$482(1989 b)$

Argauer, R.J. and Landolt, G.R., U.S. Patent 3,702,886 (1972)

Barrer, R.M., in "Hydrothermal Chemistry of Zeolites", p2, Academic Press, London (1982)

Behrsing, T., Jaeger, H. and Sanders, J.V., Applied Catalysis, 54, 289-302 (1989)

Beyer, H. and Belenykaja, I., Stud. Surf. Sci. Catalysis, 5, 203-210 (1980)

Bhatia, S., Beltramini, J. and Do, D.D., Catal. Rev.-Sci. Eng., 31(4), 431-480 (1989-90)

Bibby, D.M., Milestone, N.B., Patterson, J.E. and Aldridge, L.P., Journal of Catalysis, 97, 493-502 (1986) 
Boxhoorn, G., Sudmeijer, O. and Van Kasteren, P.H.G., J. Chem. Soc., Chem. Commun., 1416-1418 (1983)

Bulow, M., Caro, J., Volter, J. and Karger, J., Stud. Surf. Sci. Catalysis, 34, 343-354 (1987)

Choudhary, V.R. and Akolekar, D.B., Journal of Catalysis, 117, 542-548 (1989)

Choudhary, V.R. and Akolekar, D.B., Journal of Molecular Catalysis, 66, 215222 (1991)

Csicsery, S.M., in "Zeolite Chemistry and Catalysis, ACS Monograph 171", Rabo, J.A. (Ed), 680-713 (1979)

Cvetanovic, R.J. and Amenomiya, Y., Advances in Catalysis, 17, 103-149 (1967)

Cvetanovic, R.J. and Amenomiya, Y., Catalysis Reviews, 6(1), 21-48 (1972)

Demmin, R.A. and Gorte, R.J., Journal of Catalysis, 90, 32-39 (1984)

Derouane, E.G., Detremmerie, S., Gabelica, Z. and Blom, N., Applied Catalysis, 1, 201-224 (1981)

Derouane, E.G., Journal of Catalysis, 100, 541-544 (1986)

Derouane, E.G. and Gabelica, Z., Journal of Solid State Chemistry, 64, 296-304 (1986)

De Vos Burchart, E., Van Bekkum, H. and Van de Graaf, B., Zeolites, 13, $212-$ 215 (1993)

Dwyer, J., Fitch, F.R., Machado, F., Qin, G., Smyth, S.M. and Vickerman, J.C., J. Chem. Soc., Chem. Commun., $422-424$ (1981)

Fletcher, J.C.Q., in "The acidity of synthetic mica-montmorillonite and its activity for propene oligomerization", PhD Thesis, University of Cape Town (1984)

Fraenkel, D., Cherniavsky, M. and Levy, M., in "Proceedings, $8^{\text {th }}$ International Congress on Catalysis, Berlin, 1984," Vol IV, 545-554, Dechema, Frankfurt-am-Main (1984)

Fraenkel, D., Cherniavsky, M., Ittah, B. and Levy, M., Journal of Catalysis, 101, 273-283 (1986)

Fraenkel, D. and Levy, M., Journal of Catalysis, 118, 10-21 (1989a)

Fraenkel, D. and Levy, M., Journal of Catalysis, 118, 487-493 (1989b)

Gabelica, Z., Derouane, E.G. and Blom, N., Applied Catalysis, 5, 109-117 (1983a)

Gabelica, Z., Blom, N. and Derouane, E.G., Applied Catalysis, 5, 227-248 (1983b)

Gallezot, P., Leclercq, C., Guisnet, M. and Magnoux, P., Journal of Catalysis, $114,100-111$ (1988) 
Gorte, R.J., Journal of Catalysis, 75, 164-174 (1982)

Guisnet, M. and Magnoux, P., Applied Catalysis, 54, 1-27 (1989)

Haag, W.O., Lago, R.M. and Weisz, P.B., Disc. Faraday Soc., 72, 317-330 (1982)

Haag, W.O. and Chen, N.Y., in "Catalyst Design Progress and Perspectives", p165-170, Hegedus, L.L, John Wiley and Sons (1987)

Handreck, G.P. and Smith, T.D., Zeolites, 10, 746-752 (1990)

Hardenberg, T.A.J., Mertens, L., Mesman, P., Muller, H.C. and Nicolaides, C.P., Zeolites, 12, 685-689 (1992)

Herz, R.K., Kiela, J.B. and Marin, S.P., Journal of Catalysis, 73, 66-75 (1982)

Hibino, T., Niwa, M. and Murakami, Y., Journal of Catalysis, 128, 551-558 (1991)

Hidalgo, C.V., Itoh, H., Hattori, T., Niwa, M. and Murakami, Y., Journal of Catalysis, 85, 362-369 (1984)

Hunger, B, Hoffmann, J., Heitsch, O. and Hunger, M., Journal of Thermal Analysis, 36, 1379-1391 (1990)

Iwamoto, M., Tajima, M. and Kagawa, S., J. Chem. Soc., Chem. Commun., 598-600 (1986)

Jacobs, P.A. and Martens, J.A., Stud. Surf. Sci. Catalysis, 33, 100-103 (1987) Jones, D.M. and Griffin, G.L., Journal of Catalysis, 80, 40-46 (1983)

Kapustin, G.I., Brueva, T.R., Klyachko, A.L., Beran, S. and Wichterlova, B., Applied Catalysis, 42, 239-246 (1988)

Karge, H.G., Stud. Surf. Sci. Catalysis, 58, 531-570 (1991)

Kerr, G.T., Journal of Physical Chemistry, 72, 2594-2596 (1968)

Kiskinova, M., Griffin, G.L. and Yates, J.T.,Jr., Journal of Catalysis, 71, 278287 (1981)

Kofke, G.T.J., Gorte, R.J. and Farneth, W.E., Journal of Catalysis, 114, 34-45 (1988)

Kofke, G.T.J. and Gorte, R.J., Journal of Catalysis, 115, 233-243 (1989)

Kofke, G.T.J., Gorte, R.J., Kokotailo, G.T. and Farneth, W.E., Journal of Catalysis, 115, 265-272 (1989)

Kokotailo, G.T., Lawton, S.L., Olson, D.H. and Meier, W.M., Nature, 272, 437 438 (1978)

Lago, R.M., Haag, W.O., Mikovsky, R.J., Olson, D.H., Hellring, S.D., Schmitt, K.D. and Kerr, G.T., Stud. Surf. Sci. Catalysis, 28, 677-684 (1986)

Lee, C.S., Park, T.J. and Lee, W.Y., Applied Catalysis A: General, 96, 151-161 (1993)

Liu, X. and Xu, R., J. Chem. Soc., Chem. Commun., 1837-1839 (1989) 
Lunsford, J.H., Journal of Physical Chemistry, 72, 4163-4168 (1968)

Magnoux, P., Cartraud, P., Mignard, S. and Guisnet, M., Journal of Catalysis, 106, 242-250 (1987)

Martens, J.A., Geerts, M., Grobet, P.J. and Jacobs, P.A., J. Chem. Soc., Chem. Commun., 1418-1419 (1990)

Meier, W.M., in "Molecular Sieves", p10, Society for Chemical Industry, London (1968)

Meier, W.M. and Olson, D.H., in "Atlas of Zeolite Structure Types", Structure Commission of IZA, Third Revised Edition, Butterworth-Heinemann (1992)

Middleditch, B.S., in "Practical Mass Spectrometry", Middleditch, B.S. (Ed), p21, Plenum Press, New York (1979)

Nagy, J.B., Gabelica, Z. and Derouane, E.G., Zeolites, 3, 43-49 (1983)

Namba, S., Inaka, A. and Yashima, T., Zeolites, 6, 107-110 (1986)

Nayak, V.S. and Choudhary, V.R., Journal of Catalysis, 81, 26-45 (1983)

Nayak, V.S. and Choudhary, V.R., Applied Catalysis, 10, 137-145 (1984)

Neuber, M., Dondur, V., Karge, H.G., Pachedo, L., Ernst, S. and Weitkamp, J., Stud. Surf. Sci. Catalysis, 37, 461-469 (1988)

Neuber, M. and Weitkamp, J., in "Proceedings, 8th International Zeolite Conference", Amsterdam, July 1989, Jansen, J.C., Moscou, L. and Post, M.F.M. (Eds), 425-426 (1989)

Niwa, M., Kato, S., Hattori, T. and Murakami, Y., J. Chem. Soc, Faraday Trans. l, 80, 3135-3145 (1984a)

Niwa, M., Morimoto, S., Kato, M., Hattori, T. and Murakami, Y., Preprint from the $8^{\text {th }}$ Int. Congr. Catal., IV, 701-711 (1984b)

Niwa, M., Kato, M., Hattori, T. and Murakami, Y., Journal of Physical Chemistry, 90, 6233-6237 (1986)

Niwa, M., Kawashima, Y., Hibino, T. and Murakami, Y., J. Chem. Soc, Faraday Trans. I, 84, 4327-4336 (1988)

Niwa, M. and Murakami, Y., Journal of Physical Chemistry Solids, 50, 487-496 (1989)

Parrillo, D.J., Adamo, A.T., Kokotailo, G.T. and Gorte, R.J., Applied Catalysis, 67, 107-118 (1990)

Parrillo, D.J. and Gorte, R.J., Journal of Physical Chemistry, 97, 8786-8792 (1993)

Pope, C.G., Zeolites, 10, 28-31 (1990)

Post, J.G. and Van Hooff, J.H.C., Zeolites, 4, 9-14 (1984)

Richter, M., Janchen, J., Jerschkewitz, H.-G., Parlitz, B. and Schreier, E., J. Chem. Soc, Faraday Trans. I, 87, 1461-1466 (1991) 
Rieck, J.S. and Bell, A.T., Journal of Catalysis, 85, 143-153 (1984)

Rollmann, L.D., Journal of Catalysis, 47, 113-121 (1977)

Rollmann, L.D. and Walsh, D.E., Journal of Catalysis, 56, 139-140 (1979)

Rollmann, L.D., U.S. Patent 4,203,869 (1980)

Rollmann, L.D., in "Zeolites: Sci \& Tech.", Ribeiro, F.R. and Nijhoff, M. (Ed), Den Haag (1983)

Rollmann, L.D., Stud. Surf. Sci. Catalysis, 68, 791-797 (1991)

Roozeboom, F.G., Robson, H.E. and Chan, S.S., Zeolites, 3, 321 (1983)

Sand, L.B., Pure and Applied Chemistry, 52, 2105-2113 (1980)

Santilli, D.S. and Zones, S.I., Catalysis Letters, 7, 383-388 (1990)

Sayari, A., Crusson, E., Kaliaguine, S. and Brown, J.R., Langmuir, 7, 314-317 (1991)

Scherzer, J., ACS Symp. Series 248, 157-200 (1984)

Schulz, M., Zhao Siwei and Baumgartner, W., Stud. Surf. Sci. Catalysis, 34, 479-492 (1987)

Schwarz, J.A., Russell, B.G. and Harnsberger, H.F., Journal of Catalysis, 54, 303-317 (1978)

Sharma, S.B., Meyers, B.L., Chen, D.T., Miller, J. and Dumesic, J.A., Applied Catalysis, 102, 253-265 (1993)

Skeels, G.W. and Breck, D.W., in "Proc. 6 $6^{\text {th }}$ Intern. Zeolite Conf.", Reno, July 1983, Olson, D.H. and Bisio, A. (Eds), 87-96, Butterworth, Guildford (1984)

Smith, J.V., in "Zeolite Chemistry and Catalysis, ACS Monograph 171", Rabo, J.A. (Ed) 1-79 (1979)

Szostak, R., in "Molecular Sieves - Principles of Synthesis and Identification", Davis, B.H. (Ed), Van Nostrand Reinhold, New York (1989)

Szostak, R., Stud. Surf. Sci. Catalysis, 58, 153-199 (1991)

Szostak, R. in "Handbook of Molecular Sieves", p527, Van Nostrand Reinhold, New York (1992)

Topsoe, N.-Y., Pedersen, K. and Derouane, E.G., Journal of Catalysis, 70, 4152 (1981)

Tronconi, E. and Forzatti, P., Journal of Catalysis, 93, 197-200 (1985)

Uytterhoeven, J.B., Christner, L.G. and Hall, W.K., Journal of Physical Chemistry, 69, 2117-2126 (1965)

Van der Gaag, F.J., Jansen, J.C. and Van Bekkum, H., Applied Catalysis, 17, 201-211 (1985) 
Von Ballmoos, R. and Higgins, J.B., in "Collection of Simulated XRD Powder Patterns for Zeolites", Structure Commission of IZA, Second Revised Edition, Butterworth-Heinemann (1990)

Ward, J.W., Journal of Catalysis, 9, 225-236 (1967)

Warzywoda, J., Edelman, R.D. and Thompson, R.W., Zeolites, 11, 318-324 (1991)

Zholobenko, V.L., Kustov, L.M., Kazansky, V.B., Loeffler, E., Lohser, U., Peuker, Ch. and OehImann, G., Zeolites, 10, 304-306 (1990) 